University of Redlands

\title{
A Geographic Information System Supporting Ocean Institute Research on Benthic and Demersal Species in the San Pedro Channel
}

A Major Individual Project submitted in partial satisfaction of the requirements for the degree of Master of Science in Geographic Information Systems

\author{
By \\ Peter C. Bigley
}

Committee in charge:

Mark Kumler, Ph.D., Chair

Mr. Mark Howe 
A Geographic Information System Supporting Ocean Institute Research on Benthic and Demersal Species in the San Pedro Channel

Copyright @ August 2006

by

Peter C. Bigley 
The report of Peter C. Bigley is approved.

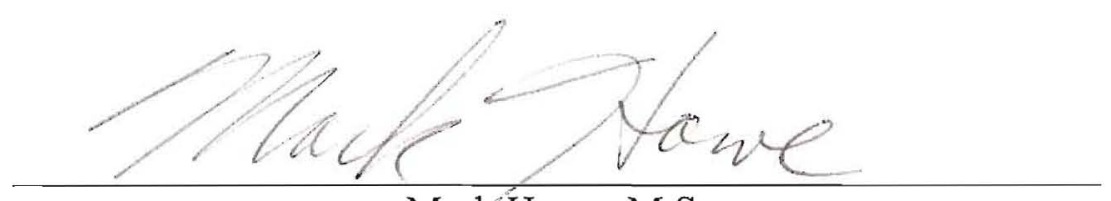

Mark Howe, M.S.

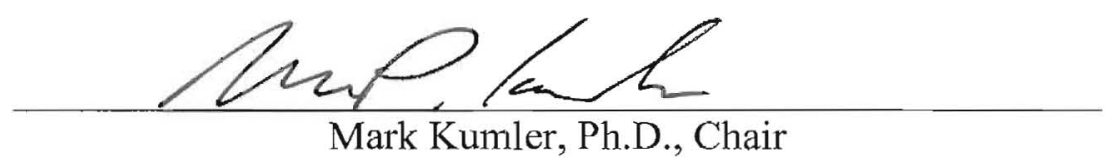

September 2006 



\section{ACKNOWLEDGEMENTS}

I would like to thank all the people who helped me over the past eleven months. Without the help and support of these individuals, the successful completion of this project would not have been possible.

Firstly, I would like to extend my gratitude and appreciation to all the students of Cohort 8 for their friendship, innumerable acts of assistance, and for creating an environment that made this year one of the most positive experiences of my life.

My sincere appreciation goes out to Larry Cooper who supplied a substantial amount of useful guidance along with the Ocean Institute data. This project owes much to his vision of what could be done with the technology and data.

Special thanks go to Mark Kumler for his effective guidance as an advisor, instructor, committee member, and MS GIS Program Director. It has been a wonderful year and I thank you for providing me with the opportunity to participate in this program. I hope that my professional endeavors going forward will reflect positively on this excellent program.

I deeply appreciate my wife, Sharon, for being a source of stability during this last year and being understanding with respect to the major investment in time and effort that this program required of me. I would not have undertaken this program or succeeded without her.

Sincere thanks go to Mark Howe for his good advice, useful assistance, unfailing enthusiasm and for the time he has invested in opting to participate as part of my committee.

My gratitude and appreciation go out to Theresa Ellis for all the organizational support, advice, and for her indefatigably positive outlook.

I would like to thank my client, Rick Baker, and the Ocean Institute for taking a chance on a phone call from a complete stranger (me) and remaining an enthusiastic and supportive partner in the execution of this project throughout the year.

I would like to extend my thanks to Rob Burke of ESRI for the extensive help rendered in developing the VBA program providing the analytical power critical to the success of this system.

Finally, I would like to express my gratitude to the Father of Creation for blessing me with all the opportunities that I have been given and for making such a beautiful world to study. 



\begin{abstract}
A Geographic Information System Supporting Ocean Institute Research on Benthic and Demersal Species in the San Pedro Channel
\end{abstract}

By

Peter C. Bigley

This project utilizes GIS to investigate changes in benthic and demersal habitats in the San Pedro Channel, off the coast of California, over time. This project will also use a variety of ESRI products. The work was carried out for the Ocean Institute at Dana Point, which functioned as the client institution for the project. The Ocean Institute is heavily involved in the gathering of sample data for the purpose of monitoring benthic and demersal species that are native to the San Pedro Channel, for the State of California. Using this system will enable the Institute to use its sample data to detect changes in the populations of various species due to the effects of ocean temperature change, and to determine the extent of correlation between the two phenomena. This GIS enables the client to produce maps that depict the location of the sample points of their surveys, and simple statistical charts that measure the level of correlation between the changes in frequency of species occurrence and changes in the ocean temperature. These maps and charts can be output in either paper or digital format and be updated in near real-time from the client's server, and are designed to be understood by an audience comprised of students from elementary school through high school. This functionality supports the client's stewardship of the Dana Point Marine Wildlife Sanctuary, as well as its stated objective to inspire all generations, through education, to become responsible stewards of our oceans. 



\section{Table of Contents}

1. Project Overview and Background ..................................................................... 1

1.1. Theoretical Context on the Cause-and-Effect of the El Nino Phenomenon ........ 3

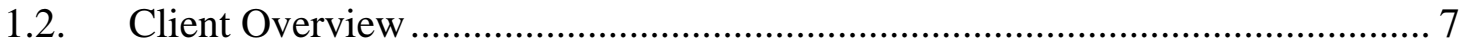

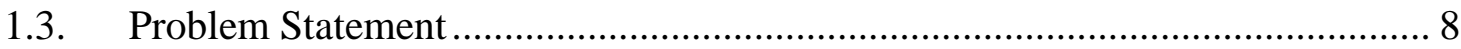

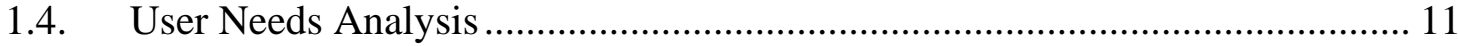

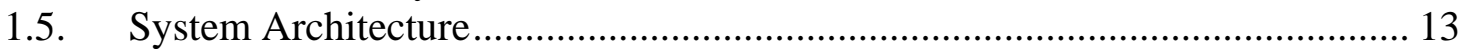

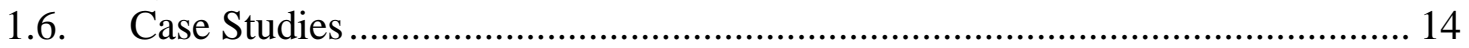

1.6.1. Rockfish Habitat in British Columbia..................................................... 14

1.6.2. Identifying Regions of Persistent Giant Kelp (Macrocystis pyrifera)

Around Santa Catalina Island for the Designation of Marine Protected Areas ........ 16

1.6.3. Marine Life Alliance.......................................................................... 19

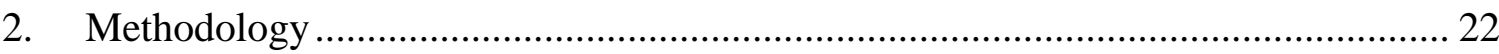

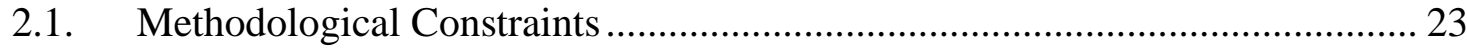

2.2. Consultations with Subject-Matter Experts ...................................................... 24

2.3. Chosen Methodologies............................................................................. 25

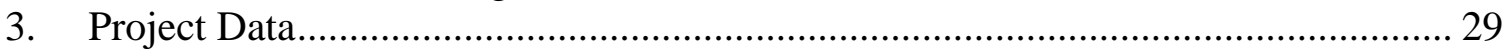

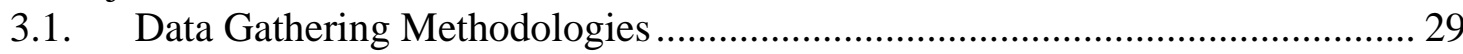

3.1.1. San Pedro Channel Trawls................................................................. 29

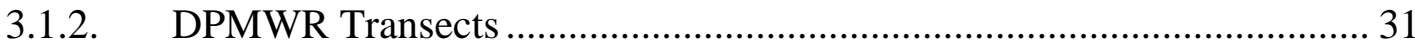

3.2. General Marine Data Accuracy Issues........................................................ 32

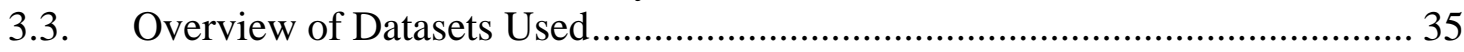

3.4. San Pedro Channel Overview ............................................................................ 39

3.5. Dana Point Marine Wildlife Refuge Overview …………………………........ 39

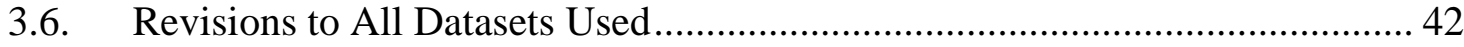

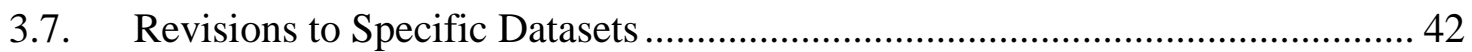

3.8. Recommendations for Additional Datasets .................................................. 43

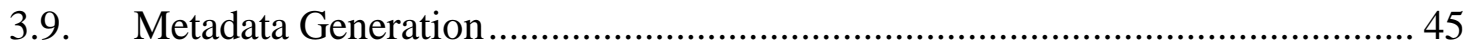

4. Discussion: System Development and Design ……….......................................... 47

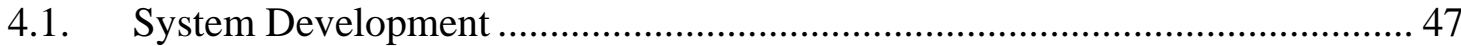

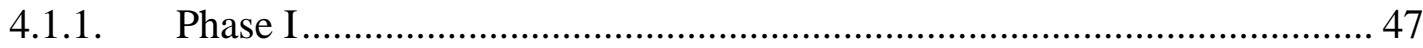

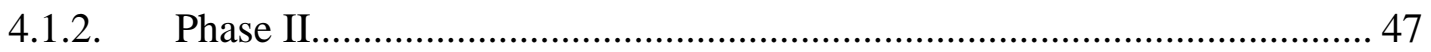

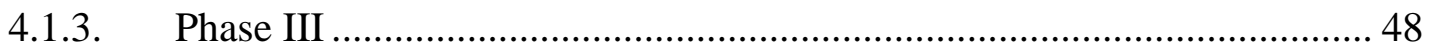

4.1.4. Future Development....................................................................... 48

4.1.5. System Development Workflow ............................................................. 50

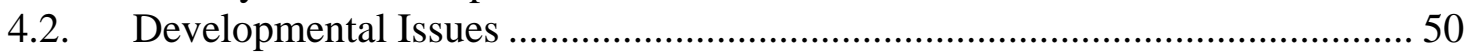

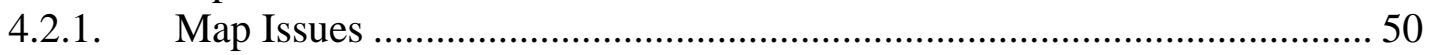

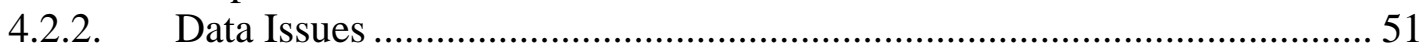

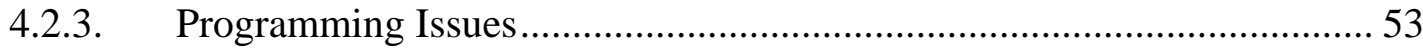

4.2.4. Implementation Issues ....................................................................... 54

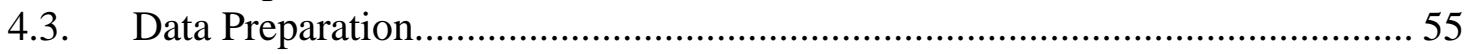

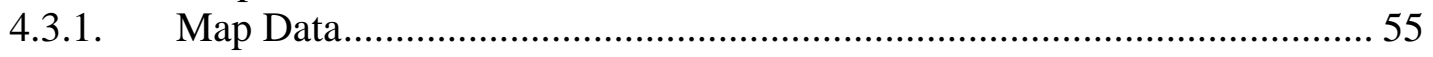

4.3.2. San Pedro Species Occurrence Data ....................................................... 55

4.3.3. Dana Point Marine Wildlife Refuge Occurrence Data .............................. 55

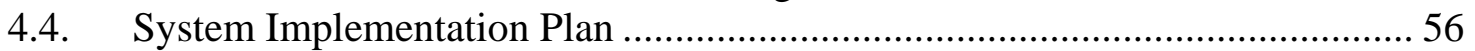




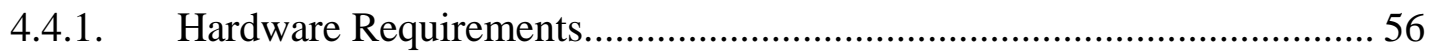

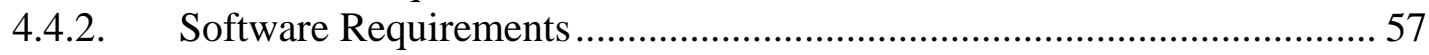

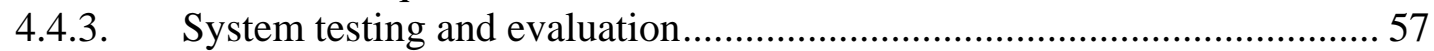

4.4.4. System Migration and Turnover ....................................................................... 60

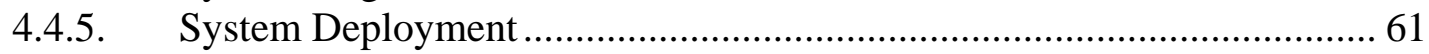

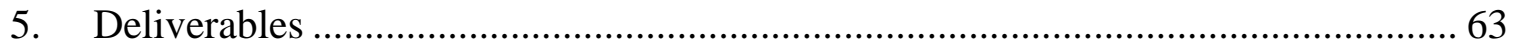

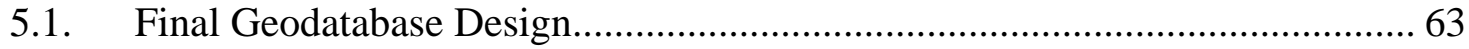

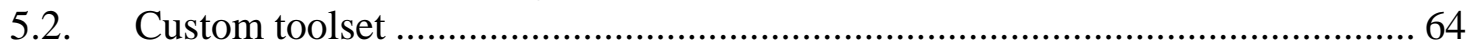

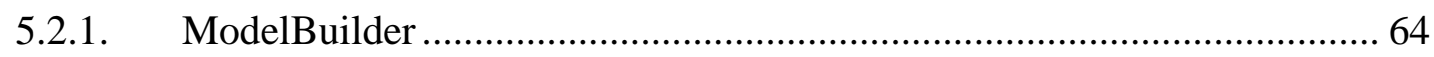

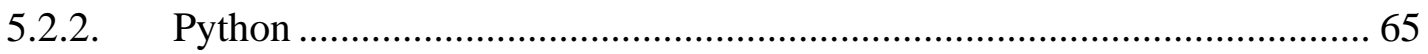

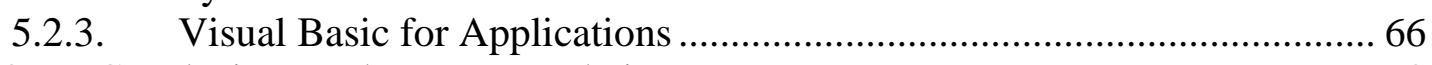

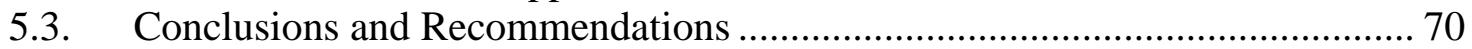

5.4. Suggestions for Further Research ........................................................... 71

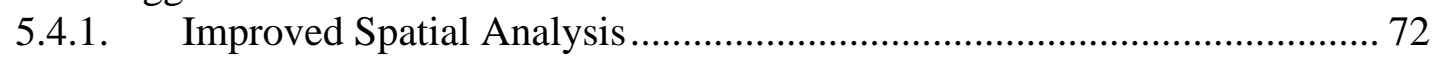

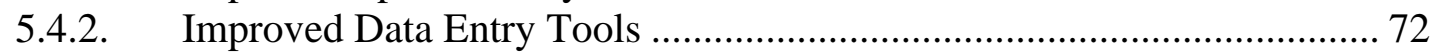

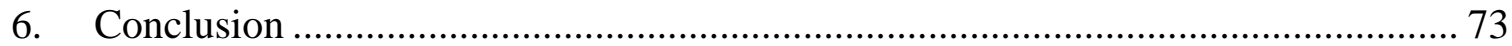

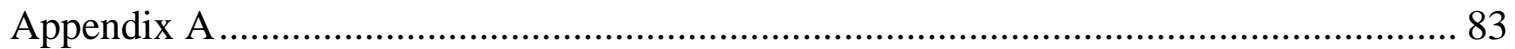

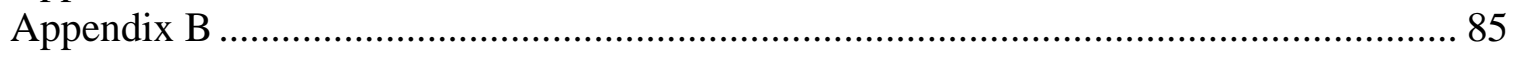

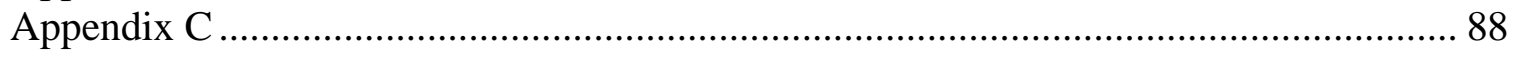

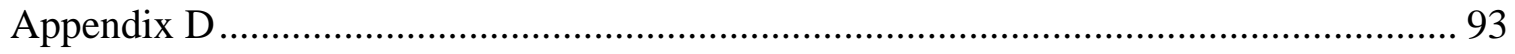

\section{Table of Figures}

Figure 1. Marine Environment..................................................................................... 1

Figure 2. Typical wind and current conditions for the tropical Pacific............................ 5

Figure 3. El Nino conditions for the tropical Pacific...................................................... 6

Figure 4. Benthic invertebrate species survey being conducted by the Ocean Institute.... 8 Figure 5. Pacific Ocean, beyond the tidal zone, looking northwest from Ocean Institute

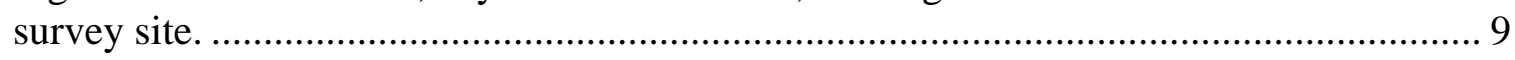

Figure 6. Dana Point Marine Wildlife Refuge............................................................... 9

Figure 7. Ocean Institute Geographical Information System Architecture. ................... 13 Figure 8. Marine reserves and Areas of Special Biological Significance (ASBS) around

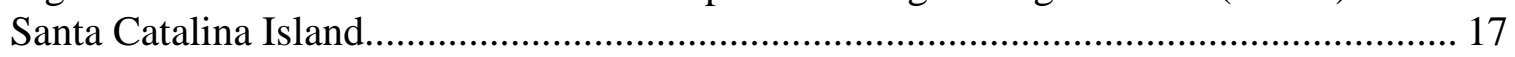

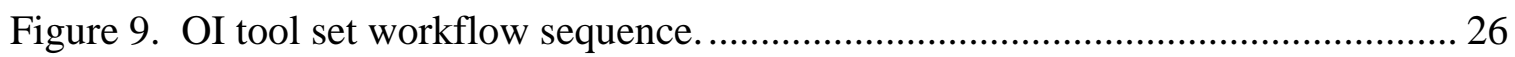

Figure 10. R/V Explorer making ready for sail at the Ocean Institute. ........................... 29

Figure 11. Transect survey being conducted in the DPMWR. ...................................... 30

Figure 12. Transect Survey being conducted in the DPMWR........................................ 31

Figure 13. Tidal bore Qiantang River near Hangzhou, China. ………………………..... 33

Figure 14. San Pedro Channel. ................................................................................... 39

Figure 15. Dana Point Marine Wildlife Refuge............................................................. 39

Figure 16. San Pedro Map Layers............................................................................ 41

Figure 17. Dana Point Map Layers.............................................................................. 42

Figure 18. System Development Workflow Diagram. ................................................... 50

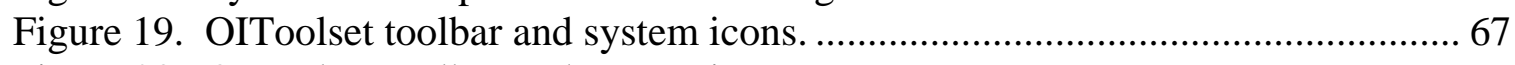

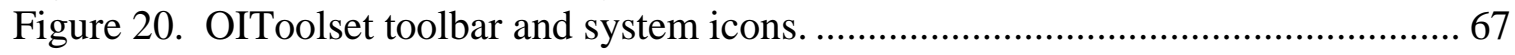

Figure 21. Generate Reports Icon and Dialogue Window.............................................. 69 
Figure 22. Swap Maps Icon and Dialogue Window.

\section{List of Tables}

Table 1 - Dataset overview

Table 2 - Extract from Species Occurrence Dataset for the Dana Point Marine Wildlife

Refuge.

Table 3 - Extract from Species Occurrence Dataset for the San Pedro Channel Trawl

Surveys.

Table 4 - System Test, Conditions and Operator Qualifications.

\section{List of Acronyms}

AOI - Area of Interest

ASBS - Areas of Special Biological Significance

CaSIL - California Spatial Information Library

CALCOFI - CALifornia Cooperative Oceanic Fisheries Investigations

DEM - Digital Elevation Model

DBF - Data Base File

DPMWR - Dana Point Marine Wildlife Refuge

FGDC - Federal Geographic Data Committee

GIS - Geographic Information System

GPS - Global Positioning System

GUI - Graphic User Interface

IMA - International Marine Life Alliance

Lat/lon - Latitude / Longitude

MHW - Mean High Water

MLLW - Mean Lower Low Water

MPA - Marine Protected Area

MWR - Marine Wildlife Refuge

MXD - Map Document

NOAA - National Oceanic and Atmospheric Administration

OIGIS - Ocean Institute Geographic Information System

OIToolset - Ocean Institute Toolset

$\mathrm{R} / \mathrm{V}$ - Research Vessel

RAD - Rapid Application Development

RCA - Rockfish Conservation Areas

ROV - Remotely Operated Vehicle (in this case, a submersible)

SCCWRP - Southern California Coastal Water Research Program

UCSD - University of California at San Diego

UTM - Universal Transverse Mercator

VB - Visual Basic

VBA - Visual Basic for Applications 



\section{Project Overview and Background}

The ocean ecosystem is subdivided into several uniquely different environmental regions arranged vertically in layers from the surface (see Figure 1). These marine environments are distinct from one another because of the differing environmental processes at work within them. The intertidal region is the region that is under water at high tide, and which becomes dry land at low tide. The photic region encompasses any portion of the ocean that receives significant sunlight. This is significant because in these regions photosynthesis can take place, enabling the survival and reproduction of numerous organisms, such as kelp and algae, which have profound effects on this region of the ocean as well as the creatures living therein. The subtidal photic region is generally described as the region below the intertidal region, which is shallow enough to receive significant sunlight. The benthic and demersal regions refer to the sea floor, extending through the intertidal region, across the bottom of the subtidal photic region near the coast, and down beyond the photic regions, to the deep ocean floor. Benthic refers specifically to the ocean floor where the water meets the rock, silt, or coral floor. Demersal refers to the region just above the benthos, in which the native organisms typically are able to swim (rather than simply drift, crawl or burrow) in order to feed on benthic or other demersal organisms. The pelagic region is the open sea, above the demersal region. The pelagic region includes both photic and subphotic areas (areas that do not receive significant sunlight) and is generally characterized by oceanic currents and migratory marine organisms. There is no measurable delineation of where the demersal region ends, and where the pelagic region above it starts. The species that are commonly found in the pelagic zone typically do not derive their sustenance directly from the benthos (Anderson, 2003).

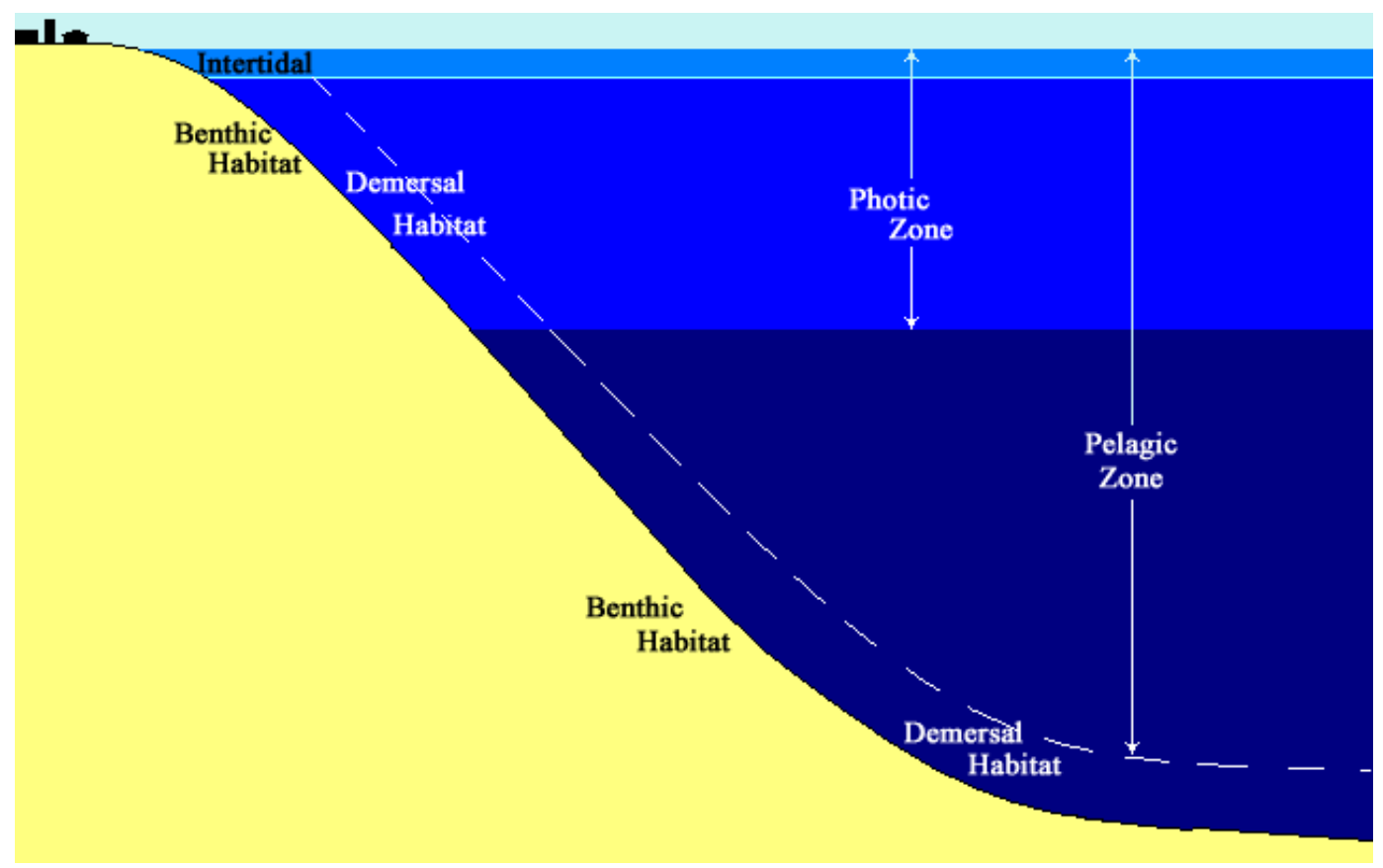

Figure 1. Marine Environment. 
Within the field of oceanography, much attention has been given to the creatures and phenomena of the pelagic zone. The near extinction and subsequent recovery of whale populations, the over-fishing of game fish such as tuna, marlin, and salmon, and the more recent exploitation of dolphins are all high profile environmental causes that frequently appear in the news. In the field of marine GIS, coral reef management, pollution patterns ocean currents, and ocean geology have been prominent research issues (Wright, 1996), all of which are either stationary phenomena or characterized by movement in a relatively predictable pattern. Despite considerable focus being given to the study of fish within the field of oceanography, the GIS world has found it difficult to extensively address the subject due to the high mobility and the low degree of conformation to predictable patterns characterized by a large number of fish populations. To these difficulties for GIS application, can be added the fact that the oceans still remain largely unexplored (Cava, Straing, \& Tuddenham, 2005).

Like their relatives on land, marine organisms have evolved into a complex and interconnected food web comprised of predators, prey, and scavengers. Similar to all other known ecosystems, when a predator, which resides at the top of the ecosystem's food chain dies, its body eventually settles on the ground (or benthos) and is consumed first by scavengers, then by some of the smallest and least developed organisms in the environment. These simple creatures are preyed upon by more advanced creatures that, in turn, are preyed upon by other, still more advanced creatures, and so on. Thus, every organism living in an environment is an important part of that environment, being interconnected with the other organisms and inter-dependent on them.

Environmentalists recognize the interconnectedness that exists in any ecosystem and, therefore are forced to assess the overall wellbeing of an ecosystem in general terms. One method of accomplishing this is to select a number of indicator species (O'Neill, 2001) to track within the ecosystem and to monitor as an indication of how the ecosystem is doing overall. These species are typically selected for some special characteristic that they possess, such as a particularly high vulnerability to pollution, predators, or temperature change. Another characteristic for which a species might be selected as an indicator species could be that it exists at an interface with another ecosystem, such as the interface between the water table and the land, otherwise known as wetlands, or the interface between the ocean and the land, otherwise known as the coastal zone.

Within the marine environment, an oft overlooked group of organisms exists at the bottom of the ocean, just above the interface between the ocean floor and water environment, referred to as the benthos (Evans, 1998). These species live where a high percentage of ocean pollution tends to accumulate, and many of them prey upon the simple organisms that feed on the dead bodies of the highly developed marine species when they sink to the ocean floor from the pelagic zone. Closely interconnected with these species are the demersal species that swim just above the ocean floor, typically deriving their sustenance from the benthic organisms. From this group of fish species, marine biologists have frequently selected indicator species that are particularly reactive to the phenomenon that they were studying.

The client for this project was the Ocean Institute at Dana Point in California, which has been engaged in surveying the San Pedro Channel benthic habitat for many years. The Ocean Institute is a non-profit research and educational organization which has, for many 
years, participated in government supported environmental research programs by meticulously gathering species and environmental data from the coastal zone within a few miles of Dana Point Harbor. These surveys do not concentrate on any particular type of benthic fish, but gather a cross section of the variety of species that inhabit the San Pedro Channel benthos. This paper reports on the development of a Geographic Information System to organize and present the Ocean Institute's spatial and non-spatial data in the form of maps and reports designed to support their primary task of educating the public to become responsible stewards of the oceans.

This GIS is intended to provide the Ocean Institute at Dana Point with an effective analytical tool for identifying opportunities for initial planning for future surveys, for subsequent research, and for public education. The directors of the Ocean Institute have recognized the need to have a dedicated GIS in order to receive and display their benthic species occurrence data. This will enable them to conduct correlation analysis, improve decision making, and educate the public, all of which support their organizational mission statement. With no prior in-house GIS, the client's personnel will therefore be in need of training, which has been included in the implementation process, and a system that has been included with user interfaces to make operating a geographic information system as simple as possible. To support the client's mission statement and stated goals for this project, this GIS has been designed as a management tool for receiving and making use of the data being gathered by the Ocean Institute, as well as an educational tool for the Institute to use with its programs, which are conducted in conjunction with local schools.

The basic objectives of this project are to create a state-of-the-art geodatabase for the Ocean Institute with which they will be able to receive and meaningfully display the species occurrence data that they generate with the San Pedro Channel surveys, or have generated as with the completed survey project conducted in the Dana Point Marine Wildlife Refuge. In utilizing this system, Ocean Institute operators will be capable of conducting species-specific, frequency-based statistical analysis. These results will then be compared to ocean temperature data for the region in order to investigate possible correlations between temperature changes and changes in species population. Subsequent to the system's inception, the system's capabilities are expected to be expanded by the Ocean Institute's researchers so as to compare variations in the species occurrence data with other environmental factors, in addition to ocean temperature.

\subsection{Theoretical Context on the Cause-and-Effect of the El Nino Phenomenon}

El Nino refers to an abnormal warming of surface ocean waters in the eastern tropical Pacific, and is part of an even larger chain of events called the Southern Oscillation (NOAA, 2005). The Southern Oscillation is an intermittently recurring pattern of reversing surface air pressure between the eastern and western tropical Pacific regions. When the surface pressure is high in the eastern tropical Pacific, it is low in the western tropical Pacific, and vice-versa. Because the ocean warming and pressure reversals are, for the most part, simultaneous, this phenomenon has come to be known as the El Nino/Southern Oscillation or ENSO for short. South American fisherman have given this phenomenon the name El Nino, which in Spanish means "The Christ Child," because it 
occurs at about the time of the celebration of the birth of Christ (late December) (Hare \& Mantua, 2002).

Under normal conditions, the trade winds blow from the east towards the west across the tropical Pacific. These winds are the result of a normal pattern of relatively high atmospheric pressure in the northeastern tropical Pacific (Japan and the Philippine Islands) and a lower atmospheric pressure in the western tropical Pacific (off the west coast of Central America and southern North America). Normally, these winds blow the warm surface water that accumulates along the coast of Central America westward toward Asia. Eventually, the warm water arrives and gathers near Indonesia while it is still winter in North America, actually causing the Pacific Ocean to be half a meter deeper there than at other times of the year (NOAA, 2005). In the eastern Pacific along the coast of Central America an upwelling occurs as the cool, nutrient-rich waters from the bottom of the ocean move up toward the surface away from the shore to replace the surface water being blown westward by the trade winds. This nutrient-rich water is responsible for supporting the large fish population commonly found off the west coast of the Americas. Indeed, the Peruvian fishing grounds are one of the five richest in the world (NOAA, 2005). This accumulation of warm water in the western tropical Pacific creates a weather pattern that typically leaves the western coasts of the Americas relatively dry, and brings plenty of rain to parts of Indonesia, the Philippine Islands, and northern Australia (NOAA, 2005).

Every few years, however, the pressure patterns reverse (or oscillate) causing the trade winds to weaken, or sometimes even to reverse direction (See Figure 2 and Figure 3). This situation allows the warm water near Indonesia to drift back toward Central America which causes weather patterns throughout the Pacific region to alter dramatically. What happens to the ocean also affects the atmosphere. In years when this phenomenon is particularly pronounced, the well known winter-time El Nino effects are felt by humans as heavy rainfall. Tropical thunderstorms are fueled by hot, humid air over the oceans. Hotter air tends to generate stronger and bigger thunderstorms because it rises more rapidly, and to a higher altitude. As the Pacific's warmest water spreads eastward, the biggest thunderstorms move with it, causing floods in California, Mexico, and Peru, and drought in Indonesia, the Philippines, and Australia (Cavaides, 2001). 


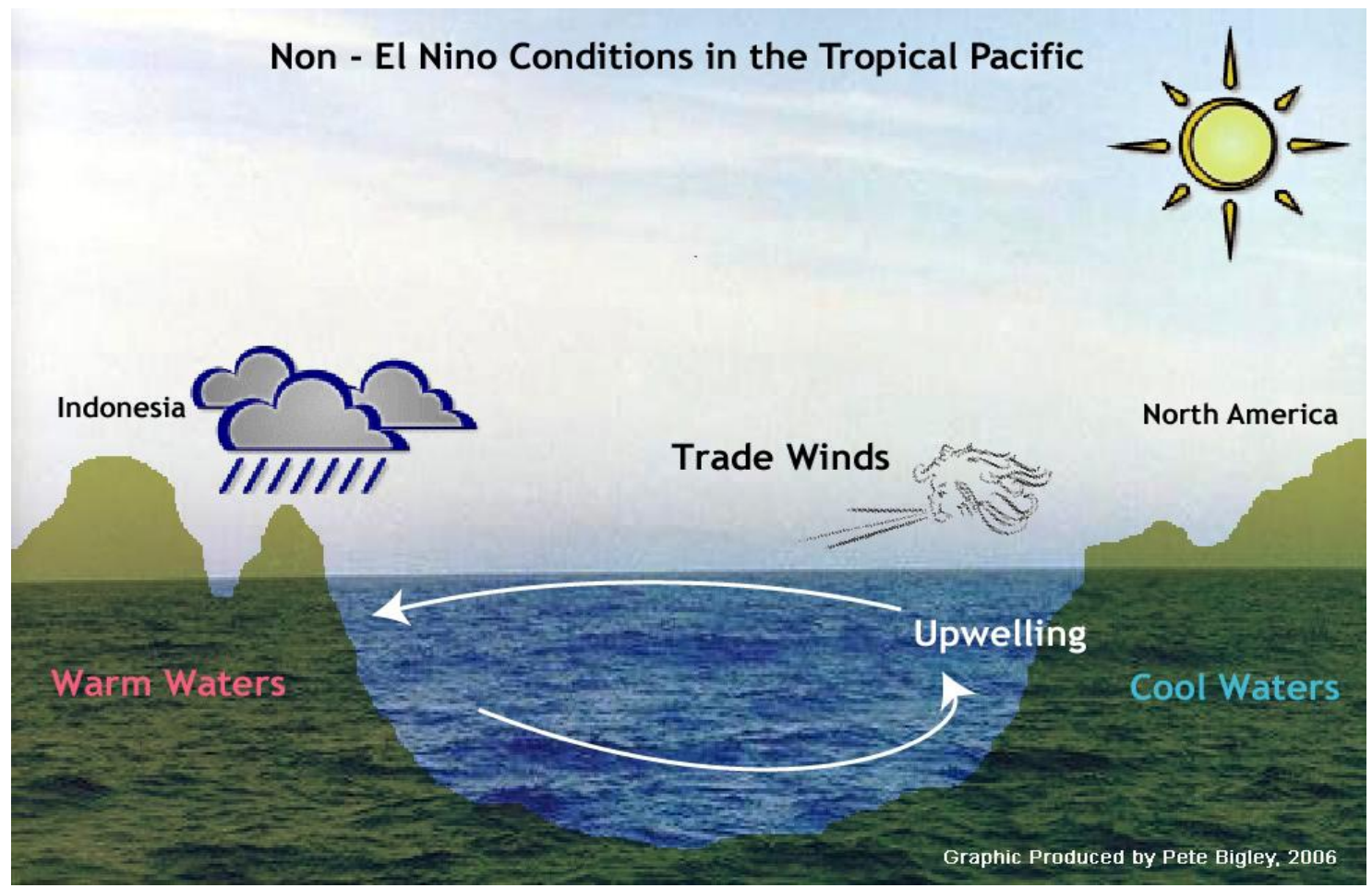

Figure 2. Typical wind and current conditions for the tropical Pacific.

This uncharacteristic rise in ocean temperatures is also known to drive pelagic fish populations, normally found in tropical waters, far to the north and south as the fish seek water temperatures that are to their liking (NOAA, 2005). Marine food chains are also disrupted due to the atypical ocean temperature at the surface of the eastern Pacific which impedes the upwelling of nutrient-rich deeper waters that otherwise would occur. This sets off a chain reaction in the marine food web, as the lack of nutrients reduces the abundance of plankton which has a similar effect on the marine species that feed on plankton and which, in turn, has a similar effect on the creatures that feed on them. 


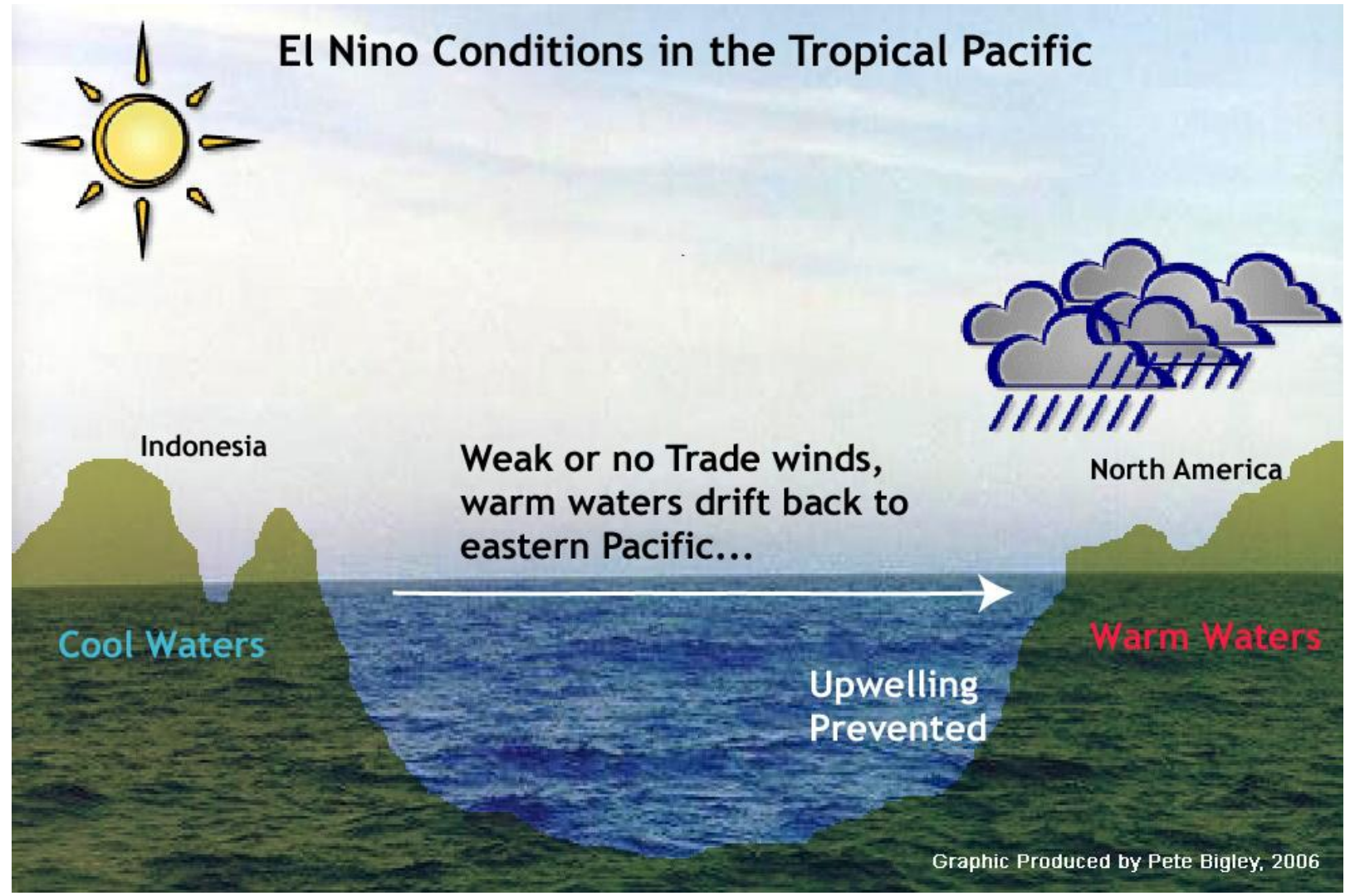

Figure 3. El Nino conditions for the tropical Pacific.

During past El Nino events, scientists working for the fisheries industry have documented an increase in the local populations of pelagic fish such as mahi-mahi and billfish, as well as certain small schooling fish such as mackerel and sardine that are found off California at the northern extreme of their ranges. Marine biologists have further noted that the appearance of yellowtail, albacore, and bluefin tuna in southern California waters in the month of May could be an early indication that a strong El Nino event is underway (NOAA, 2005).

Along California coastal regions, there has been an observable increase in dead and live strandings of seals and sea lions, and a poor survival and growth rate of seal and sea lion pups at island breeding sites is also seen (National Marine Mammal Laboratory, 2006). Fisheries industry scientists suspect that El Nino conditions trigger a decline in the food supply of some marine predators, but this has not yet been conclusively investigated.

Within the context of this project, marine biologists have theorized that "the commercially valuable rockfish may also be vulnerable because they are bound to local bottom topography" (NOAA, 2005).

From these studies, it is clear that a strong El Nino causes profound changes in marine environments throughout the Pacific Ocean, and that marine biologists still have much to learn about the extent and nature of these changes. The client for this project and associated marine biology experts with specific knowledge of the Southern California marine environment suspect that another El Nino event will occur in the next one to three years (NOAA, 2006). With an ongoing survey of the San Pedro Channel benthos in progress, the Ocean Institute hopes to develop a dataset which will allow them to 
investigate numerous long-term environmental phenomena for this region. By investigating possible correlations between species occurrences and the variation in ocean temperature, the Ocean Institute GIS (OIGIS) is the first tool developed for the Ocean Institute that is designed to utilize the benthic survey data for this sort of application. During the next one to three year period, it is expected that the Ocean Institute survey data will continue to accumulate, which will form an established baseline describing nominal conditions in the San Pedro Channel benthos, prior to the arrival of the next El Nino.

\subsection{Client Overview}

The specific individual within the Ocean Institute for whom the work was performed was Mr. Rick Baker (Director of At-Sea Operation for the Ocean Institute). The Ocean Institute was originally established by a Joint Powers Agreement (JPA) adopted in 1977 (Ocean Institute, 2005). The JPA included the Orange County government, the Orange County Department of Education, Saddleback Community College District, Rancho Santiago Community College District, North Orange County Community College District, and Coast Community College District. The agreement was expanded to include the City of Dana Point as a member in 1992. In 1996, the Board of Directors transferred the assets and operation to a non-profit organization known as Friends of the Marine Institute in Orange County.

The Ocean Institute has for its stated objective "to inspire all generations, through education, to become responsible stewards of our oceans" (Ocean Institute, 2005). The Ocean Institute has become nationally known for its hands-on marine science, environmental education, and maritime history programs (see Figure 3). More than $78,000 \mathrm{~K}-12$ students and 6,000 teachers participate annually in the Institute's 61 awardwinning, immersion style programs (Ocean Institute, 2005). By way of educating the public, the Ocean Institute engages in much actual research, primarily in support of scientific studies being conducted by the State of California. One of the Ocean Institute's primary partners in these efforts is the Southern California Coastal Water Research Program (SCCWRP), headquartered in Westminster, California, which is one of the primary ocean research organization in Southern California. SCCWRP is the recipient of most of the data generated by the Ocean Institute's research. This information is georeferenced and after having been copied and supplied to SCCWRP, is then archived at the Ocean Institute. To date, the Ocean Institute possesses only a limited ability to use the data it has compiled analytically for its own purposes, which (to date) does not include spatial analysis of any kind. 


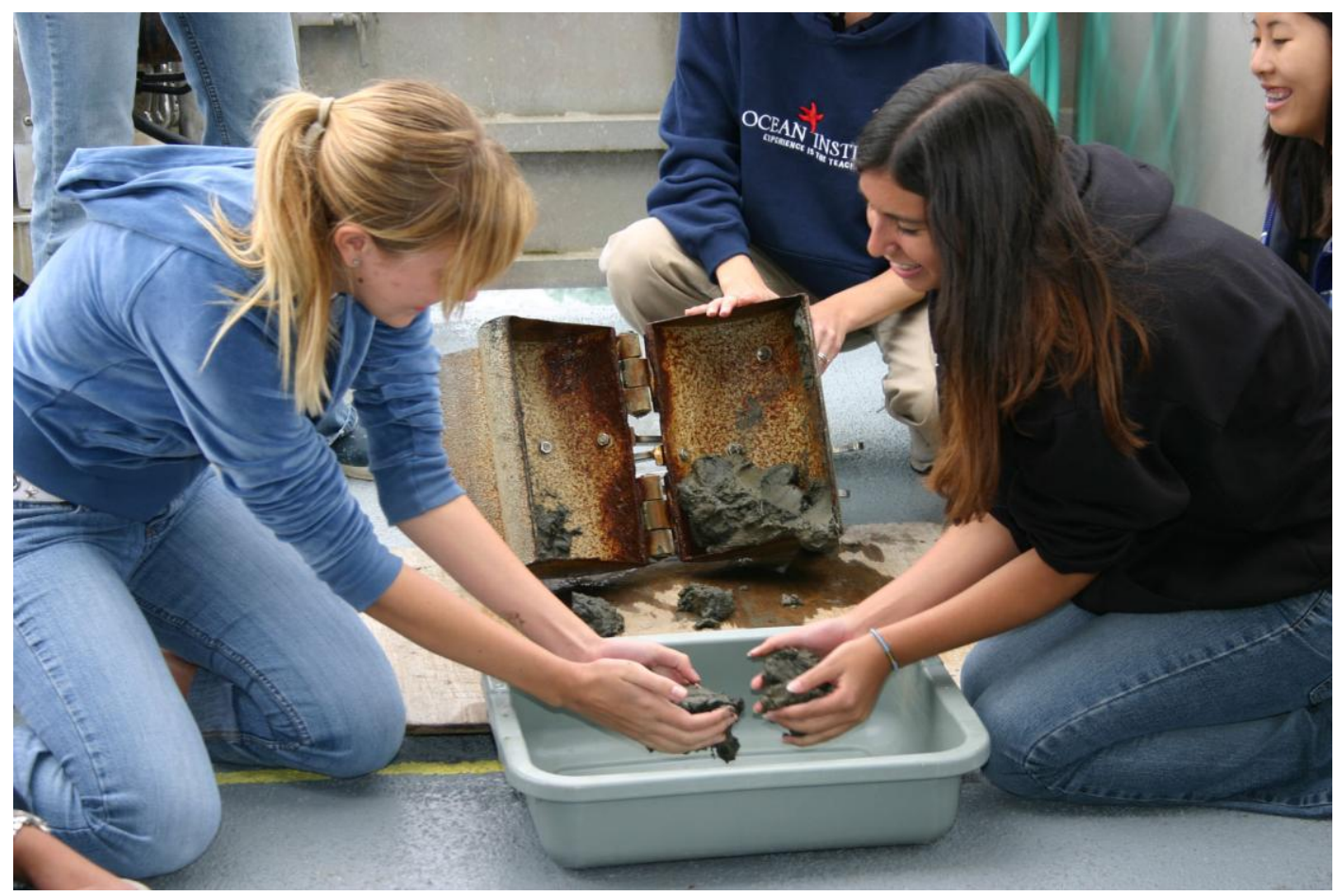

Figure 4. Benthic invertebrate species survey being conducted by the Ocean Institute.

The Ocean Institute has been given custodial responsibility for one of the State of California's Marine Wildlife Refuges known as the Dana Point Marine Wildlife Refuge, and is accumulating species occurrence data from it, as well as the surrounding portion of the San Pedro Channel. A geographic information system with appropriate, built-in analytical tools was identified by the Institute's directors as a necessary tool for effective environmental research, planning, and education in these two regions. When approached, the directors were enthusiastic to support the development of this system which they felt will support their need for environmental research and planning as well as their stated objective of educating their K-12 clientele in ocean science and maritime history (Baker, 2005).

\subsection{Problem Statement}

Given that the Ocean Institute's primary mission is "to inspire all generations, through education, to become responsible stewards of our oceans" (Ocean Institute, 2005), it follows that its primary clientele is comprised of many of the region's elementary, middle, and high schools. As a result, much of the Ocean Institute data collection is accomplished by students from these schools under the direct supervision of marine biologists working for the Institute, and virtually all of its programs are designed for the education of these age groups. At the present time, the Dana Point Ocean Institute possesses no in-house GIS capability. Some of the staff have had some exposure and training in GIS during the course of their education, and the staff members, in general, are very anxious to get the Ocean Institute involved in its usage.

Since its establishment, the Ocean Institute has been collecting georeferenced marine species data and now possesses species occurrence datasets that span many years. This data collection is ongoing and specific to two distinct areas, the San Pedro Channel 
(between Santa Catalina Island and the Orange County coast) and the Dana Point Marine Wildlife Refuge (the tidal shoreline region directly west of the Ocean Institute campus). Although the two regions overlap in extent, surveys conducted in these two areas are taking place in distinctly different portions of the marine environment (see Figures 5 and 6). Both of these regions are areas of special interest to the Ocean Institute and are the location of all Ocean Institute training and research programs.

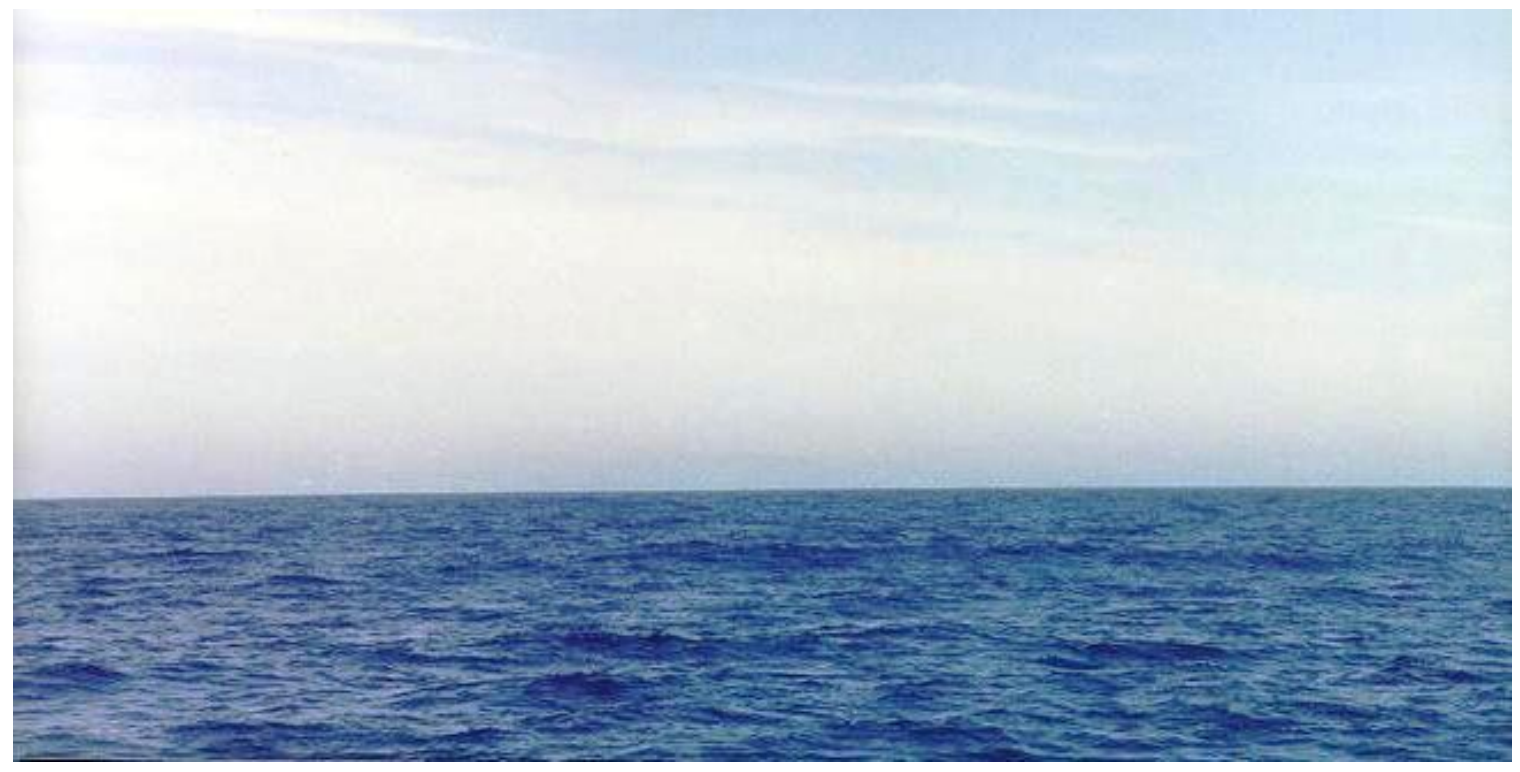

Figure 5. Pacific Ocean, beyond the tidal zone, looking northwest from Ocean Institute survey site.
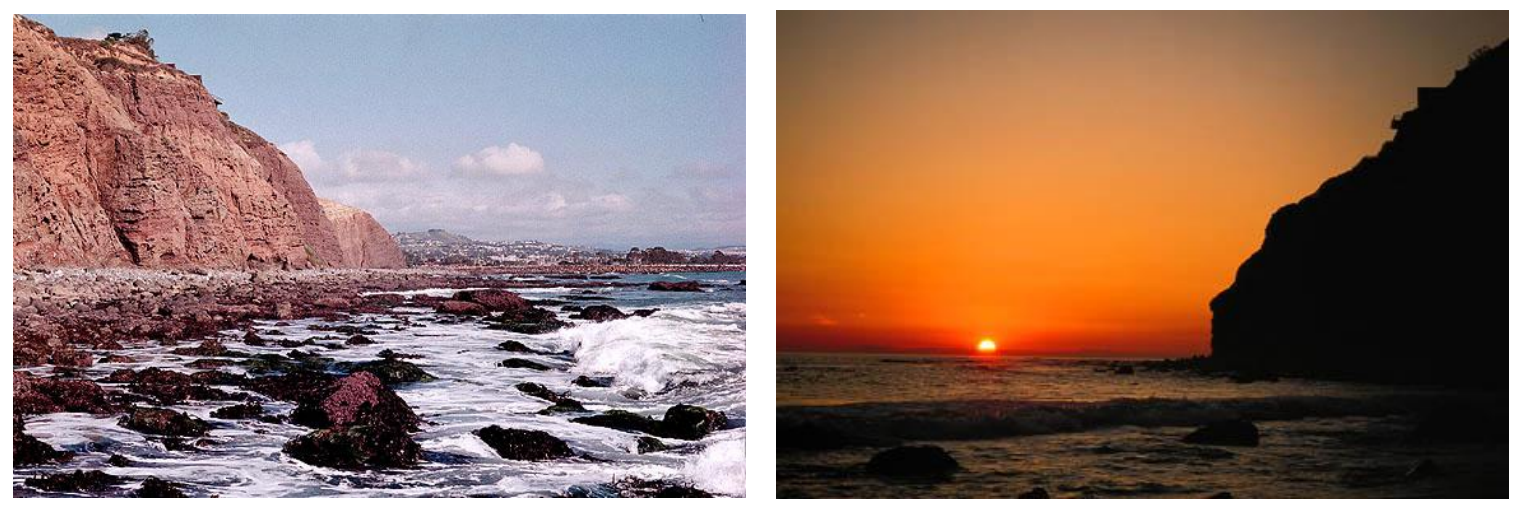

Figure 6. Dana Point Marine Wildlife Refuge.

The variety of animal species that are of concern to the client and which are the focus of this project are Benthic (bottom dwelling) and Demersal (near bottom dwelling) fishes that inhabit the intertidal and subtidal photic regions of the San Pedro Channel and the Dana Point Marine Wildlife Refuge. These creatures are considered important to marine biologists for several reasons. The fish species that live in these two zones either inhabit the ocean floor or derive their sustenance directly from the organisms that inhabit the ocean floor. With the inclusion of the deep ocean Benthos, this is the largest habitat on earth and, relative to other habitats, is highly resistant to change due to its size and inaccessibility to humans. Therefore, if marine scientists do observe significant 
environmental changes to this part of the global ecosystem (e.g., temperature), it signifies fundamental change to the regional marine ecosystem (Chavez, 2003). Many benthic species possess only limited mobility in comparison to pelagic fish, and therefore have limited ability to relocate in order to avoid detrimental changes in their environment. For these reasons many benthic creatures are categorized as indicator species for various phenomenon by marine scientists.

Most varieties of benthic and demersal creatures swim relatively short distances to avoid predators or catch prey. They have ranges that are sharply defined by depth, pressure, and other related factors that tend to follow the bathymetric contours of the California coast. These creatures tend to have a tolerance for regions with lower water temperatures and lower oxygen levels (NOAA, 2005). When environmental factors change unfavorably for one of these species, the population becomes stressed, and they tend to die out rather than just swim away, as done by species native to the pelagic zones above. These characteristics make benthic species uniquely suited to gauging the overall environmental conditions in the San Pedro Channel marine environment.

The client's desire for this project is to equip the Ocean Institute with a GIS that will enable them to display the location of recent surveys, conduct top-line planning for new surveys which will utilize both new and existing transects, and to enable a basic, speciesspecific analysis comparing species occurrence with ocean temperature variation. This system is expected to increase in functionality after implementation, possibly using the ocean temperature analysis as a blueprint for future analyses that will take into account other environmental variables.

For purposes of implementing this GIS, the client felt that ocean temperature was the most logical environmental variable to start with. This is due to the commonly held belief that ocean temperature is one of the fundamental factors impacting a marine environment's suitability for hosting a given marine species (Francour, 1998). Moreover, it is also due to the client's belief that the eastern Pacific, including southern California, will experience another major El Nino event in the near future. Local marine biologists (including those at the Dana Point Ocean Institute) have speculated about the effects that an El Nino event would have upon the benthic and demersal fish species that are native to the coastal regions of southern California. Due to the limited ability of many of these species to relocate to more favorable locations, a reduction in frequency of occurrences of a species in the surveys could indicate a reduction in population or a migration northward or southward to more favorable water temperatures.

Conversely, the warmer water temperatures associated with a powerful El Nino event could cause the San Pedro Channel to become more favorable to some other species that are typically sparse or not found in the region. The significant ocean temperature changes associated with El Nino events may have little or no detectable effect on some or all of the local benthic species, and this would be a significant finding as well, leading to entirely new inquiries.

Fundamentally, the Ocean Institute requires a GIS that will display their fish catch data in a spatially and statistically meaningful way, allowing them to observe temperature induced changes to the frequency and location of occurrence of the various species represented in their surveys. The analysis portion of this project uses historical data to 
begin investigating these relationships by attempting to detect changes to the frequency of species occurrence in the survey data, and establishing positive, negative, or no correlation with ocean temperature. Data collection from the surveys of benthic and demersal species is an ongoing activity at the Ocean Institute. Whether or not the data, as it currently stands, contains such variation, the client's hope is that this system will equip the Ocean Institute with a tool to study some of the effects of upcoming El Nino events. The effectiveness of the OIGIS in meeting the client's needs will depend largely upon their establishment of a baseline for normal conditions in the survey area by the accumulation of species occurrence data during time periods unaffected by El Ninos.

\subsection{User Needs Analysis}

While covering a considerable span of time, the Ocean Institute species data is very limited in geographical extent when compared with the data for the San Pedro Channel. At the client's request, the entire region has been included in the base map to facilitate the planning of future surveys. The client has also requested that a similarly equipped database and map be developed for the Dana Point Marine Wildlife Refuge, although the Ocean Institute's naturalists are only just starting to archive survey data from this region. Therefore, similar programming and analytical tools were built into both maps completed for this project, but currently the data will only support meaningful analysis for the portion of the San Pedro Channel within approximately 10 kilometers of the Ocean Institute.

In comparison to the known ranges of most of the species occurring in the surveys which span large portions of the southern California coast, a 10 kilometer survey area is a very small region from which to extrapolate conclusions about what is happening to the entire population of a particular benthic species, or even to make conclusions about what is happening to a species within the San Pedro Channel. Many Benthic species inhabit relatively narrow depth ranges corresponding to their pressure and temperature preferences (Scholz \& Wright, 2005). The distribution of these species may exhibit a north, south variation over time, corresponding closely to the bathymetric contours of the California coastline, but elaborate patterns of distribution over wide ranges of the ocean floor are not typical among these species (Baker, 2006). For these reasons, the client is primarily interested in developing a tool capable of detecting variations in the frequency of occurrence of a species and investigating whether this variation is correlated with ocean temperature variation over the same period of time.

The operational concept of this GIS is to directly address the client's requirements in the areas of survey planning and educational functionality. Considering the lack of GIStrained employees within the Ocean Institute, I decided to address these needs with a personal geodatabase. The personal geodatabase will be structured for the purpose of archiving, displaying, and identifying trends in species occurrence data gathered from the benthic habitats. The system will be equipped with an extensive, customized toolset and built in topologies that will enable the Ocean Institute to update, analyze, and display their data in a standardized and error-resistant manner despite the overall lack of GIS training.

The custom tools will enable Institute specialists to enter new datasets which will then be archived in a standardized format and in a standardized location on the Institute server. 
Other custom tools will enable detection of statistically significant variations in various benthic species being tracked by the Institute. Additional custom tools will control the updating, displaying, and charting of ocean temperature variations for the purpose of seeking correlations with the species occurrence data. A large portion of the audience for this GIS will be elementary school to high school students, so significant effort has been invested in creating a visually attractive display, keeping the statistical analysis simple and easily understood, and ensuring that the user interface is basic, robust, and easy to use.

Operator queries to this GIS will take two basic forms and will result in a thematic map display with simple graphs designed to clearly display the level of correlation between the ocean temperature and the occurrence of a given species. One type of query results in displaying a map in order to illustrate the primary undersea features of the San Pedro Channel, and the Ocean Institute's relative position on its fringes. Another type of query will be species-specific investigations to determine if variation in species occurrence is positively or negatively correlated with environmental variations. The results of these queries will be suitable for printing on standard size paper, display on a standard size computer screen, or large-sized projections for a large audience. Initially, the functionality of this system will be limited to the two aforementioned queries, but the client intends this GIS to eventually be equipped with the capability of comparing species occurrence data with a variety of environmental variables in addition to ocean temperature.

This GIS has been designed to deliver functionality in the areas of operational planning, trend analysis, and public education, which were design priorities set by the client, and which support Ocean Institute's mission statement and vision (Ocean Institute, 2005). Functional design requirements to be addressed in constructing this GIS will include;
- Data input; species samples
- Data retrieval; environmental data
- Display; map of survey areas; user interface
- Query; ocean temperature / species occurrence
- Product Output; display graphics
- Product statistical analysis
- Product output; paper maps

Analytical capabilities are expected to continue to be developed into the system after system implementation takes place. The client is very confident that temperature is the most salient effect of all the usual environmental variables that affect the benthic and demersal fish species inhabiting the San Pedro Channel. For this reason, and to equip the Ocean Institute with a means to analyze any upcoming El Nino events, initial OIGIS analytical capabilities will be limited to detecting statistically significant changes in species occurrence, and to determining whether there is a correlation with ocean temperature changes for the same time period.

Suitable ocean temperature data proved to be a challenging item to locate and, once found, to incorporate into this system. Although very extensive datasets exist, (e.g., CALCOFI, - CALifornia Cooperative Oceanic Fisheries Investigations) most are too coarse for the purposes of the study area. 


\subsection{System Architecture}

One of the primary functions that this GIS will be required to perform will be presentations and demonstrations delivered via a projector to a large audience. To address this requirement, extensive raster backdrops have been developed for the maps, and care was taken to ensure that the GIS presents well in this media. The raster backdrops will be uploaded onto the Ocean Institute server, but will remain outside of the geodatabases.

Two separate geodatabases have been created in order to effectively deal with diversities between the two areas of interest, and the fact that species data gathering has only recently started to be archived in the Dana Point Marine Wildlife Refuge. To support these requirements and to ensure a uniformed affective appearance (Buckley, 2006) on the diverse Ocean Institute computer terminals, standardized symbology and cartographical design have been utilized, in both geodatabases. Standardized system behaviors and topologies and tools are built into both geodatabases to ensure that they interact with the system operator in the same way and that operation of the two systems is accomplished via the same workflow.

Since this GIS is composed of two geodatabases (the San Pedro Channel and the Dana Point Marine Wildlife Refuge), it is necessary to ensure that they behave and appear in a very similar or identical manner. The underlying purpose, necessary analytical tools, environment depicted and owning institution all support a common affective design for both maps. In the following diagram (See Figure 7) the basic internal structure or architecture is outlined, depicting the San Pedro Geodatabase and the Dana Point Marine Wildlife Refuge Geodatabase (MWR in the diagram). In subsequent sections of this document, steps taken to ensure uniformity of appearance and uniformity of behavior will be explained in much greater detail.

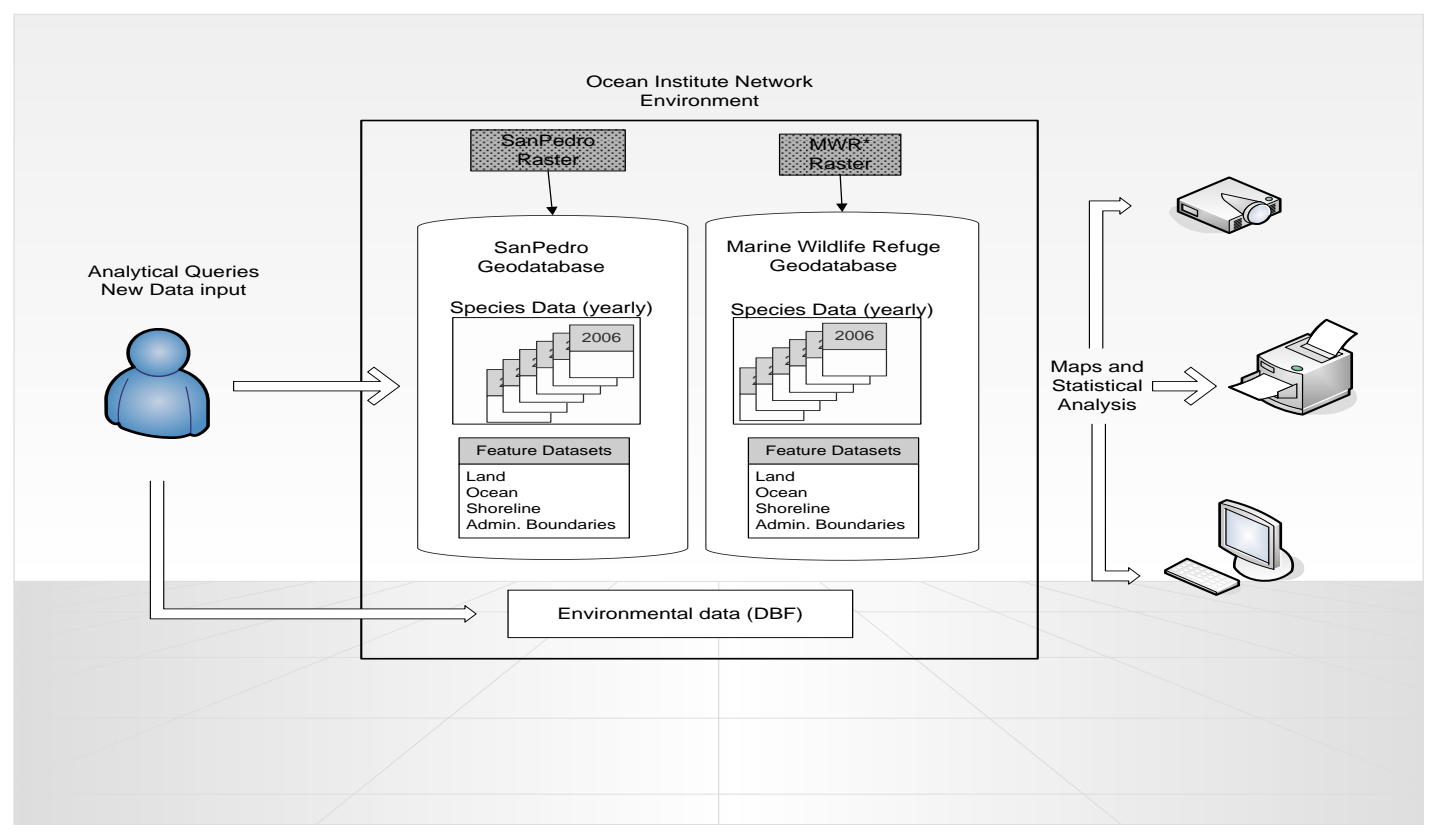

Figure 7. Ocean Institute Geographical Information System Architecture. 
After conducting a thoughtful evaluation of the manner and frequency in which the client intended to use this system, a personal geodatabase was deemed adequate for the task, as well as desirable because of its simplicity. Although this GIS resides on the Ocean Institute's server, it is expected that the Institute will purchase four or five ArcView licenses in total. One of these will be for the computer on board the Institute's research vessel which will work with a version of this system that will be self-contained in terms of its datasets, and separate from the Institute network. System usage on the research vessel will be the only instance where simultaneous use of this GIS is anticipated by the client. The purpose of installing this system onto the server and having multiple licenses is to ensure that the system can be updated while the surveys are taking place on board the R/V Explorer. When the ship is docked, the new data can be transferred to the Ocean Institute offices and tested on a PC terminal, and then shown to a large audience via a projector receiving its signal from a different $\mathrm{PC}$ terminal located in a different building on the Ocean Institute campus.

\subsection{Case Studies}

While the concept of mapping something as dynamic and constantly changing as the location of fish in the ocean may seem to have little meaning due to the limitations of a static map depicting a temporally changing phenomenon, in the context of this project, the limited mobility of the marine species being studied has to be considered. While marine GIS in general, and studies of benthic habitats with GIS in particular can be regarded as emerging fields, there are an increasing number of projects which compare well with this project. During the course of development of the Ocean Institute Geographic Information System (OIGIS), a number of existing systems with strong similarities were examined in order to determine how the authors had approached some of the considerations unique to applying GIS to benthic phenomena. In this section, a description of and a comparison with some of the GIS projects that were particularly influential in the development of the OIGIS are made for the purpose of establishing the credibility of the OIGIS project.

\subsubsection{Rockfish Habitat in British Columbia}

The following case study represents a sample of an increasing number of projects that apply GIS to the modeling of benthic fish habitats based upon conditions known to be conducive to hosting a particular species. This and similar projects have been used with great success to direct conservation and fishery management efforts in the absence of reliable survey data of the sort being generated by the Ocean Institute. This project established a precedent for the analysis of benthic fish species occurrences as well as for the handling and depiction of Marine Protected Areas (MPAs) of the sort that formed the basis for the Dana Point Marine Wildlife Refuge portion of the OIGIS.

A case study designed to predict rockfish habitats in British Columbia, Canada, was conducted in order to research the establishment of MPAs dedicated to the conservation of rockfish. These MPAs, referred to as Rockfish Conservation Areas (RCAs), were part of a strategy to rebuild depleted inshore populations of this benthic fish.(Scholz \&

Wright, 2006). Up to the time of this study, MPAs dedicated to rockfish preservation had been established by evaluating candidate sites in public meetings in consultation with 
fishing associations. This methodology was primarily based upon anecdotal observations from the fishermen, but it lacked any empirical data or systematic basis. Despite the establishment of these MPAs, rockfish numbers continued to decline in British Columbia waters over the next several years (Scholz \& Wright, 2006). The method of establishing Marine Conservation Areas based upon the advice of the fishermen had lead to instances wherein conservation areas were inappropriately placed, and instances wherein decisions were affected by conflicts of interest on the part of some of the decision makers. (Scholz \& Wright, 2006)

The same data that was being generated in order to evaluate the effectiveness of the MPAs became the basis for a GIS-based model to predict where critical habitats for the rockfish would occur, and where the MPAs should be established, based upon the survey data and the known characteristics of the rockfish behavior. Once implemented, the GISbased model displayed a high degree of correlation with areas subsequently identified by local fishers and by the survey data as having high population concentrations of rockfish. In addition to the predicted high population concentration areas, this model included the previously established MPAs which were found to exhibit relatively poor correlation with the areas predicted by the model. After a period of in situ confirmation on the part of local fishers, revised MPAs were established in 2004 (Scholz \& Wright, 2006) In addition to aligning the MPAs with regions critical to the replenishment and sustenance of rockfish populations in British Columbia, the GIS also suggested and, ultimately, confirmed the limited effectiveness of the previously established MPAs which were included in the GIS and which were found to be poorly aligned with the critical habitats suggested by the GIS.

Although the rockfish GIS project was created to be a predictive model, which the OIGIS is not, there are important similarities in the two systems. Rockfish are a benthic species of fish. A number of rockfish varieties are native to the San Pedro Channel region, and occur in the Ocean Institute's surveys. The effect of the GIS for the Rockfish Conservation Area on the balancing of fishing industry activities, and conservation efforts, was difficult to assess because confirmatory surveys done by the fishers were laboriously slow to accumulate data. In addition, the surveys and GIS cover very limited extents in comparison to the known habitat of the rockfish species being studied.

This is similarly a significant limitation of the species occurrence data upon which the OIGIS relies. Within the time spans being estimated by the Ocean Institute, species occurrence correlation with ocean temperature is detectable. However, the data is, at the present time, too sparse and too limited in extent to conclude much about the distribution of a benthic species throughout the San Pedro Channel (Frankfurt, 2005). An interesting comparison to the development of the OIGIS project is the author's observation that "affordable, good quality bathymetry data are difficult to acquire in Canada" (Scholz \& Wright, 2005). Sparce species occurrence data, limited extents and elusive bathymetry data were definitely factors impacting the development of the OIGIS, as discussed in section 4.2 of this paper. Fortunately the data that was available allowed the construction of the bathymetric backdrop for the San Pedro Map that is sufficient for the client's survey planning purposes.

The stated purpose of the GIS analysis of rockfish MPAs was to find solutions that optimized both conservation and fishing industry activities. Both fishing and 
conservation efforts pertaining to rockfish continue in British Columbia and the resulting effects of this GIS project on the rockfish population have yet to yield conclusive results. Furthermore, the project only covered a small percentage of the coast of British Columbia and only 7 of the 90 Rockfish Protected Areas around the coastal region. Within the study area, comparisons of high population areas indicated by the GIS model with the previously established RCAs led to a number of them being rescinded, and consideration of the reinstatement of an additional number that had already been rescinded. Scholz and Wright conclude that the model should be applied on a much more widespread basis throughout the British Columbia region in order to achieve its objectives. Based upon their analysis of how the older RCAs matched the regions that the model predicted as having high population concentrations, they estimate that approximately $40 \%$ of existing RCAs around British Columbia are inappropriately placed to protect valuable rockfish habitat (Scholz \& Wright, 2005).

\subsubsection{Identifying Regions of Persistent Giant Kelp (Macrocystis pyrifera) Around} Santa Catalina Island for the Designation of Marine Protected Areas

This case study utilized a GIS to investigate the influence of various physical environmental variables on the distribution of giant kelp around Santa Catalina Island, off the southern California coast (Bushing, 1995). Giant kelp (Macrocystis pyrifera) is an important species in the marine environment around Santa Catalina Island, serving both as habitat and as food for a wide range of marine species. This study provided an example of an increasing number of GIS applications to the management and study of Marine Protected Areas (MPAs) in the Southern California region. The OIGIS utilized both MPA and giant kelp data layers that were either utilized of developed as a result of this project. This study was also relevant to the development of the OIGIS due to the underlying concern about the effects of El Nino events on the southern California marine environment.

The deliverables from this GIS project consisted of disturbance models which were created to predict the effects of El Nino events on the giant kelp located around Santa Catalina Island. Ecologically, the term disturbance has been defined as the discrete removal of individual organisms from a biological population, a detectable change in population response to sudden changes in resources, or an event causing a community or ecosystem characteristic (e.g., species diversity) to diverge from its normal range. (Bushing, 1995) Therefore, for the purpose of this study, a disturbance model can be defined as a simplified representation of a system or phenomenon in which sudden changes in resources, or events are simulated for the purpose of observing divergence from the system's normal range.

Although the OIGIS was not designed to be a predictive model in its current form, a comparative examination of this study helped to develop concepts for addressing the presence of kelp beds and MPAs as features having substantial effects in the San Pedro and DPMWR environments, as well as developing ideas about the probable effects of future El Nino events on the marine habitats of interest to the client for this project, and how to detect them. In this case study, the occurrence and persistence of giant kelp was viewed as an important habitat and food source supporting biodiversity in the marine environment, and supporting the inclusion of this feature as a data layer in the OIGIS. 
Most of southern California's giant kelp currently resides along the coastlines of the Channel Islands, including Santa Catalina Island. Personal observations of long term residents familiar with the San Pedro and Channel Island marine environments suggest major variations in the extents of the kelp beds over the past 25 year period. (Howe, 2005) In recent years, the extents of the giant kelp beds have been on the decline. These changes have been attributed to increased sewage pollution, sea urchin grazing, elevated temperatures associated with global warming, and various other causes. The desire to understand the factors driving these variations has been a major influence in the establishment of marine reserves throughout the southern California coastal region, and around Santa Catalina Island in particular (see Figure 8).

Santa Catalina Island's highly dissected 54 mile coastline offers a wide range of habitats characterized by vastly different physical variables in terms of storm exposure, water temperature and illumination levels. GIS data layers included in this study were developed for physical variables thought to be significant to kelp persistence such as digital terrain model, digital bathymetric model, submarine slope, submarine aspect, bottom relief, insolation (incoming solar radiation), wave height, and kelp distribution over several survey years. (Bushing, 1995) Definite patterns in distribution were observed relative to aspect, depth, slope, temperature, and insolation. GIS overlay methods used on the kelp distribution maps from the different survey years were used to develop a layer representing the temporally persistent kelp beds around Catalina Island. Correlations between the temporally persistent kelp beds and the various physical variables were used to identify regions suitable for designation as MPAs

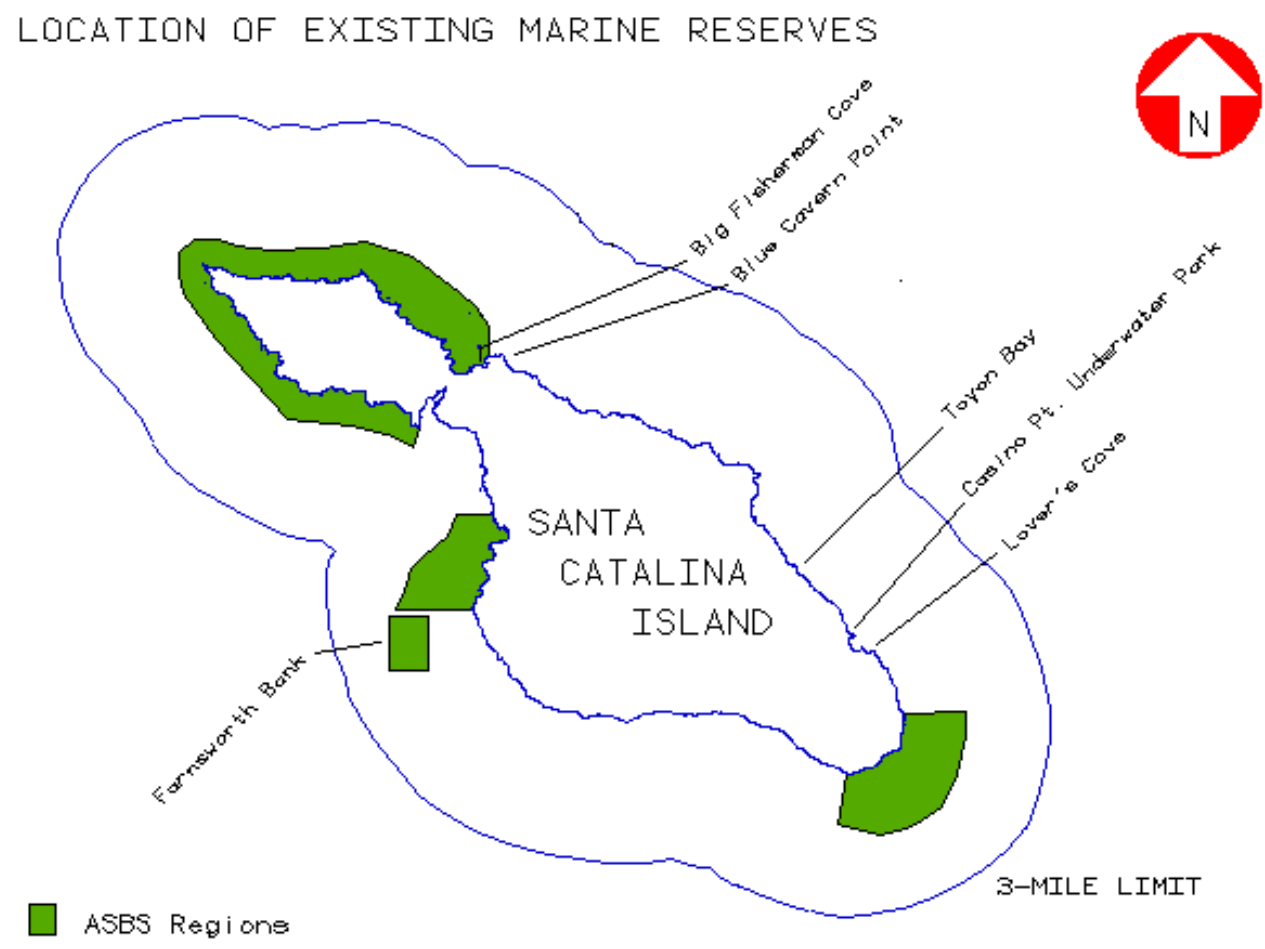

Figure 8. Marine reserves and Areas of Special Biological Significance (ASBS) around Santa Catalina Island 
The analysis used the data layers to create models of wave and storm exposure, insolation and the persistence of kelp around the island. These models helped decision makers visualize the effects of ecological disturbances generated by one or more of the physical variables simulated in the model. This in turn enabled the development of disturbance models for predicting the effects of submarine slope, submarine aspect, bottom relief, insolation, wave height, etc., on the kelp beds, their ability to recover from ecological disturbances, and to predict areas of kelp persistence over time. (Bushing, 1995) The GIS used these disturbance models to create kelp persistence layers which incorporated kelp maps from several years, enabling the analysis of kelp distribution change over long spans of time.

Warm water episodes such as an El Nino have particularly serious negative effects on the growth and survival of giant kelp (Bushing, 1995). El Nino events have played a role in the decrease of the kelp beds directly by subjecting the species to the physiological stress caused by elevated temperature or indirectly due to other associated phenomena such as reduced nutrient levels or increased offshore storm-related phenomena, such as a powerful south swell. On a local scale, exposure to wind, waves, and storms play important roles in the disturbance models. Storms impact the island's windward side primarily from the northwest or west during winter, but may also strike from the south during summer or autumn, or on the leeward side during Santa Ana winds. Storms occur with greater frequency during years experiencing strong El Nino events, and the ocean temperatures are persistently above normal (Bushing, 1995). Kelp plants weakened by persistently elevated ocean temperatures are less resistant to wave activity, which is generally increased by the frequent storms spawned by an El Nino condition.

Kelp distributions for several years were used to generate levels of kelp persistence for diverse zones around the island. The spatial distribution of these levels was evaluated statistically to determine what physical factors contributed to kelp's persistence or decline. The kelp distribution maps were based on survey data gathered by Southern California Edison. This data layer was used by Southern California Edison to determine (among other things) the persistence of kelp near its San Onofre nuclear power plant. (Bushing, 1995) Further statistical tests were run to differentiate environmental factors related to the persistence of kelp on the windward coasts and leeward coasts, respectively.

Physical variables consistent with El Nino events emerged as a major source of reductions in giant kelp over large spatial extents. (Bushing, 1995) The waters surrounding Santa Catalina Island are persistently the warmest in the Channel Islands region, with temperatures regularly exceeding 20 degrees Celsius during the warmer months. In this temperature range, the kelp around the island is near the limits of its preferred temperature range (Bushing, 1995) under nominal conditions, and for this reason even mild El Nino events will tend to have dramatic negative impacts on the persistence of this species. At more localized extents, surge and waves associated with storms emerged as the most important cause of kelp mortality in the disturbance models. The windward side of Santa Catalina Island receives incoming winter storm energy with little protection. Its steep bathymetry intensifies the impact of incoming storm surge and waves. An interesting finding of the disturbance models was that, contrary to expectations, kelp on the windward side of the island did not favor deeper water zones 
where the waves and surge effects would be lessened. This prediction was supported by observations which confirmed that its distribution was in uniformly shallower depths than on the leeward side of the island. The incorporation of storm exposure, as measured by the significant wave height, offered an improvement over research into kelp persistence conducted in the past.

For the purposes of this case study, GIS was found to be an effective tool for modeling the effects of physical variables in the marine environment that have an impact on the giant kelp habitats, and it is also an excellent means to identify locations warranting more intensive field work. Regionally, distinct differences in storm exposure between the windward and leeward sides of the island resulted in significant local differences in the reduction of kelp within the region. An important observation and recommendation of this study was that environmental phenomena known to be detrimental to giant kelp may decimate the kelp beds located in MPAs if the MPAs are restricted to geographically homogeneous site conditions or too small of a range as is presently believed to be the case around Santa Catalina Island. (Bushing, 1995) This study concluded that establishing new marine reserves on the windward side of the island was advisable since storm-related surge and waves were not found to be as potentially disturbing to the kelp as elevated water temperatures, which are most pronounced on the relatively protected leeward side of the island. Therefore, in the event of a wide-spread and persistent change in the environment, such as elevated ocean water temperatures, which facilitate extensive mortality among the giant kelp, remnant patches of kelp surviving on the cooler windward side of the island could provide "seed stock" for the re-establishment of population all around the island.

\subsubsection{Marine Life Alliance}

In researching GIS solutions which addressed coastal marine phenomena, the efforts of the International Marine Life Alliance (IMA) were examined due to their use of GIS in the establishment and management of MPAs. To protect ecologically unique regions of the ocean around the Philippine Islands, IMA is making extensive use of GIS for coordinating coastal wildlife conservation efforts, and for educating the local population on conservation techniques. This effort has met with great success which has largely been attributed to the analytical and educational effectiveness of GIS (Convis, 2001).

The Philippine Islands possess an extremely rich, diverse, and fragile marine ecosystem which has been a favored source for salt water aquarium fish for many years. The Philippines has also been a major exporter of live-food fishes favored throughout Asia. Fueled by this demand, rural fishermen on some of the islands were engaging in destructive and non-sustainable fishing techniques such as the use of sodium cyanide to stun coral reef fish so that they could easily be gathered for sale to collectors (aquarists), and the use of rocks and poles to break apart reefs and drive the larger fish into nets to be sold as food. Since a mature coral reef takes decades to develop, it is obvious that this method of livelihood could not be sustained for long, and was highly destructive to this rich and beautiful environment. Although the Republic of the Philippines has strict laws protecting the coral reefs and prohibiting destructive fishing practices such as these, the laws are difficult to enforce due to " 770,000 small scale municipal and commercial fishermen and more than 4000 aquarium fish collectors spread across 7000 islands." 
(Convis, 2001) Where law enforcement was ineffective, the IMA has met with great success. Starting in 1998, the IMA initially undertook an urgent campaign to map the remaining coastal habitats and to re-educate the Filipino fishermen in the use of nondestructive fishing methods. Once the habitats were mapped, the IMA employed GIS as an educational tool to model sustainable fishing practices for the fishermen and village leaders. The IMA provided extensive GIS training for personnel in the Philippines Bureau of Fisheries and Aquatic Resources and developed a database with portal locations scattered across five cities in three provinces staffed by Filipino GIS technicians. As of the printing of the story these offices had created numerous maps for fishing villages and continued to promote sustainable fishing techniques throughout the nation. (Convis, 2001)

The work of the IMA and the Philippines Bureau of Fisheries and Aquatic Resources GIS was in this case geared to the creation of coverages to support community decision making, such as deciding where to establish Marine Protected Areas, or evaluating new sites for the emerging industry of mariculture (fish farming) which is less costly and more productive than traditional fishing, when properly managed. (Convis, 2001) The IMA also supervised and financed the re-education of many of the Filipino fishermen into the mariculturists who now staff the fish farms.

This account contained an example in the form of the Ca-oy coral farm, which became the regional training center on Olango Island (situated in the municipality of Lapu Lapu, near the island of Cebu) for the IMA and the Philippines Bureau of Fisheries and Aquatic Resources. On this island the IMA initiated protection measures to rehabilitate the damaged coral reef areas in the region (including several other islands) and expand training in coral farming throughout the same region. In addition to educating fishermen formerly employed in destructive, non-sustainable fishing (and coral collecting) methods in the ways of sustainable fishing, many of these people were educated at this facility to the point where they were able to make a career transition of sorts into mariculture pursuits, specifically fish farming and coral farming. The fishermen now understand the difference between sustainable and non-sustainable practices and are actually helping to enforce the Marine Protected Areas. The account acknowledges that some challenges remain and that the management and protection of the Philippine coral reefs is still not as robust as the IMA would like to see it, but huge progress has been made toward a more harmonious relationship between the Filipino fishermen and their environment. The communication tool that succeeded in a multinational group with many language barriers was GIS, and the management tool of choice for the IMA, the Philippine National Government, and the rural fishing villages was GIS.

Although the Ocean Institute faces and entirely different variety and extent of problems in comparison to what the IMA faced in its efforts to protect the coastal marine environment, both organizations do share significant similarities. Both environmental protection efforts contain Marine Protected Areas (or as at the Ocean Institute, a Marine Wildlife Refuge) that are bounded by and experiencing stress from areas open to use by an ever growing human population. Both environmental protection efforts deal with coastal zones and both concern themselves with phenomenon that are relatively stationary and limited in extent. Both ecosystems are fragile and take many years to 
recover if damaged, and both are inhabited by numerous life forms that are (if not rare) not common and, therefore, worth preserving. 


\section{Methodology}

The client specified two very different purposes for the OIGIS. One purpose is to better enable the Ocean Institute personnel to plan future surveys. The other purpose is to display the results of these surveys in meaningful ways in order to detect temperatureinduced changes to the frequency in which a particular species is encountered, and to present these findings to an audience comprised of school-aged children. From the initial discussions with the client, map extents were specified that included the L.A. harbor as the northern extent, Santa Catalina Island as the western extent, and San Onofre as the southern extent (Baker, 2006). This specification was intended to support the planning of future surveys and other research. The marine wildlife surveys that the Ocean Institute has conducted to date can be accommodated by much smaller extents. Therefore, in order to address the analytical requirement for this academic program, and the needs of both proposed audiences for this GIS, a very limited portion of the map image is used in the output reports.

Operator queries to this GIS will take three basic forms and will be delivered via three different media: a) display the map in order to visualize (or illustrate for the audience) the primary sub-marine features of the San Pedro Channel, and Dana Point's relative position on its fringes; b) species-specific investigations of whether statistically significant variation is occurring within the sample for that species; c) determine if there is any detectable variation in a particular species occurrence data-subset, and whether it is positively or negatively correlated with environmental variations. Initially, the environmental variation will be limited to comparisons between the species occurrence and changes in the ambient ocean temperatures in the study area.

From an analysis standpoint, the OIGIS constitutes a tool for conducting an ongoing analysis that will become increasingly credible as the data that is input into it is accumulated going forward over time. As the data from the ongoing surveys comes to include more and more species occurrences, and the variations in ocean temperature continue to be input into the OIGIS, the observations that can be derived from the system with respect to a given species will be increasingly credible and relevant to the reality of that species' overall situation within the survey area. It is beyond the scope of this project to develop a finished analysis with carefully researched conclusions to put forward at this time, even though that may be possible with respect to some of the more commonly occurring species represented in the dataset. The primary effort in completing this project was therefore in mechanizing the analytical process for a large number of indigenous species and for a relatively long time frame to enable the client to identify what species and/or what time frame to formulate further questions around. Additionally, these things had to be accomplished in a consistent manner by personnel untrained in the use of ESRI software.

To address all these design considerations, a simple custom toolset or user interface was clearly required, and there are numerous methodologies for accomplishing this that are either compatible with, or built into the ArcMap software such as Model Builder, VBA (Visual Basic for Applications) and Python Script. Due to considerations of convenience to the user, seamless interface with ESRI software, and resistance to inadvertent operator induced damage, the design of the OIGIS custom toolset was based upon ArcObjects with VBA. 


\subsection{Methodological Constraints}

The analytical portion of this project features an output that is rather simplistic due in part to the inability to exactly georeference the species occurrences to anything more precise than the trawl line midpoint, and due to the limited capacity that the intended audience is assumed to possess. Although the output does not constitute an especially rigorous spatial analysis, it is entirely valid and meaningful as far as it goes. By far the most challenging part of completing this project was the development of the extensive code that provides the functionality of pulling the temperature data off the internet as well as out of the species occurrence datasets, and then executing a statistical comparison of the two.

Although the starting point and direction of these survey trawls are accurately georeferenced, the personnel conducting the survey face ongoing challenges to their ability to execute the surveys with a high degree of accuracy. Additionally, the survey personnel have no idea of the exact point along their trawl line at which a particular fish enters the survey net. Common practice in Marine GIS is to associate all fish species occurrences with the midpoint of the transect line along which they were caught (Cooper, 2006). Without the ability to georeference the occurrences to anything more affirmative than a transect line midpoint, it is obvious that limitations exist in terms of the precision to which a spatial analysis can be conducted with this data. However, the creatures being surveyed are not stationary objects on the ocean floor and therefore some generalization with respect to their exact location of occurrence is necessarily acceptable. An example of one type of analysis that continues to be used frequently is the estimation of population density calculations for a given species (Howe, 2006). For this type of analysis, each trawl station is calculated as being $16^{\prime}$ wide and $1 / 3^{\text {rd }}$ of a nautical mile long (or 2023'). Although this assumption does not address data accuracy issues such as wind, current, and tide effects, an abstract picture of population distribution within the extents of the survey can be derived through comparison of the resulting metric for each of the trawl stations.

Another fundamental consideration with respect to the sophistication of possible spatial analysis on this data is the fact that the surveyed area constitutes a very limited fraction of the known habitat of each of the fish species occurring in it. This consideration suggests that distributions of a given species that are calculated and depicted by this GIS are only meaningful to the client in determining where the various species are occurring within the extents of their survey. Any detected changes or variations in the distribution of a species' occurrences from one survey to the next will amount to local, random, and ephemeral variations within a much greater range throughout which the given species is found. For purposes of calculating species density, the Ocean Institute and SCCWRP estimate the trawl to be $16 \mathrm{ft}$ wide by $1 / 3^{\text {rd }}$ nautical miles long, and then extrapolating this figure throughout the survey area (Howe, 2006). Given this limitation, distribution variations among the trawl lines are not expected to be of any relevance to the overall habitat of the species until a much more extensive survey is possible. With these limitations in mind, the client must regard the map symbology as indicating only the locations within the survey where the occurrences of a species are taking place, and carefully avoid drawing conclusions about the species of a more extensive nature (Black, 1985). Changes to the frequency of occurrence of a given species over time throughout 
the entire survey area would be significant, indicating a general decline or increase in that species in the San Pedro Channel region.

An additional significant variation that could be detected with this GIS would be the occurrence of one or more species that are not native to the region (Baker, 2006). In one possible hypothetical instance, benthic fish that are indigenous to areas south of the San Pedro Channel are displaced northward along the coast, seeking cooler temperatures that are to their liking (or to that of their food source). This sort of migration would be motivated by the need of the fish to move northward in an effort to find water temperatures that are to their liking during a major and sustained increase in regional ocean temperatures to the south, as occurs with the higher magnitude El Nino events. These sorts of variations are what the client will be hoping to detect and to communicate by using this GIS, but other possible variations are foreseen as well.

Some fish species indigenous to the San Pedro Channel may actually experience dramatic increases in their population as a result of elevated ocean temperatures, either because the warmer temperature suits them physiologically, or because the portion of the population living further south may be displaced northward into the San Pedro Channel where temperatures still suit them or their food source (Baker, 2006; Howe, 2006). Other species will exhibit little or no change, indicating that whatever ocean temperature change has occurred, the result is still within their range of tolerance. Some detected variations in species occurrence frequency will likely occur with no correlation to the variations in ocean temperature for the same time period, indicating that the variation detected by this system is attributable to something other than ocean temperature variations, or to secondary factors that may be influenced by the temperature variations indirectly or with delayed effects.

This GIS and the analytical tools with which it is equipped represent only a basic first step into lines of inquiry about the effects of the El Nino phenomenon as well as about the life cycles of numerous but often overlooked and, therefore, little understood fish species. From the data presented in this system, it is possible to reach conclusions about whether species occurrence variations are taking place within the survey area, and whether those variations are correlated with variations in ocean temperature.

Additionally, it will be possible to identify the location within the survey area where the highest concentration of a given species resides. The output of this system includes a distribution analysis; however until the surveys become much more extensive and frequent, this will only serve to tell the client where, within their survey area, a given

species is being most frequently encountered, and for the time being, have little meaning beyond this (Kumler, 2006).

\subsection{Consultations with Subject-Matter Experts}

Before the final determination of the methodologies to be used, various subject matter experts were consulted. Their advice and guidance became central to the success of this project.

For answers to the numerous questions regarding marine biology that came to light during the development of this system, Mark Howe, marine biologist and instructor at 
Saddleback Community College, was the primary source of information. Mr. Howe once worked at the Ocean Institute, and currently teaches at Saddleback Community College, one of the institutions included in the original Joint Powers Agreement establishing the existence of the Ocean Institute. Mr. Howe's experience as a marine biologist and his association with the Ocean Institute spans many years. Initially, the Ocean Institute's survey methodology was somewhat difficult to understand. However, Mr. Howe was instrumental in making this procedure clear and also suggested the use of the trawl line midpoints as a georeference for the species occurrence data which is in use with this system. Along with the client, Mr. Howe was the source for much of the understanding of benthic fish species behavior that gives meaning to this project.

Larry Cooper, Information Systems Manager at the Southern California Coastal Water Research Program (SCCWRP), has been the recipient of the survey data that the Ocean Institute, as well as other sources, has generated over the last few decades. With the data that they have received, SCCWRP has created the Bight Field Device and numerous other MS Access databases including the OCMI Fish Data Entry and Analysis program for use by the Ocean Institute. These programs are databases designed for entering survey data into, and for running non-spatial queries on, the Ocean Institute's survey data. Although fluent in GIS as well, Mr. Cooper's accountabilities and concerns encompass a much greater range than the Ocean Institute alone and, therefore, he and his GIS associates at SCCWRP are devoted to a broader range of tasks than developing GIS specifically for the client of this project. Mr. Cooper was more than supportive in supplying the Ocean Institute's species occurrence data and offering any other useful datasets that SCCWRP possessed, and also suggested the use of the Scripps Pier data and the internet link to the source of that data that are utilized in this system.

Rob Burke, GIS Programmer at ESRI, and author of Getting to Know ArcObjects, ESRI Press book (Burke, 2003), served as the primary advisor for the development of the Visual Basic for Applications code and ArcObject programming from which the automated functionality of the OIToolset is created. Mr. Burke was consulted, soon after a number of early analyses on the data were conducted, to answer questions about the suitability of the analysis process being automated through the use of VBA and ArcObjects. These inquiries led to Mr. Burke's increasing involvement in guiding the development of this system in the final months prior to system implementation with the client. Mr. Burke also suggested the symbolic data presentation scheme that was ultimately adopted for displaying the distribution of species occurrence on these maps. Mr. Burke's contributions to this project became invaluable and many of the later design refinements can be attributed to him.

\subsection{Chosen Methodologies}

After extensive consultation with the subject-matter experts involved in the development of this project, development was undertaken by simultaneously creating a suitable set of maps upon which to base this GIS, and a conceptual workflow (See Figure 9) designed to address the needs of untrained system operators and young, $\mathrm{K}-12$ grade audiences. 


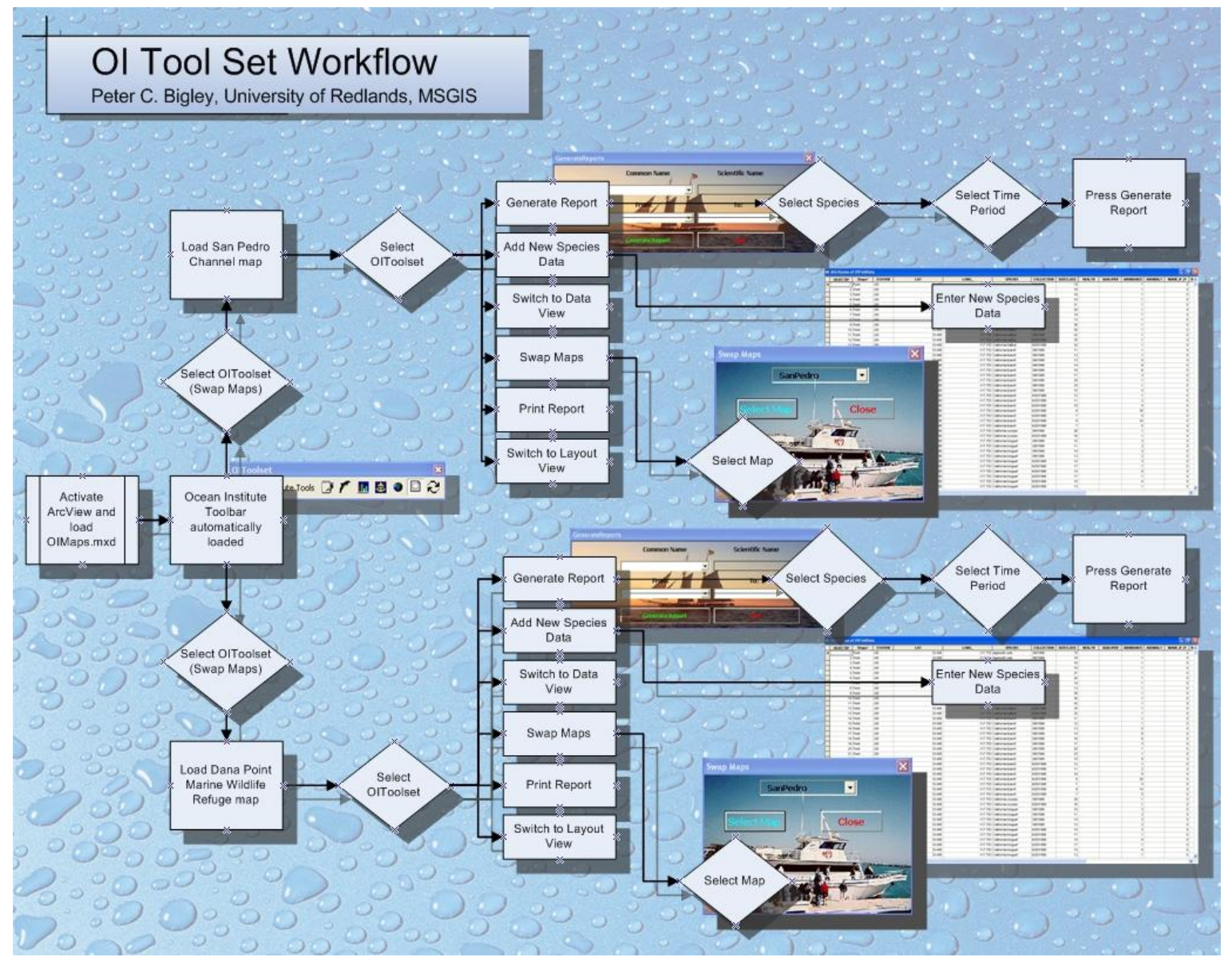

Figure 9. OI tool set workflow sequence.

A primary consideration for the operators was to develop a system which, for the most part, could function through all tasks depicted in the workflow by the exclusive use of the ArcMap main toolbar and OIToolset toolbar. The OIToolset is comprised of the custom tools that were created using VBA and ArcObjects. At this time, the Ocean Institute possesses no trained GIS operators, and operation of the system is expected to fall mainly on the shoulders of the Institute's numerous marine biologists who are otherwise engaged in their primary tasks of teaching the clientele and the day-to-day operations of numerous other systems. Considering the busy operational tempo of the client's employees, whatever operator training was to take place in the short-term, would be undertaken shortly after system deployment at the Ocean Institute. In order to quickly achieve basic functionality with this system, and to make it as easy as possible to use, one of the fundamental design considerations was to keep the workflow as simple as possible while still meeting the client's requirements on the functional level.

To accommodate data that will be generated in future surveys, the design of the OIGIS incorporated Larry Cooper's advice of equipping the system to extract the needed ocean temperature data from the UCSD Scripps Pier website. With this accomplished, the system would be usable into the foreseeable future, with the only necessary maintenance being the input of new survey data as it was generated. The primary drawbacks of this decision are that full system functionality is dependant upon internet access (which 
presents a challenge for the system loaded onto the ship's computer), and that the system is vulnerable to format changes to the Scripps Pier website.

To accommodate the use of this GIS on board the R/V Sea Explorer, where internet access is not available, a simplified version of the system is being developed which features its own temperature datasets. This version of the system will require periodic updating in order to be utilized with newer data. This presents a problem due to the fact that the ship is the source of the new species datasets for the San Pedro Channel surveys and, therefore, the time span for which the ocean temperature correlation analysis can be conducted will perpetually lag behind the species datasets generated by the ship's survey activity. Possible future development of this system might take advantage of the fact that the ship's instrumentation does include water temperature monitoring. Use of this data would have to be researched to address the possibility that it may be too sparse to sustain a correlation analysis, and for possible discrepancies with the Scripps Institute data that might generate differing results to an otherwise identical analysis conducted by the system located on the Ocean Institute campus.

In addition to being easy to use, this GIS had to be understood by a young audience for reasons that have already been addressed. In order to display the data in such a way as to facilitate analysis that could be understood by the young clientele, and due to the inherent abstractions built into the surveying method that I have discussed in the earlier sections, I was obliged to keep map and graph symbology simple. This characteristic also lent itself to the automation that I was striving to build into the system.

In order to graphically reinforce that the occurrences of a given benthic fish species in the Ocean Institute surveys were or were not correlated with ocean temperature variation, I chose to communicate the results of the analysis by the use simple histograms. This comparison is given a more empirical measure with the text indicating the R-value, or the coefficient of correlation (Brase \& Brase, 1987; Freund \& Simon, 1970), between the fish species (y) which can be attributed to the relationship with ocean temperature (x). The Rvalue is calculated by taking the square root of the total variation of the ocean temperature and the species occurrence, which is then expressed in a continuous range between -1 to 1 , with 1 being highly positively correlated (fish occurrence increases as water temperature increases), 0 being not correlated (fish occurrence has no relationship to ocean temperature), and -1 being highly negatively correlated (as ocean temperature increases, fish occurrences decreases). This part of the analysis is nonspatial and could easily be accomplished without a GIS. While the extents of the Ocean Institute's surveys remain as limited as they are in comparison to the extents of the San Pedro Channel this will also remain the most meaningful part of the analysis.

The spatial analysis portion of this GIS consists of map symbology, which reveals the trawl lines on which the species occurrences comprising the correlation analysis are derived. The Ocean Institute conducts trawls at sixteen established locations in total. These trawls have location, length, and direction, but are not features in physical space. For this reason, the OIGIS programming depicts only the line or lines which are associated with the species occurrences from which the charts and the correlation coefficient were generated. This provides the system operator with a simple spatial analysis which communicates where the species occurrences took place, as well as how 
strongly or weakly variations in the occurrences are correlated with variations in ocean temperature for the same time period.

This functionality is provided to the client with the intent that it will yield meaningful information in the future when the Ocean Institute surveys are expanded to include other sites throughout the San Pedro Channel. At the present time, this portion of the analysis covers such a limited portion of the San Pedro Channel (and an even smaller portion of the known habitat of most of the benthic fish species) that it is very difficult to draw conclusions about the distribution of a given species within the channel with any level of confidence. As it currently exists, the OIGIS should be considered a tool for conducting analysis rather than a completed analysis in and of itself. System operators and map viewers should bear in mind that the results of the analysis that the OIGIS is capable of delivering will become more meaningful and more accurate as more data and/or more survey sites are added. At the present time, observations and conclusions based on the results of the OIGIS should be circumscribed to the immediate area covered by the trawls and considered in the context of the number of species occurrences that generated the results (which is indicated by the number of subdivisions on the charts). 


\section{Project Data}

The data utilized in the development of this GIS was, with the exception of the Ocean Institute Species Occurrence datasets, entirely obtained or derived from open sources. All data was georeferenced using the WGS1984 projection and UTM, Zone 11 reference system. There were several justifications for this decision. Primarily, this was accomplished to facilitate compatibility between datasets from diverse sources (specifically governmental research organizations which tend to favor this system) and to minimize distortion on the maps (the UTM projection central meridian for Zone 11 is located close by at 117 degrees west. On the map, distance display is expressed in nautical miles to facilitate ease of comparison to nautical charts which use this standard. Each map is based upon a raster backdrop created from a hillshade and an accompanying DEM to which a color ramp and transparency were applied. Due to the necessity of combining DEM's and bathymetric grid data to produce a raster background for a map which accommodated the coastal terrain and the ocean floor contours, the resolution achieved on the raster backdrop was only 10 meters. Although a higher level of resolution would have been preferable for displaying the Ocean Institute's current survey area, the client stated that the 10 meter resolution was acceptable considering the necessity of including the entire San Pedro Channel within the map extent (Baker, 2006).

\subsection{Data Gathering Methodologies}

\subsubsection{San Pedro Channel Trawls}

The species occurrence data utilized in the development of the OIGIS is generated by the Ocean Institute at Dana Point. Although surveys of the San Pedro benthos were being conducted since the mid-1970s, the data that I have available for this project begins in late 1997 and extends to the present time. Data from earlier surveys may eventually be incorporated into this system; however, this data is currently in a non-digital format, requiring significant processing before this can be accomplished.
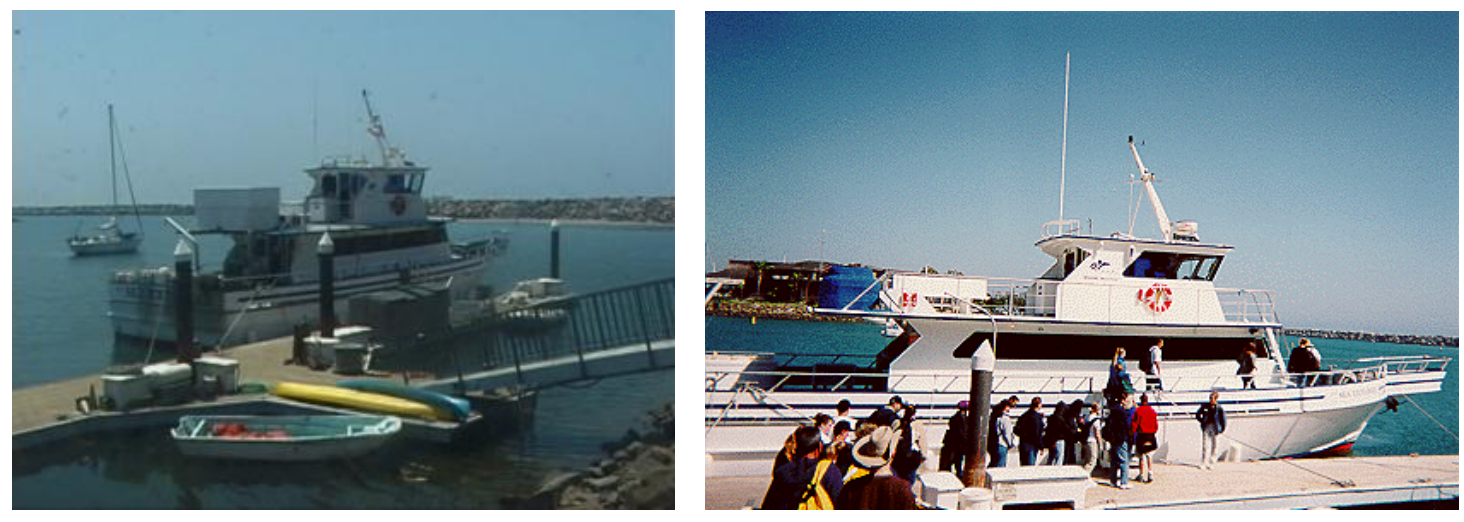

Figure 10. R/V Explorer making ready for sail at the Ocean Institute.

The process is a non-destructive, catch-and-release method of gathering samples, employing a trawl net which is towed behind the Institute's research vessel (R/V Sea 
Explorer, See Figure 10). This $16 \mathrm{ft}$. (4.87meters) wide trawl net employs weights, floats and wooden panels to ensure that the mouth of the net remains fully opened when under water and that the net sinks to the bottom when being towed. The sampling is conducted in the San Pedro Channel from trawl stations located on established transect lines (running perpendicular to the local coastline, down the local bathymetric slope). The trawls begin at the trawl stations (locate on the transect lines), but run across the slope, roughly parallel to the bathymetric contour lines (See Figure 11). In this way, diverse (albeit localized) areas of the benthos are monitored, each of which is sampled at a known, and consistent depth.

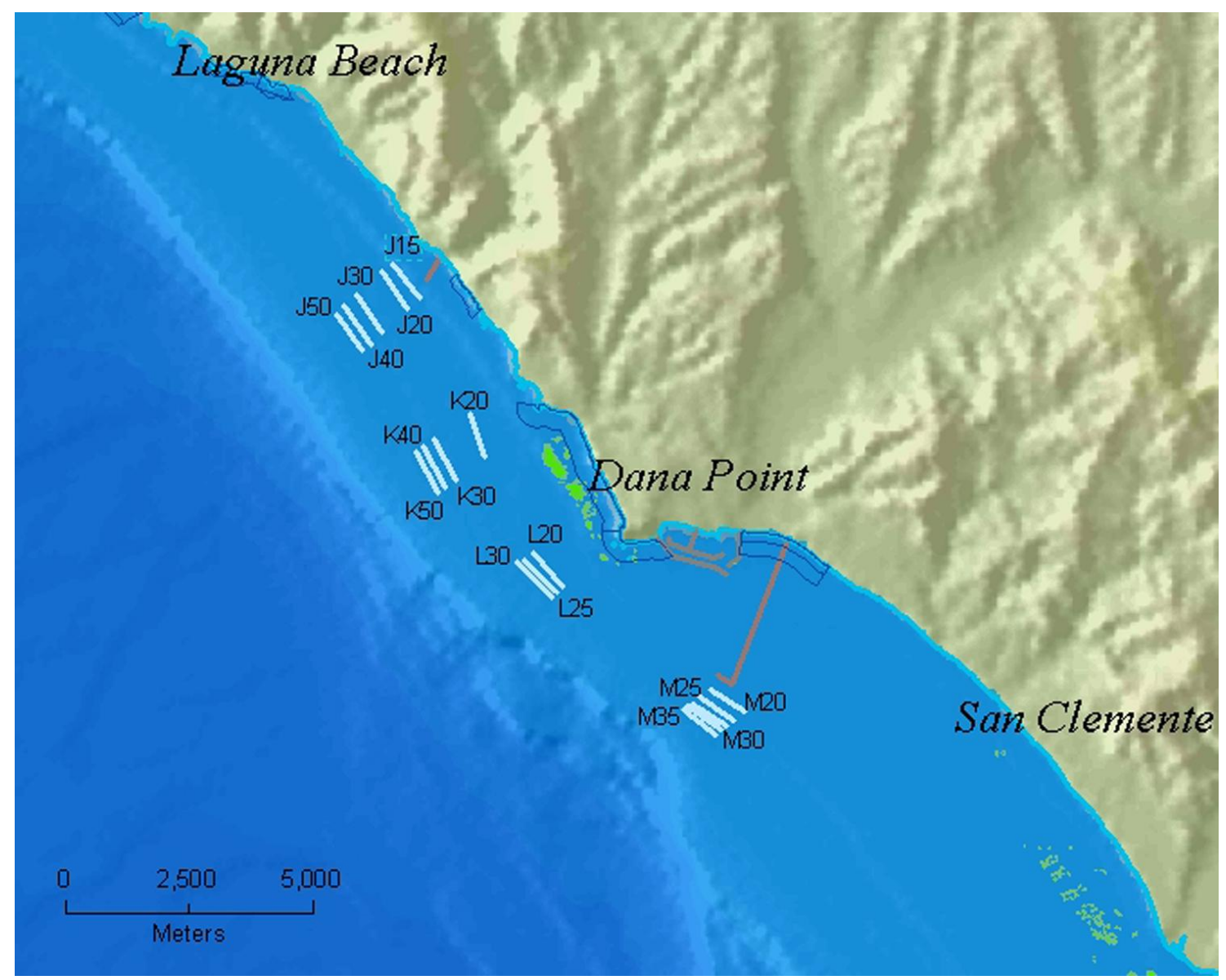

Figure 11. Transect survey being conducted in the DPMWR.

Once established at the transect line, with a heading appropriate to achieve a sample from a consistent depth, the R/V Sea Explorer deploys the net and records the ship's position via GPS. As the net sinks, the ship is brought to a 2 knot speed which is slow enough to avoid injury to the fish being caught in the net, yet fast enough to prevent their escape from it. The net is brought back up from the bottom after precisely 10 minutes so that the distance covered on each trawl is always approximately one-third of a nautical mile (or about four-tenths of a statute mile). A discussion of the precision of the R/V Sea Explorer in starting the trawls at the actual trawl station, and of the distance covered during the two-knot cruise would be lengthy and include such topics as wind conditions, 
ocean current patterns, and time of day (which would preface a discussion of tide patterns) along the portion of the San Pedro Channel where these surveys are conducted. In support of the Ocean Institute's operations, it must be observed that they are equipped with state-of-the-art GPS navigational equipment and the latest maritime charts with which to meet the challenges of wind, tide, and current. On the other hand, these factors create a highly dynamic environment in which to try and hit an unseen target (a trawl line). Based upon reference to the GPS the crew of the Sea Explorer estimates that the surveys can be conservatively estimated to adhere to an accuracy of approximately 350 '. Typically the Ocean Institute conducts these surveys off one of four transect lines within a 20 kilometer radius of the Ocean Institute. Additional transect sites are planned in the future, which is one of the primary considerations in the client specification that the entire San Pedro channel be included in the map extent.

\subsubsection{DPMWR Transects}

When the Ocean Institute began their current study of the Dana Point Marine Wildlife Refuge in 2002, permanent transect locations were chosen within the DPMWR. These locations were generally selected because they contained areas with good representative tide pool type habitat. Utilizing these established transect locations, surveys are laid out perpendicular to the shoreline, typically 25-30 meters in length, depending on the available distance between the cliffs located at the top of the beach and the low tide. All surveys are sufficiently long enough to cross through the upper, middle, and lower intertidal zones. Upper zones are defined by the client as areas covered during high tides only, and are characterized by biological species such as barnacles, periwinkle snails, etc. Middle zones are areas that spend approximately equal time submerged and exposed to the air. Lower zones are only exposed during the lowest tides and are typically inhabited by fish, surfgrass, octopus, sea cucumbers, etc. (Graver, 2006)

From all the possible points located on all the DPMWR transects, 5 points were randomly chosen from each intertidal zone as the permanent sampling areas. These points were sampled 3-4 times per year from 2002 through 2004 to look for changes in populations of the most commonly collected species from the tide pools (turban snails, hermit crabs, sea stars, etc.) over an extended period of time (See Figure 12). For this reason, only the top eight species occurring most frequently were monitored during this project and the dataset is likewise limited to these species.
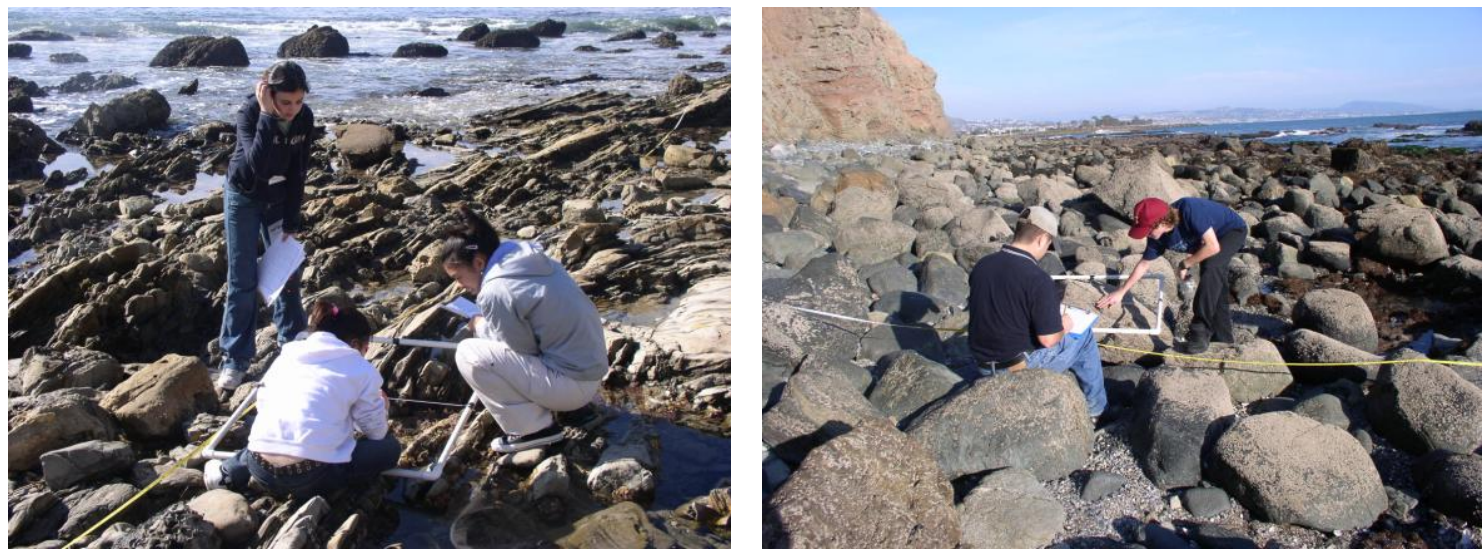

Figure 12. Transect Survey being conducted in the DPMWR. 
An example of a typical record of a sampling from these locations includes the following attributes, in addition to the species and abundance of the species: DP1, Upper Zone, 3.2 $\mathrm{m}$ DC. In this dataset, DP1 describes the name of the transect (Dana Point \#1), Upper means that the sampling point falls within the upper intertidal zone for that area, $3.2 \mathrm{~m}$ is the distance in meters down the transect tape from the starting point $(0.0 \mathrm{~m}$ is the top of the upper intertidal zone). A one-meter square plastic quadrat is then placed with its top corner resting at the $3.2 \mathrm{~m}$ mark on the transect tape. Therefore, the sampling area extends from $3.2 \mathrm{~m}$ to $4.2 \mathrm{~m}$ down the tape and 1 meter out to the side, and $D C$ indicates that the quadrat was placed so the sampling area covers the 1sq meter area on the down-coast (generally more south) side of the tape. The figure of $3.2 \mathrm{~m} \mathrm{UC}$ would indicate that the quadrat should be placed from $3.2 \mathrm{~m}$ to $4.2 \mathrm{~m}$ and the sampling area should extend $1 \mathrm{~m}$ out to the up-coast (generally more north) side of the tape.

\subsection{General Marine Data Accuracy Issues}

One of the most serious potential problems in applying GIS to benthic habitat mapping is a prevailing, general, inattention to the type, quality, and origin of the data used to construct the habitat maps, and the incomplete documentation of data collection and modification (Buckley, 2006). Marine GIS frequently makes use of datasets that are derived or adapted from data that was originally developed to support GIS, and non-GIS applications in other fields. Examples of this are common, and can be found within the data used in this project, such as the California coastline, which was obtained via the California Spatial Information Library (CASIL) data portal, and was apparently developed to support cadastral GIS applications, Coastal Cities boundaries obtained via the CASIL data portal for use by city and county governments, and waste water pipes which were developed from data about the Orange County infrastructure. Each of these datasets were either developed into GIS layers from tables, or modified from their original purpose, and clipped to the customer specified extents of the maps. Typically the modification of datasets from their original purposes introduce a level of abstraction by removing many of the technical details that were critical to the dataset having useful applications to the industry of field for which they were originally constructed.

Abstraction of datasets frequently introduces a level of inaccuracy to the datasets that is determined to be acceptable or even desirable. Specifically, elimination of details extraneous to the new purpose for which the old dataset is being applied trades off accuracy for a measure of geodatabase performance. The long-term tendency here is to derive datasets from earlier, more complete datasets, and neglect to document the procedures used, or the lineage from which the new datasets were derived. Counteracting this tendency is what makes metadata updates of vital importance. Even within a particular industry like environmental conservation the specific purposes to which a dataset may be applied will vary. For instance waste water pipes might be included in one environmental conservation project as a source of pollution, in another project as a hazard to survey equipment, and included in yet another conservation project as a location of potential biodiversity. For this reason, datasets will frequently be modified even when used for more than one project within the same industry or field. Each time the layers are modified, the data deviates further from the original data, abstraction 
increases, and inaccuracies compound. Without documentation of these modifications and their intended purposes, a user may assume that a habitat map was created from sources of equal quality and therefore should be of uniform accuracy. These problems can be exacerbated when the data is used to map highly dynamic and therefore changeable environments such as the oceans.

The precise locations of ocean shorelines are oft-cited examples of the dynamic and changeable nature of the marine environment and of the difficulties inherent in mapping these regions. Under normal conditions the constantly changing tides shift the location of the actual shoreline anywhere from a few feet in the vertical dimension (where the ocean shore meets a sheer cliff, to as much as 10 meters in places such as the Sea of Okhotsk, the northern coast of Australia, the Bristol Channel on the west coast of England, and Canada at the Ungava Bay in northern Quebec, and up to 16 meters in the Bay of Fundy between New Brunswick and Nova Scotia (Geological Survey of Canada, 2005). This magnitude of water level change is sufficient to create dramatic changes to the location of the local shoreline since millions of metric tons of water is moved every six hours with the normal swing of the ocean tides. Shoreline location shift is especially ambiguous in regions of gradual topography, where relatively modest vertical changes in sea level can cause the position of the shoreline to change by miles (see Figure 13) (Christopherson, 2005).

The normal tidal cycle induced by the moon and the sun assures considerable ambiguity in determining the position of an ocean shoreline and along much of the world's coasts. This phenomenon occurs upon a loosely packed sediment or fine gravel. In these cases, the movement of ocean water in the form of wind driven waves and tides is constantly acting upon the sediment, and all that is required is a storm of modest magnitude to displace significant amounts of sediment. These sorts of storms are common in coastal regions which are complex systems characterized by the confluence of land, water, and atmosphere. These effects serve to alter the contours of ocean coastlines on a routine basis (Bartlett, 2004).

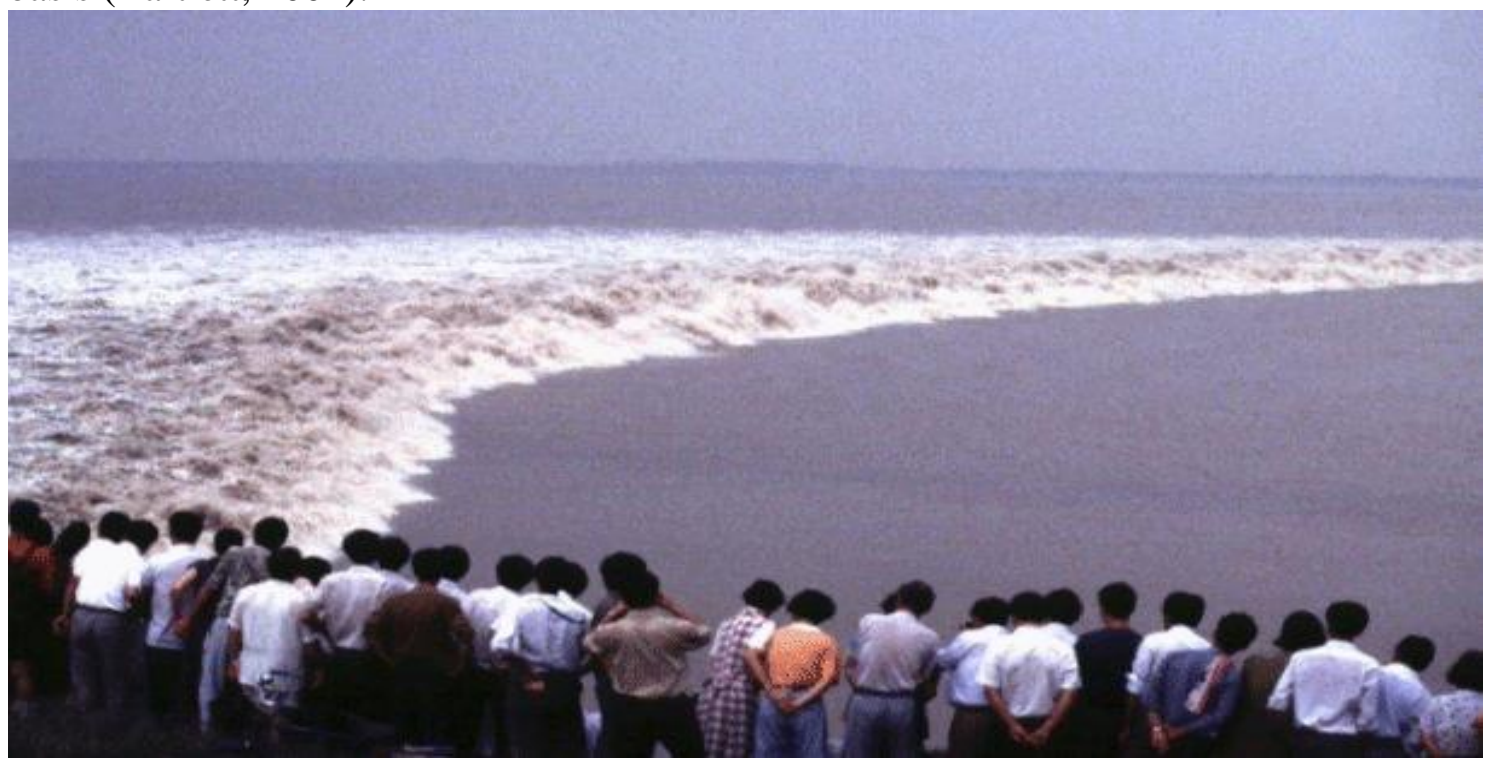

Figure 13. Tidal bore Qiantang River near Hangzhou, China. 
To counteract the tendency for inaccuracies and abstractions to compound as derived datasets are unknowingly developed from sources which are themselves derived datasets, the data utilized in this project were obtained from the original source whenever possible, and detailed descriptions of the modifications applied to them were included in the metadata. In specific instances, where a data layer is known to have inherent ambiguities associated with the feature or features being depicted, as with the location of coastlines, the established conventions prevalent in cartographic science were utilized. In the case of delineating the position of coastlines (especially at small scales such as the DPMWR map), unforeseen complications arose in determining just what conventions to adhere to.

Marine navigational charts are designed to facilitate the safe navigation of ships. In support of this, navigational charts are conservative in their depiction of obstacles that could pose hazards to shipping. Marine navigational charts depict objects such as rocks and shorelines, and display depths as they would appear at Mean Lower Low Water (MLLW), (Stenbel, 2006). Mean Lower Low Water level is the average height of the lowest low tides recorded at a particular point or station over the last 19-year period (Stenbel, 2006). In cases where such data has not been gathered, or where dramatic and atypical events may skew this data, corrections are applied to eliminate known variations and reduce the result to the equivalent of a mean 19-year value. This accomplishes a very conservative estimate of coastline position, depth at a given location, and obstacle clearance which is desirable in the safe navigation of ships.

In the case of political and cadastral applications, as well as city planning and management, coastline delineation typically occurs at the Mean High Water (MHW) level which is the average elevation of all high waters recorded at a particular point or station over a period of 19 years (Stenbel, 2006). As with MLLW, if data is only available for shorter periods of observation, or where atypical events would otherwise skew the data, corrections are applied to eliminate known variations and derive the equivalent of a mean 19-year value. This serves to conservatively set the boundary between state land under navigable waters and uplands subject to private or city ownership (Gibeaut, Gutierrez, \& Kysera, 1998).

The California coastline data layer featured in the OIGIS was obtained via the CASIL website and was originally developed to support cadastral applications. Derivatives of this coastline were utilized in the construction of both the San Pedro Channel map and the DPMWR map, therefore both maps depict the coastline as it would appear at MHW level. This particular design detail constitutes a departure from the original philosophy on which the creation of the OIGIS maps was based. In all other respects, an effort was made to create maps that conformed closely to the cartographic conventions upon which marine navigational charts are based. Depicting the shoreline at its mean high water level also simplifies the use of this feature (and the map layers derived from it) with the raster layers providing the backdrop for the other map layers, and makes the map document, as a whole, more effective. There are several reasons for this. However, the primary reason that the map document is made more effective is that the coastline, depicted at the MHW level, cleanly delineates many of the details such as canals, estuaries, and wetlands that become highly ambiguous due to similar or identical elevations when depicted with a DEM derived raster backdrop. 


\subsection{Overview of Datasets Used}

In addition to the raster backdrops, a number of vector data layers were included to provide the Ocean Institute with an accurate model of the environment in which they are conducting their surveys. Table 1 itemizes what data sets were used in each map, why they were included, and the source from which the dataset was obtained. The client's purposes for mapping these two regions in this GIS were conceptually close enough that basically the same features and elements comprise each. Exceptions were made for features which do not occur within the extents of the Dana Point Marine Wildlife Refuge map, and the coastline was retained in the San Pedro map in order to graphically render the major canals and wetlands that occur along this portion of the California coast. This included layers depicting shipwrecks and wastewater pipes. In addition, the 10 meter bathymetric contour lines were excluded from the DPMWR map since only two of the contour lines would occur within the extents of the DPMWR map, if included.

Table 1 - Dataset overview

\begin{tabular}{|c|l|l|}
\hline Dataset Name & \multicolumn{1}{|c|}{ Purpose } & \multicolumn{1}{c|}{ Source } \\
\hline $\begin{array}{l}\text { San Pedro } \\
\text { Shipwrecks }\end{array}$ & $\begin{array}{l}\text { This data layer is included to } \\
\text { depict known hazards to survey } \\
\text { equipment and, therefore, aid in } \\
\text { planning future surveys. The } \\
\text { Ocean Institute also promotes } \\
\text { interest in local maritime history } \\
\text { and, therefore, searches for these } \\
\text { wreaks in order to plan future } \\
\text { visits with a new submersible } \\
\text { ROV that it is purchasing. }\end{array}$ & $\begin{array}{l}\text { California Spatial } \\
\text { Information Library - } \\
\text { CASIL (www.gis.ca.gov) }\end{array}$ \\
\hline Coastal Cities & $\begin{array}{l}\text { This dataset is included as an aid } \\
\text { to help orient the map reader. }\end{array}$ & $\begin{array}{l}\text { California Spatial } \\
\text { Information Library - } \\
\text { CASIL (www.gis.ca.gov) }\end{array}$ \\
\hline Subsurface Features & $\begin{array}{l}\text { This data layer is included in } \\
\text { order to work in conjunction with } \\
\text { the raster backdrop to allow } \\
\text { flexibility in labeling bathymetric } \\
\text { features and, therefore, aid in } \\
\text { planning future surveys. }\end{array}$ & $\begin{array}{l}\text { Vector points, derived from } \\
\text { nautical charts and input as } \\
\text { point features based on } \\
\text { Lat/long positions }\end{array}$ \\
\hline $\begin{array}{l}\text { 10 meter } \\
\text { Conthymetric }\end{array}$ & $\begin{array}{l}\text { This dataset depicts bathymetric } \\
\text { contours down to a depth of 560 } \\
\text { meters and is included to aid in } \\
\text { the planning of future surveys } \\
\text { by allowing the client to } \\
\text { establish the location of a } \\
\text { desired depth. }\end{array}$ & $\begin{array}{l}\text { Obtained from California } \\
\text { Department of Fish and } \\
\text { Game (www.dfg.ca.gov) }\end{array}$ \\
\hline
\end{tabular}




\begin{tabular}{|c|c|c|}
\hline $\begin{array}{l}\text { Marine Protected } \\
\text { Areas }\end{array}$ & $\begin{array}{l}\text { This dataset is provided to enable } \\
\text { the map reader to observe the } \\
\text { position of Marine Protected } \\
\text { Area boundaries including the } \\
\text { Dana Point Marine Wildlife } \\
\text { Refuge. }\end{array}$ & $\begin{array}{l}\text { California State Lands } \\
\text { Commission (www. } \\
\text { gis.slc.ca.gov) }\end{array}$ \\
\hline Kelp Forests & $\begin{array}{l}\text { This data layer is included to } \\
\text { depict major features in the } \\
\text { marine environment. Although } \\
\text { the kelp is a potential hazard to } \\
\text { survey equipment, the Ocean } \\
\text { Institute also seeks to preserve } \\
\text { these habitats as well. These } \\
\text { surveys conducted annually } \\
\text { since } 2002 \text {. }\end{array}$ & $\begin{array}{l}\text { California Department of } \\
\text { Fish and Game - Dataset } \\
\text { based on surveys } \\
\text { conducted in 2005, which } \\
\text { is the most resent survey to } \\
\text { be released in shapefile } \\
\text { format. (www.dfg.ca.gov) }\end{array}$ \\
\hline Breakwaters & $\begin{array}{l}\text { This dataset depicts the major } \\
\text { harbors, breakwaters, and jetties } \\
\text { in the area. This data is } \\
\text { included to aid in the orientation } \\
\text { of the map reader. }\end{array}$ & $\begin{array}{l}\text { Digitized from } \\
\text { georeferenced imagery } \\
\text { obtained from California } \\
\text { Spatial Information Library } \\
\text { - CASIL (www.gis.ca.gov) }\end{array}$ \\
\hline Coastline & $\begin{array}{l}\text { This dataset is the official } \\
\text { recognized coastline of } \\
\text { California depicted at MHW } \\
\text { level. }\end{array}$ & $\begin{array}{l}\text { California State Lands } \\
\text { Commission, Resource } \\
\text { Management GIS } \\
\text { (www.gis.ca.gov) }\end{array}$ \\
\hline Ocean Polygon & $\begin{array}{l}\text { Based on the Coastline data, this } \\
\text { polygon was created to help } \\
\text { enforce topology rules built into } \\
\text { the GDB. }\end{array}$ & $\begin{array}{l}\text { Derived dataset constructed } \\
\text { using Coastline feature. }\end{array}$ \\
\hline $\begin{array}{l}\text { Trawl stations / } \\
\text { Survey Transects }\end{array}$ & $\begin{array}{l}\text { Based on georeferencing } \\
\text { conducted at the Ocean Institute. } \\
\text { This dataset shows the actual } \\
\text { beginning and end points of the } \\
\text { trawl stations used in their } \\
\text { surveys. }\end{array}$ & $\begin{array}{l}\text { Derived datasets } \\
\text { constructed using Ocean } \\
\text { Institute Information. }\end{array}$ \\
\hline
\end{tabular}

Two datasets that are critical the analysis portion of the OIGIS, but that were not directly utilized in the producing the OIGIS map were the species occurrence dataset and the ocean temperature dataset. 
The species occurrence datasets for the two areas of interest of this project are comprised of two separate dbf files in which the species occurrences are organized as records in tabular form, and attributes associated with each occurrence are arranged into columns (See Table 2). This data arrangement facilitated querying and analysis, and was the original format of the species occurrences associated with the San Pedro Channel trawls. The OIGIS was designed to utilize this data in the same format as the client currently gathers and archives it, which is intended to make data from new trawls available for inclusion into the analysis as soon as it is input by the client. Unfortunately, the species occurrences associated with the DPMWR required fundamental reworking to achieve the same format since, in this dataset, each survey was recorded in an individual table which did not lend itself to easy querying. Due to time constraints related to completing the MS GIS program, data for this region has yet to be included in the OIGIS.

Table 2 - Extract from Species Occurrence Dataset for the Dana Point Marine Wildlife Refuge.

\begin{tabular}{|c|c|c|c|}
\hline Station & Species & CollectionDate Sizeclass & Abundance \\
\hline 1 TC1lower & & $4 / 13 / 2002$ & 11 \\
\hline 2 TC1lower & Turban Snail & 4/13/2002 & 1 \\
\hline 3 TC1middle & Hermit Crab & $4 / 13 / 2002$ & 18 \\
\hline 4 TC1middle & Owl Limpet & 4/13/2002 & 3 \\
\hline 5 TC1middle & Turban Snail & 4/13/2002 & 2 \\
\hline 6 RP2lower & Hermit Crab & $12 / 2 / 2002$ & 19 \\
\hline 7 RP3lower & Hermit Crab & $12 / 2 / 2002$ & 4 \\
\hline 8 RP3lower & Turban Snail & $12 / 2 / 2002$ & 2 \\
\hline 9 RP3middle & Hermit Crab & $12 / 2 / 2002$ & 3 \\
\hline 10 RP3middle & Owl Limpet & $12 / 2 / 2002$ & 5 \\
\hline 11 RP3middle & Turban Snail & $12 / 2 / 2002$ & 2 \\
\hline 12 RP3upper & Owl Limpet & $12 / 2 / 2002$ & 14 \\
\hline 13 RP4lower & Hermit Crab & $12 / 2 / 2002$ & 11 \\
\hline 14 RP4lower & Owl Limpet & $12 / 2 / 2002$ & 1 \\
\hline
\end{tabular}

The nomenclature of these features (the fish species) is included in the attributes of the species occurrences as is the trawl line on which the occurrence took place and the date. This enables the OIGIS to programmatically include all fish species occurring in the dbf (including newly occurring species) into the analysis. It also enables the distribution of the various species appearing in the species occurrence dbf's to be depicted on the maps in association with the trawl line or transect lines on which they occurred. Although it is of a very simplistic variety, this illustration of species occurrence distribution does constitute the spatial portion of the analysis supplied by the OIGIS. Depiction of the trawl stations in the San Pedro Channel map, as well as the transects in the DPMWR independent of the species data supports the client's use of the OIGIS maps as tools with which to plan future surveys.

The ocean temperature datasets are derived from text files that are automatically generated by a research buoy tethered in the northern portion of the San Pedro Channel, and are posted in monthly increments on the Scripps Pier website. The datasets are 
comprised of temperature readings taken every 30 minutes for a period of one month. The records are arranged in columnar format displaying the date and time of each reading as well as the ocean temperature in both Fahrenheit and Celsius degrees (See Table 3).

Once again, the OIGIS was equipped to utilize this data in the same format as the client is able to download it from the Scripps Pier website. Once downloaded, this data is programmatically read and input into a dbf file which the OIGIS uses to conduct the correlation analysis. This provides the client with the capability to easily download the data and update the temperature data in the OIGIS on a monthly basis with very little operator training.

Table 3 - Extract from Species Occurrence Dataset for the San Pedro Channel Trawl Surveys

\begin{tabular}{|r|l|l|r|r|r|}
\hline OID & Station & Species & CollectionDate & SizeClass & Abundance \\
\hline 1 & L30 & Citharichthys sordidus & $2 / 28 / 03$ & 4 & 17 \\
2 & L30 & Porichthys notatus & $2 / 28 / 03$ & 6 & 2 \\
3 & L30 & Porichthys myriaster & $5 / 18 / 02$ & 7 & 8 \\
4 & L30 & Citharichthys sordidus & $5 / 18 / 02$ & 10 & 45 \\
5 & L30 & Citharichthys sordidus & $5 / 18 / 02$ & 11 & 18 \\
6 & L30 & Citharichthys sordidus & $5 / 18 / 02$ & 13 & 1 \\
7 & L30 & Icelinus quadriseriatus & $5 / 18 / 02$ & 5 & 34 \\
8 & L30 & Icelinus quadriseriatus & $5 / 18 / 02$ & 6 & 4 \\
9 & L30 & Icelinus quadriseriatus & $5 / 18 / 02$ & 7 & 24 \\
10 & L30 & Paralichthys californicus & $5 / 18 / 02$ & 18 & 1 \\
\hline
\end{tabular}




\subsection{San Pedro Channel Overview}

Generally speaking, the San Pedro Channel consists of that portion of the Pacific Ocean bounded by the Orange and L.A. County portions of the California coast, and by Santa Catalina Island. By specification of the client, the extent of the San Pedro map was limited to L.A. Harbor in the North, Santa Catalina Island in the West, and the San Onofre nuclear power facility in the South (See Figure 14). These distances are considered to be more than adequate to accommodate any possible future growth in the Ocean Institute survey program. This resulted in a map that is seemingly inappropriately large in extent considering the localized survey area, but that includes plenty of features to help orient the map viewer and to assist in planning future surveys. This map was designed to be viewed at a wide range of scales depending on the purpose for which it is being used. For viewing the surveys as they exist at the present time, optimum map scale is approximately $1: 125,000$ to $1: 70,000$.

\subsection{Dana Point Marine Wildlife Refuge Overview}

Dana Point Marine Wildlife Refuge is by comparison to the San Pedro Channel very limited in extent. For this reason, the Marine Wildlife Refuge map (DPMWR) will typically be viewed at a much larger scale. The ranges for this region were specified by the client simply as encompassing the entire Marine Wildlife Refuge. As with the San Pedro Channel map, a considerable amount of the surrounding area is included to accommodate possible growth in the surveys being conducted, and to assist in the orientation of the map viewer (See Figure 15). This map is designed to be viewed at an optimum scale of approximately 1:20,000 or less.

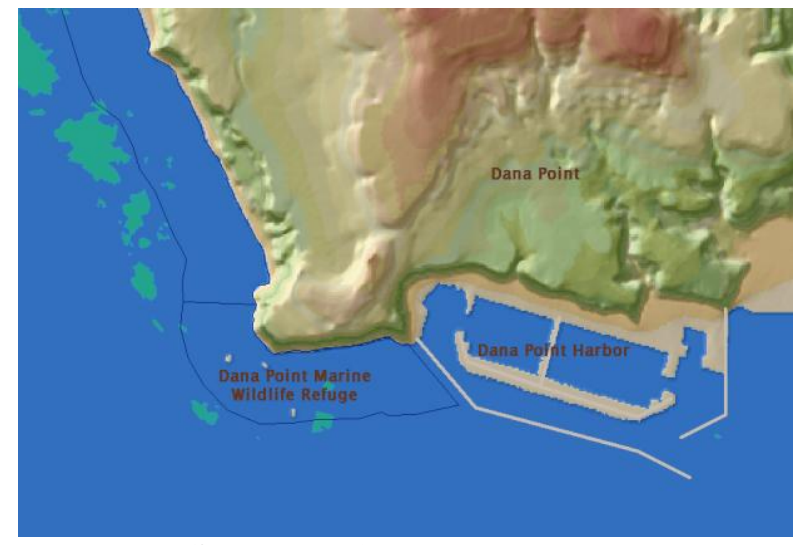

Figure 14. San Pedro Channel.

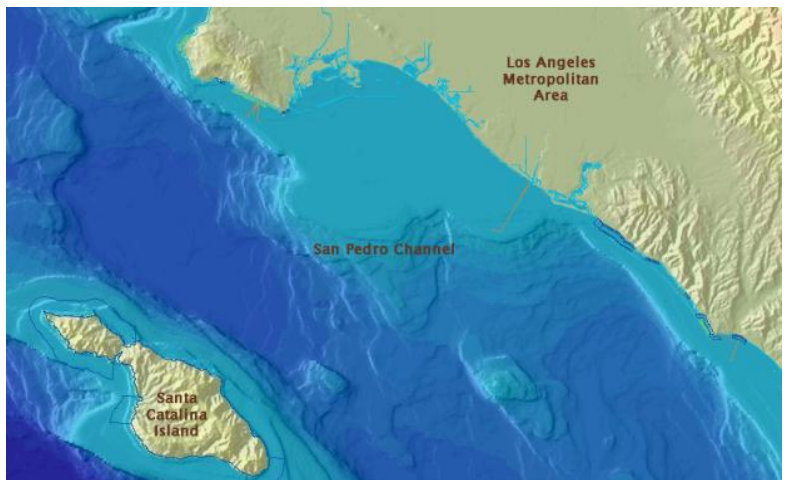

Figure 15. Dana Point Marine Wildlife Refuge. 
Data comprising the primary layers of the San Pedro map include a hillshade layer and a elevation tinting derived from a 10 meter DEM, an ocean polygon derived from an official California state coastline shapefile, polygons corresponding to the official boundaries of state Marine Protected Areas, and obstacle layers depicting the locations of kelp forests and shipwrecks in the San Pedro Channel (See Figure 16). Layers were included based on their relevance to the stated purposes of the map, which included future survey planning, the presentation of current surveys, and the phenomenon of benthic fish occurrence which is the focus of the OIGIS analysis. Additional layers depicting shipwrecks and waste water pipes were included and along with kelp forests, can be regarded as both hazards to survey equipment and as locations of potential high or low biodiversity. Their effect on the implementation of future Ocean Institute surveys will be determined by the Institute oceanographers after system implementation.

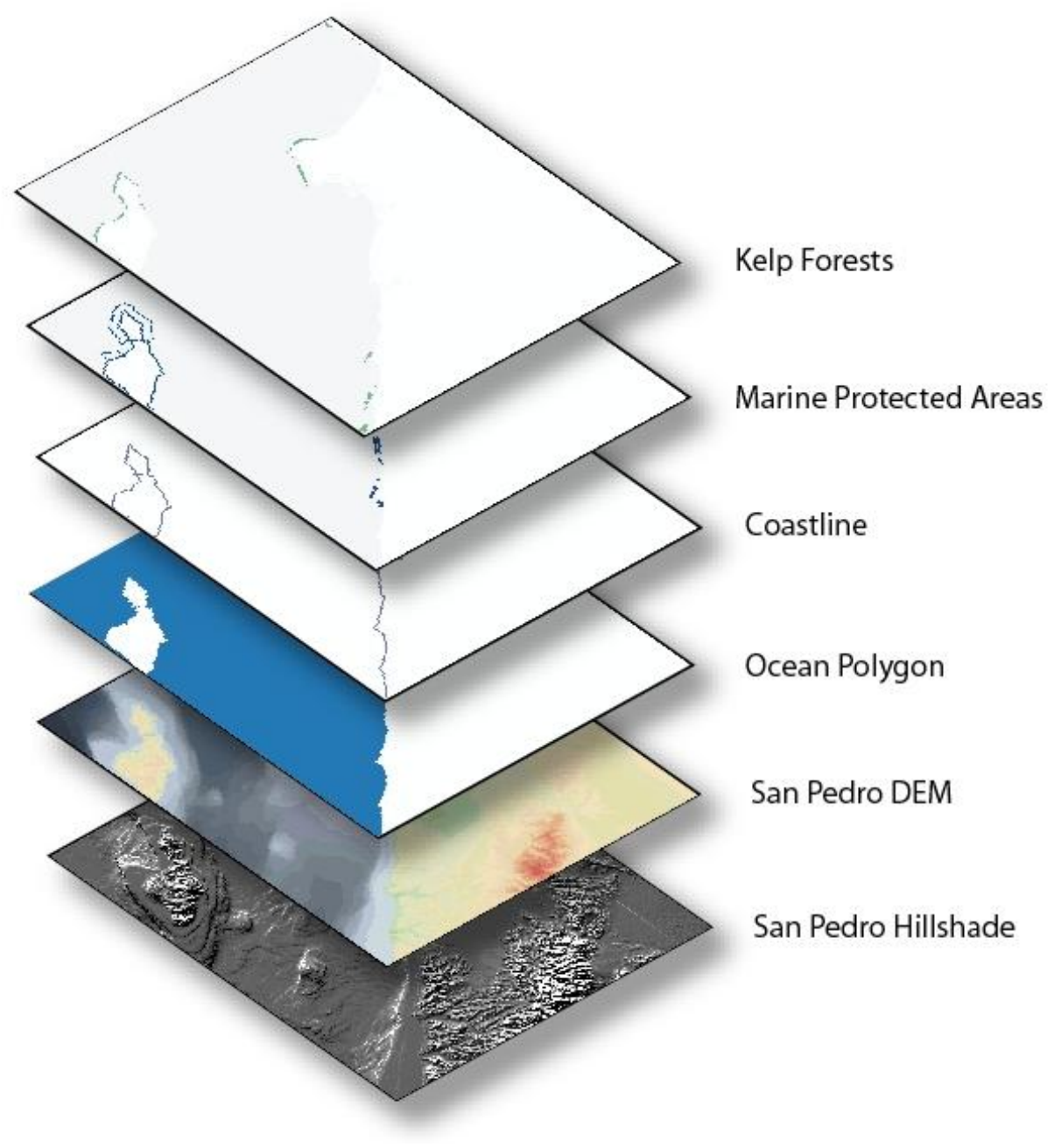




\section{Figure 16. San Pedro Map Layers.}

Data comprising the primary layers of the Dana Point Marine Wildlife Refuge map include a hillshade layer and an elevation tinting derived from a one meter DEM, an ocean polygon derived from an official California state coastline shapefile, polygons corresponding the official boundaries of state Marine Protected Areas, and obstacle layers depicting the locations of kelp forests in the vicinity of Dana Point (See Figure 17) Layers were included based on their relevance to the stated purposes of the map which in the case of the Dana Point Marine Wildlife Refuge, did not include future survey planning. Additionally, features such as shipwrecks and waste water pipes included in the San Pedro Channel map did not occur within the extent of this map. These factors led to the development of a similar, but not identical map structure.

The most obvious difference (besides the lack of shipwrecks and wastewater pipes) is the placement and use of the ocean polygon. In both maps an ocean polygon is included for the purpose of enforcing topologies which keep terrestrial and oceanic phenomenon occurring in the correct regions of the maps. In the case of the San Pedro Channel map, the ocean polygon layer can be turned on and off to reveal or hide the bathymetric contours of the channel. This may be useful when showing the map and analysis results on a large screen using a projector.

In the case of the Dana Point Marine Wildlife Refuge map, much of the refuge is tidal zone, and the portion that is below this zone is for the most part too shallow and rugged to safely operate a boat in. This allowed me to simplify the design of the Dana Point map, rendering the water as a flat plane, with the survey transects depicted along the coast. 


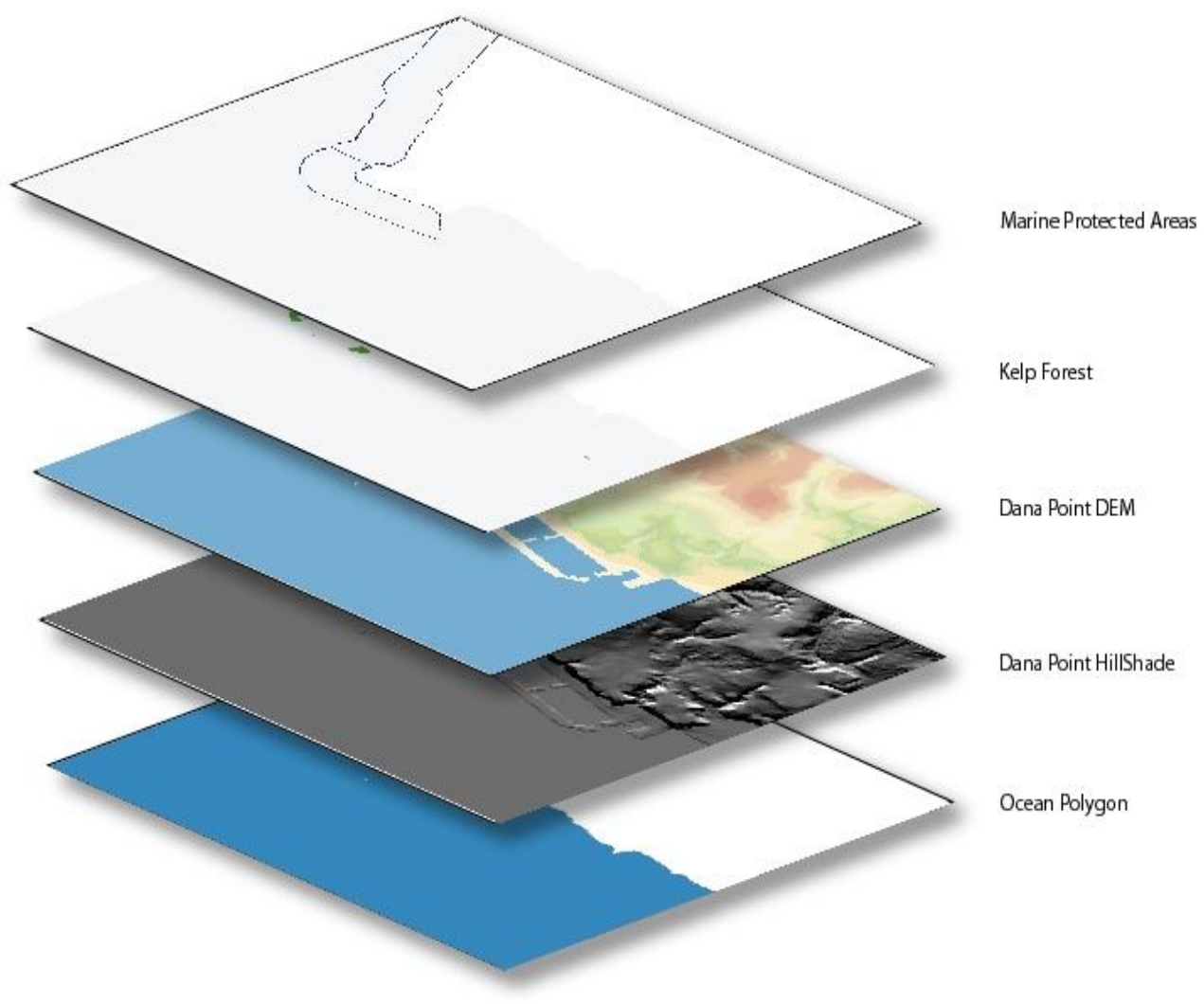

Figure 17. Dana Point Map Layers.

\subsection{Revisions to All Datasets Used}

As stated in an earlier section, all data was georeferenced using the WGS1984 projection and UTM, Zone 11 reference system. Achieving this required that many of the data layers be processed using the Project tool in ArcMap toolbox. In order to limit the extent of both maps, one of the early steps taken in their development was the establishment of bounding rectangles. These rectangles were superimposed onto the raster backdrop so as to orient the map reader. The size and location of these features was adjusted to correspond to the client's desired extents for each map. Once approved by the client, the rasters and all the subsequent map layers were clipped to these features to achieve a consistent map edge as well as to optimize performance of the software when the maps are used.

\subsection{Revisions to Specific Datasets}

In addition to getting all of the data layers into a common projection and coordinate system, specific revisions and modifications were made to some of the layers for the sake of preserving system performance. Most notably, the kelp forest layers which had been derived by remote sensing were comprised of a very high number of minuscule, irregularly shaped, highly detailed polygons requiring several minutes to render each time the map reader altered their view. In addition to being clipped to a desired extent, the 
kelp layers were simplified by applying an abstraction process referred to as the Simplify Line or Polygon tool in ArcMap toolbox. Although this simplified the larger polygons, amalgamated some of the clusters of smaller polygons, and eliminated altogether many of the isolated smaller polygons in this layer, thus sacrificing accuracy, the performance penalty of generating these features was greatly reduced. This revision was justified because although the location of kelp forests in the survey region is an important consideration in terms of avoiding damage to survey equipment and in terms of identifying areas with a high potential for biodiversity, the presence or absence of kelp is not a primary concern to the analytical portion of this project. Most of the Benthic and Demersal fish species are found far from known kelp forests and don't seem to be particularly dependent on or attracted to these areas.

For purposes of orienting the map reader, who presumably is more familiar with terrestrial features rather than marine features, a number of nearby coastal cities were depicted. In the San Pedro Channel map, the position of these cities was determined by the addition of a layer depicting city boundaries from the CASIL website. From these polygons, centroids were generated and labeled. This resulted in point features depicting the cities within the extents of the bounding rectangle that had been established as the extents of the map.

After deriving these features the decision was made to eliminate all of the city points, except those immediately adjacent to the coast since the inland cities were considered to be of lesser value for orientation from a marine frame of reference. After the inland city symbols were eliminated, the decision was made to eliminate a number of the coastal cities as well due to the fact that the number of labeled city points along the shore was visually distracting from the relatively small area being depicted, for which the foremost consideration had to be communicating which trawl lines yielded the occurrences of the species comprising the analysis. Finally, a decision was made to move the point symbols for the cities based on proximity to the coast, and based on the actual locations of the population centers for these cities. The generation of centroids based on the city boundaries occasionally lead to the point depicting the city being located some distance from the population center of the city. When the decision was made to visually relocate the points depicting the coastal cities to their population centers, or simply closer to the coast, the revisions and modifications became so extensive and complete, that the original layer is no longer listed in Table 1 as being one of the datasets used in these maps.

\subsection{Recommendations for Additional Datasets}

One of the functionalities in which the client has expressed interest for this system's future development is the inclusion of other variables besides ocean temperature with which the species occurrence variation could be compared. Some of the Scripps sensors generate data that are based on the levels of salinity, $\mathrm{PH}$, and a number of the more common pollutants in local ocean waters. Correlation comparisons between the fish occurrence data and these variables would be handled in much the same way as the temperature currently is, with some reworking of the OIGIS VB code. Fortunately, the tools that have been developed for this system will provide a good foundation for these variables to be added going forward. Like the ocean temperature correlation, these variables will each require the identification of a routinely updated (preferably 
automated) source that publishes the data in a form which the programming can easily be modified to understand. Although the possibility of modifying the OIGIS to run correlations between the fish species occurrence data and some of the other variables present in the benthic environment was discussed with the client, it was agreed that this should be investigated at some point after the implementation of the temperature correlation version due to time constraints. As with the temperature correlation, such systems installed on board the ship would have to address the limitation of not having ready access to the internet from which to obtain the latest datasets.

The OIGIS's dependency upon external sources for environmental data is a limitation that was reasoned to be acceptable in order to benefit from the very comprehensive nature of the datasets available from the Scripps Institute. Although temperature data is one of the metrics captured by the RV Sea Explorer's computerized system for operating the trawl equipment, this system was not in use at the time of some of the earliest Ocean Institute surveys, and it provides only one temperature record per survey. In contrast, the Scripps Institute data that is used in the OIGIS constitutes automated, routinely calibrated (Scripps Institute of Oceanography, 1981 - 2006) temperature data that is recorded every thirty minutes, starting from a time before the temperature reading equipment was functioning on board the RV Sea Explorer. If the client pursues further development of the OIGIS, by adapting the correlation analysis to investigate other environmental variables, the data may or may not be something that the RV Sea Explorer's system is equipped to sense and record with each survey. For these reasons, the OIGIS was designed to rely on the Scripps Institute datasets which are published monthly on their internet site.

Suggested datasets included the depiction of local terrestrial landmarks on the map, for the purposes of audience orientation (Howe, 2006). To some degree, this suggestion had already been incorporated at the time that it was proposed by the inclusion of the names of some of the coastal cities in appropriate locations on the map. Beyond these very basic features, the terrestrial portion of the map extent is left devoid of details other than the color ramp and hill shading. The phenomena that the map and the correlation analysis were designed to communicate about occur in the marine environment. For this reason details were provided mainly for the marine portions of the map, and this suggestion was rejected.

Another map layer that was suggested during the later part of the development of the OIGIS would have depicted the known extents of benthic invertebrates in the vicinity of the San Pedro Channel survey area. The purpose of this layer would have been to depict the distribution of a common food source for many varieties of the benthic fishes being studied by the client. This data might also serve to further inter-relate the Dana Point Marine Wildlife Refuge (DPMWR) map designed with the primary purpose of depicting occurrences of benthic invertebrate organisms and the San Pedro maps with a common theme. This dataset would likely have been a valuable addition to the OIGIS. However, during development of the system, supporting data that was extensive enough to cover the San Pedro Channel region could not be located. 


\subsection{Metadata Generation}

Metadata is defined as information that describes the content, quality, condition, origin, and other characteristics of data or other pieces of information (Gill, Gilliland-Swetland \& Baca, 1998), and is not unique to the field of GIS. Metadata for spatial data used in GIS typically describes and documents its subject-matter: how, when, where, and by whom the data was collected; availability and distribution information; its projection, scale, resolution, and accuracy; and its reliability with regard to some standard (ESRI, 2001). Metadata content can be subdivided into two basic subtypes, consisting of properties and documentation. Properties are derived from the data source (for example, the coordinate system and projection of the data), while documentation is entered by a person (for example, keywords used to describe the data).

In the case of the OIGIS, data origins and alterations were given close attention and carefully documented in metadata. Metadata definitions for the data used in this project were developed in accordance with the Content Standard for Digital Geospatial Metadata (CSDGM) endorsed by the Federal Geographic Data Committee (FGDC) which is in effect throughout the United States (Goodchild, Longley, Maguire, \& Rhind, 2001).

Metadata for the OIGIS was developed utilizing the standard ArcMap workflow in which the datasets within the databases were selected individually, then the metadata tab was selected, and the metadata style sheet was filled out using the metadata editor. Minimum data required by the MS GIS program at the time of the development of this system included an abstract, development date, and remarks about the spatial data quality. Once the data-layer's metadata was sufficiently developed, the completed style sheets were then exported as text files using the metadata exporter button. 



\section{Discussion: System Development and Design}

Early in the conceptual development of this GIS, it became evident that the two overlapping areas of interest (AOI) had certain fundamental differences that could best be accommodated by the creation of two similar, but not identical, geodatabases. These differences were of three basic types: the first being the diversity in extent and map scale, the second being the nature of the environment being mapped, and the third being the different variety of species found in these two regions.

The map extent differences coupled with the fact that the two mapped regions (the San Pedro Channel and the Dana Point Marine Wildlife Refuge) overlap means that many of the map features in the smaller map depicting the Marine Wildlife Refuge (MWR) will be derived from the more complete map features comprising the larger map of the San Pedro Channel. Obviously, this would lead to difficulties in specifying topologies like enforcing species occurrence location or survey location which, in the case of the San Pedro Channel, must take place in the ocean (benthic fish) and, in the case of the Dana Point MWR, may take place on land (benthic mollusks and crustaceans, etc.).

The nature of the regions being mapped (or at least the regions of emphasis on each map) in each of the two maps are different. The AOI within the San Pedro Channel begins in 15 fathoms of ocean, whereas the Dana Point MWR AOI is almost entirely located on an intertidal beach (Baker, 2006).

\subsection{System Development}

\subsubsection{Phase I}

Once completed, the conceptual geodatabase design was delivered to the Ocean Institute directors for familiarization and to afford them an opportunity for further design refinements prior to development of the physical geodatabase. Adjustments to the conceptual design were made during this phase to ensure that the GIS was developed so as to address the needs of the client to the highest degree possible. Once the conceptual design had been developed to the satisfaction of the client, the development of the physical geodatabase was undertaken.

\subsubsection{Phase II}

Development of the physical geodatabase included development of topology rules and custom tools to enable Institute personnel with little GIS or computer knowledge to accurately and consistently enter relevant species occurrence and environmental observations into the geodatabase. Once final adjustments to data presentation and data input procedures were completed, the GIS was uploaded onto the Ocean Institute's server, and training of Institute technicians was undertaken by the consultant. At this point, Institute technicians are starting to take ownership of populating the GIS with the Institute's archived data, as well as the ongoing generation of new data. 


\subsubsection{Phase III}

The implementation of this project will encompass semi-formal training, written procedures, system installation, and some technical support from the consultant for this system. The central piece of this project is comprised of a functional Geographic Information System for the Ocean Institute at Dana Point, California, titled the Ocean Institute Geographic Information System (OIGIS). My personal association with, and interest in the Ocean Institute predates the development of this project at the University of Redlands by a considerable period of time. This fact will facilitate my ability to render training and some technical support which is intended to continue voluntarily after the conclusion of the academic program through which this system was developed. This training and technical support will be provided in exchange for membership benefits at the Ocean Institute.

\subsubsection{Future Development}

Early discussions with the client outlined the extent of a map document that contained all foreseeable areas of interest to the Ocean Institute. Large extent in comparison to the region being surveyed was seen as desirable due to the client's desire to eventually enlarge the surveyed regions to include several locations within the San Pedro Channel. This sort of development has been anticipated in the design of the OIGIS in that the map extent cover the entire San Pedro Channel, far more than was needed to accommodate the existing survey. When running the analysis, the VB code automatically displays the map at a pre-determined (bookmarked), appropriate scale. To accommodate new surveys into the correlation analysis will be a simple matter of adding the new trawl line locations into the appropriate map layer, creating a new bookmark displaying the new trawl lines at a meaningful scale, and adding the VB code necessary to zoom to the bookmarked when the new trawl lines are illuminated as a result of the correlation analysis being run.

Suggestions for future development of the system were given to the client including a general discussion on how to adapt much of the existing VB code to correlation analysis of other environmental variables. Currently, the only plan that the client is actively developing for the OIGIS is the possible expansion of the San Pedro Channel surveys to include other regions within the channel. This development could easily be

accommodated by adding the position data for the new trawl lines into the Trawl stations / Survey Transects layer, and ensuring that the new map features have the correct attributes to enable them to be manipulated by the VB programming. This development was foreseen and planned for during design phase of the OIGIS and, therefore, little modification is needed to accommodate it.

Further system development must also include the adaptation of the species occurrence data for the Dana Point Marine Wildlife Refuge to be displayed in a meaningful way, as in the DPMWR map. As originally conceived, the OIGIS was to have this capability at the time of deployment to the client. However, the species occurrence data for this part of the system was significantly delayed in availability. When the species occurrence datasets were received, they were found to be in tabular format, rather than a list of records, significantly complicating their programmatic manipulation by $\mathrm{Vb}$ based tools. 
For these reasons, the development of the DPMWR system was not completed and emphasis was put on delivering a fully functional San Pedro Channel Map and correlation

In addition to these suggestions, the inclusion of additional map layers was discussed and noted for future development when time constraints would allow their development. In particular it was felt that had the San Pedro Channel map included a layer that depicted such things as the distribution of benthic invertebrates, which are an important food source for many species of benthic fish, would have been useful in analyzing the distribution of some of the species occurring in the surveys (Howe, 2006). Although it was agreed that this data layer would have been a useful addition to the OIGIS, there were three distinct problems with incorporating it into the system: a) Not all of the fish species being studied in the San Pedro Channel use benthic invertebrates for their primary food source and, therefore, the relevance of this data would not be consistent from one species to the next, b) the data supporting this layer was not readily available for the area being surveyed, c) as with benthic fish, there is high degree of probability that there will be variation in the distribution of benthic invertebrates as time passes.

Variation in benthic invertebrate occurrences is expected to take place at a rate that is similar to the variations in distribution of benthic fish species (Baker, 2006), and like the benthic fish, to be affected to some extent by changes in ocean temperature. For this reason, addressing the subject of benthic invertebrates by equipping the OIGIS with a static layer depicting their distribution at one moment in time adds little value to the correlation analysis for which this GIS was created. Due to the variability of these phenomena, as well there probable positive correlation with the variations in distribution of benthic fish, an effective presentation of the distribution of benthic invertebrates would require data from a regularly recurring survey of the sort being conduced in the DPMWR, but covering the lager extents of the San Pedro Channel survey area. A layer of this sort would be very useful as a comparison to the distribution of benthic fish occurrences. However, at this time, the data to sustain it does not exist.

It can be concluded that there are a number of developmental paths which would increase the usefulness of the OIGIS, and the primary limitation effecting the development of this system was the availability of time. With supporting data from the client, the development of numerous other data layers, correlation analysis with a number of other environmental variables (besides temperature), or the inclusion of a number of other marine species (besides benthic fish) can be accomplished given the time necessary to acquire and/or develop the data. The maps contained in the OIGIS were designed to address the client's desire to investigate possible correlations between ocean temperature change and species occurrence in their survey, and to accommodate the eventual expansion of these surveys. In the interest of meeting time constraints required by the MS GIS program, and simplifying the development of a programmatic analysis conducted within the ArcMap software environment, suggestions that would have added significant complexity to the development of the OIGIS were documented and the system was constructed in accordance with the original requirement agreed upon with Mr. Baker in September, 2005. 


\subsubsection{System Development Workflow}

The three-phase approach to system delivery detailed above was conceived early in the program and was formalized in response to an assignment in the GIS 690 series Project Management classes. With only minor adjustments in the course of the MS GIS program, this workflow (see Figure 18) served as the procedural guideline for the development and deployment of the OIGIS.

\section{Workflow Diagram for Ocean Institute GIS}

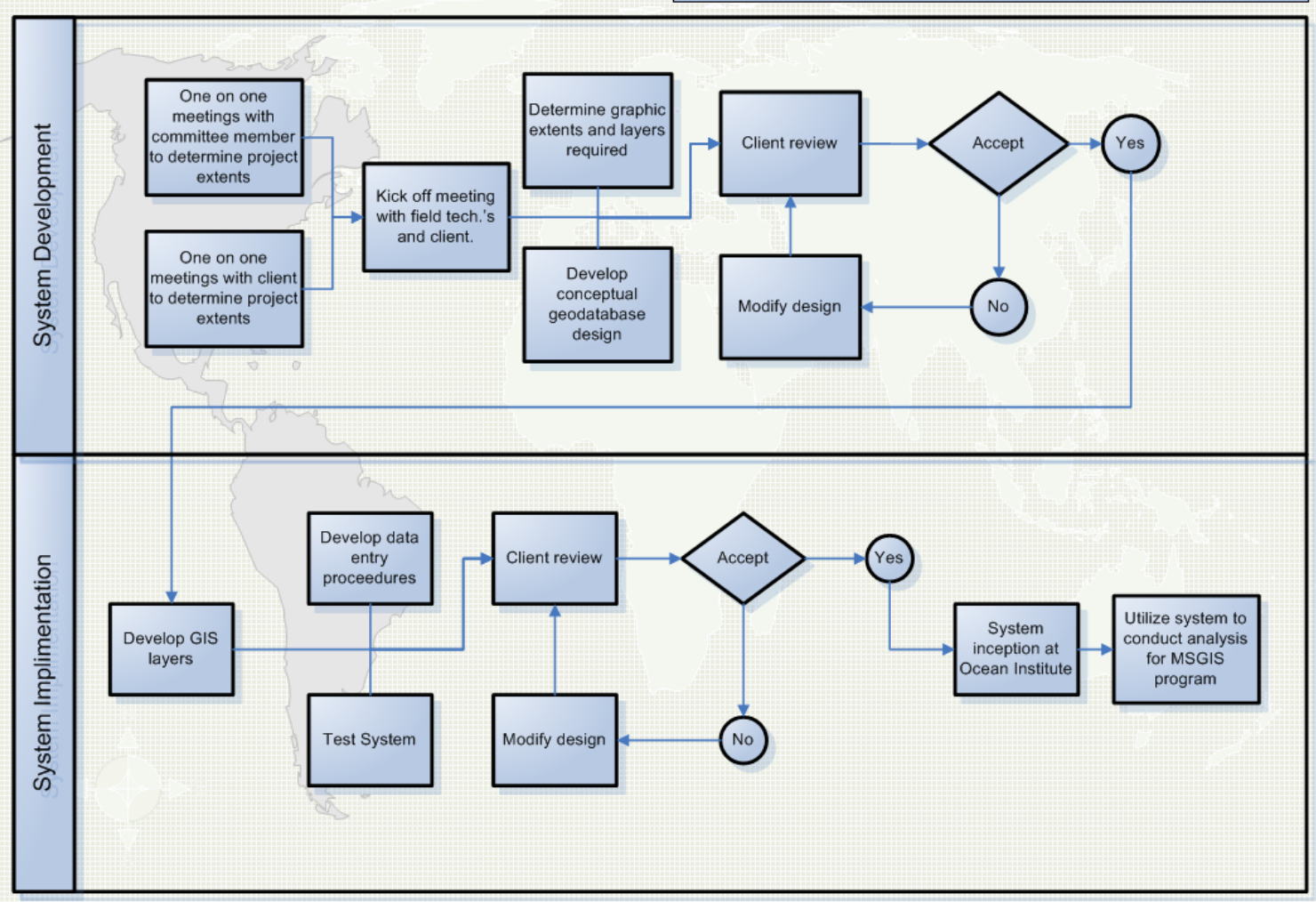

Figure 18. System Development Workflow Diagram.

\subsection{Developmental Issues}

During the course of the development of this project, a number of unforeseen issues were encountered for which solutions had to be developed. These unforeseen issues can be categorized into map issues, data issues, programming issues, and implementation issues.

\subsubsection{Map Issues}

Prior to receiving the Ocean Institute's data for the surveys being conducted in the San Pedro Channel, discussions were held with Mr. Baker and Mr. Howe who both agreed that suitable map extents would include Santa Catalina Island as the western extent, San Onofre as the southern extent, and L.A. Harbor as the northern extent. The rational for this decision was that the region defined by these boundaries constituted the limits of practical Ocean Institute survey activity. Based on this guidance, a suitable map with a 2 $1 / 2 \mathrm{D}$ raster surface background of 10 meter resolution was developed to depict the San Pedro Channel. This was the highest resolution data that was obtainable with the data 
that was available for the entire extent of the San Pedro Channel (without expending a significant sum of money). Higher resolutions were available without financial outlay for topography only, or for most of the harbor areas along the southern California coast. In order to minimize pixelization when viewing the map at the relatively large scales that also happen to be the most appropriate for viewing the survey transects and species data distribution as it currently exists, the DEM-based color gradient was smoothed using an interpolation tool called Resample from the ArcMap toolbox, and utilizing the bi-linear interpolation technique. This necessarily added abstraction to the map's raster backdrop, but this component is only being utilized to assist the client in visualizing major bathymetric features for purposes of conducting basic planning for future surveys. Since the ultimate placement of the various colors comprising the color gradient was not considered directly relevant to the analysis contained in this GIS, the interpolation was deemed acceptable in order to present a visually attractive (and accurate within 10 meter) map.

The client's desire to develop a map suitable for planning surveys as well as data presentation within relatively localized extents presented a challenge from a map making perspective. Addressing the planning needs of maritime professionals and the cognitive abilities of school-aged children on the same map required that the map be designed to address an exceptionally disparate audience. In the course of the development of the map, however, this was reconciled to some extent through the intended use of the maps that the two audiences share, specifically visualization of the location of the trawl transects (San Pedro) and sample locations (Dana Point Marine Wildlife Refuge) and the distribution of each species within the trawl lines and sample locations. Although the maritime professionals are obviously capable of assimilating a higher volume and a higher level of abstraction of information than the school-aged children, neither group will be using these maps for anything other than viewing where these surveys are and where they should be taking place.

\subsubsection{Data Issues}

Considering that the client specified extents of the map, when the species occurrence data was subsequently received, I became concerned that the extents of the survey were more localized than had been anticipated. The map had been designed to accommodate an extensive dataset depicting many more survey sites. Additionally, the data itself was much sparser than anticipated in that the surveys appeared to have been conducted on some but not all of the trawl lines in a consistent manor. The reason given for this was that, although the survey effort adhered to a schedule in which all the trawl lines saw equal sampling, if a sample yield was especially low, the survey may not have been recorded. Unfortunately, from the standpoint of conducting an analysis, the low or nonyielding survey trawls that had not been recorded introduced a serious bias into the data. If these survey trawls had been recorded and the low yield or null results for species occurrence had been included in the dataset, the options for conducting more rigorous spatial analysis would exist.

The data also lacked temporal consistency in two distinct ways. The surveys that the data represented were taken at random intervals and some years included more surveys than other years. As with the spatial extents of the species occurrence data, greater temporal 
regularity in conducting trawl surveys would afford many more opportunities for spatial analysis. The limitations of the species occurrence data is understandable, being that the Ocean Institute started conducting them as part of a much larger regional effort that was being carried out in conjunction with other researchers, and in support of an external study. Perhaps the most important factor degrading the temporal consistency of this data is that these surveys are conducted as learning experiences by volunteers and, from the standpoint of the Ocean Institute, the training of the volunteers had been their primary value. This consideration had resulted in substantial biases being built into the sampling process, since in the interest of educating their clientele, the consistently higher yielding transects have had a tendency to see a disproportionately high frequency of use.

Rules of nomenclature (naming conventions) presented another challenging aspect of the handling of this data. The fish tended to be listed in the survey datasets by their common names, but occasionally the Latin (scientific) names would be used as well. Rather than create functionality in the VBA tools that would enable this GIS to conduct the analysis using either naming convention, the decision was made to enforce the most common convention which was to use the colloquial names in the queries, but to provide a reference to the scientific name in the user interface and the report output. Consistency in the naming convention used throughout the dataset would have avoided much editing that was necessary to enable the VBA tools to work properly. This has been handled in the course of the development of this GIS by data editing. It is hoped that regular use of this GIS will further enforce the existing convention with respect to new data acquisition in future surveys.

In contrast to the columnar organization of the datasets pertaining to the San Pedro Channel surveys, the data available for the format of the Dana Point Marine Wildlife Refuge data was arranged in the form of separate tables, usually six to a page. This layout also required a reworking of the format in order to work with the VBA tools. The format of future species occurrence data from this region is still being decided by the Ocean Institute, however, without a much higher level of complexity in the VBA code, as well as very high consistency in terms of data placement on the spreadsheet page, the existing system will continue to be very difficult to use in any kind of database.

A level of abstraction was necessarily accepted with respect to the water temperature data from Scripps Pier. Scripps Pier is located south of the southern extremity of the San Pedro map extents and, therefore, well to the south of the region depicted in the Dana Point map. This means that the temperature readings reflect temperatures that can generally be associated with the southern California coastal region, but not directly with the San Pedro Channel or the Dana Point area at all. The Scripps pier ocean temperature data is recorded every 30 minutes from readings received from a sensor that is located close to the surface of the ocean. This means that the ocean temperatures are basically inaccurate as a direct reference to the ocean temperatures being experienced in the benthos during the same period of time. Temperature variation in ocean water is known to vary from place to place in a similar fashion to air temperature, but the variations are typically more gradual when examined over an equivalent horizontal spatial extent (Mantua \& Hare, 2002). 
In the vertical axis, ocean temperature can be highly variable. Throughout much of the year, ocean environments are characterized by phenomena known as thermoclines.

Thermoclines are caused by sunlight (Pidwirny, 2006). Almost all sunlight striking the ocean is absorbed within a few meters of the surface, which heats up during the daytime. Wind and waves (also generated by the sun) circulate the water in the surface layer, distributing heat within it, and the temperature may remain highly uniform for the first few hundred meters. Below this warm layer, however, the water temperature drops very rapidly (as much as $20^{\circ} \mathrm{C}$ ) with each additional $150 \mathrm{~m}$ of depth. This relatively narrow band of rapid temperature transition is referred to as the thermocline. Below the thermocline, the temperature continues to drop with depth, but far more gradually. Ninety percent of the world's water exists in the oceans, below the thermocline and is characterized by spatially highly uniformed temperatures as cold as $0^{\circ} \mathrm{C}$ to $3^{\circ} \mathrm{C}$ in this region. The depth at which the thermocline is encountered is highly variable from place to place and over time. In the relatively shallow (compared to the mid-ocean) waters of the San Pedro Channel, the thermocline is frequently encountered approximately halfway between the surface and the benthos, and gradually vanishes from this region altogether during winter months (Howe, 2006). This compounds the level of abstraction introduced by the geographic location of Scripps Pier relative to the client's area of interest.

Ultimately, the actual ocean temperatures either near the surface or in the San Pedro Channel benthos are less important at this stage of the research into this environment than are the magnitude of temperature changes experienced therein. Generally, changes in ocean temperature are of a higher magnitude and take place over a shorter amount of time near the surface in what is known as the photic zone (see Figure 1), compared to the relatively stable, cold environment of the subphotic, pelagic or benthic regions. At the present time, no source of continually updated data is available for the subphotic pelagic or benthic regions of the San Pedro Channel, and for this reason, the alternatives to accepting the Scripps Pier data in the development of this system, which is expected to receive and process data into some undefined period in the future are non-existent. Considering the open-ended nature of the analysis that the OIGIS supports, detecting variation in ocean temperature, over a user-defined period of time was considered of primary importance, superseding technical limitations associated with the data. While the limitations to ocean temperature data used in this system were acknowledged, these abstractions were deemed acceptable to the client as well as subject-mater experts serving in an advisorial capacity in the development of this system.

\subsubsection{Programming Issues}

Obtaining data from the Internet proved to be relatively difficult due the specialized nature of the subject-mater comprising this project. This can be illustrated by the issues that had to be addressed in the creation of the map's raster backdrop. Very high resolution DEMs were readily available for the Los Angeles area; however, these exist separately from bathymetric data which most often is available in grid form. Most often the resolutions of these datasets differed with high resolution topography being much easier to obtain than high resolution bathymetry. Early efforts to locate suitable data from which to develop the map revealed the difficulty involved in reconciling these 
diverse datasets. For this reason development of the maps was undertaken early in the program which allowed ample time to work through a number of issues of this sort. Research into possible data sources on the Internet presented a number of possible solutions in the form of data clearinghouses. The maximum resolution bathymetry generally available for the ocean regions beyond bays, harbors, and the immediate coast is 10 meter grids, contours and DEMs. Since the nature of the analysis desired by the client, and purpose of the maps comprising the OIGIS did not require higher resolutions, map development was undertaken using 10 meter resolution data for the San Pedro map and 1 meter resolution data for the DPMWR map.

Issues directly related to programming were encountered in the development of the VBA toolset included in this GIS. Due to the basic nature of the exposure to VB programming that the MS GIS program at the University of Redlands provides, it was not long into the development of the VBA toolset that expert assistance was required. For this phase of the project, the ESRI Press book Getting to Know ArcObjects (Burke, 2003) was extensively consulted, as was the book's author, Rob Burke. Although this facet of the ArcMap package is characterized by a somewhat arcane and difficult syntax, VBA can provide powerful functionality of the sort that the client has specified for this GIS. Due to the untrained nature of the operators of this system, one of the primary challenges was to enable the analysis to be conducted utilizing the tools available on one toolbar. The goal was to enable the operators to have full functionality of this system within the limits of the client's projected use of the system with only the main toolbar and the custom, OIToolset, toolbars.

\subsubsection{Implementation Issues}

The initial implementation issue encountered in the fielding of this system was actually encountered prior to the implementation phase. In the final development phase, during the creation of the VBA toolset, the client requested that a copy of this GIS be installed on the R/V Sea Explorer. This presented a functional issue with respect to the original design conceived for this GIS, because of the necessity of Internet access to enable the extraction of the Scripps Pier ocean temperature data. This required the development of a simpler, more self-contained system in which the Ocean temperature data would have to be embedded. Although this system is simpler and quicker, its obvious limitation is its ability to link to a dataset that is updating itself in real-time, every thirty minutes (SCRIPPS Institute of Oceanography). In theory, this system would be more straightforward to construct, so the initial system development efforts were concentrated on this part of the Ocean Institute GIS. Approaching system development in this manner allowed all efforts to be put toward the development of a functioning system, with subsequent effort applied to the query for data over the Internet, which was by far the most technical part of this project. The final design addressed the R/V Explorer's limited Internet access by constructing the ocean temperature update as a discrete query that was operationally separate from the generate reports process. In this way, temperature dataset updates could be accomplished on an as-needed (or in the case of the R/V Explorer as available) basis without slowing down the generation of the correlation reports. Another possible solution presented itself after system development was well underway. The R/V Sea Explorer's onboard instrumentation records ocean temperature on each survey mission. Utilizing this data was decided against in light of the fact that the OIGIS was 
designed primarily for use on shore, at the Ocean Institute campus where the Scripps Institute data was available and represented by far the most exhaustive dataset available for ocean temperatures in the San Pedro Channel. Utilization of the R/V Sea Explorer temperature data for the shipboard OISIS, although marginally more accurate at the point in time and space for the survey being conducted, would have lead to discrepancies with the shore based OIGIS and added system complexity since each system would require substantially different programming.

\subsection{Data Preparation}

Virtually all the datasets involved in the construction of the OIGIS required some amount of preparation. Extensive use of the Define Projection tool was used to ensure all data was projected in WGS 1984 format, using UTM zone 11 coordinate system which is commonly used in maritime applications. Virtually all the map layers were given precisely the same extents using the Clip tool found in the ArcMap toolbox.

\subsubsection{Map Data}

As previously mentioned in this paper, early difficulties were encountered in the creation of the San Pedro Channel map. These difficulties mainly pertained to locating the data necessary to create the raster backdrop which had to include both topography and bathymetry with as high a resolution as could be found without spending a substantial amount of money. After an extensive search, 10 meter resolution bathymetric grid data was found. Although higher resolution topographical data was located, a decision was made to use 10 meter topographical data so as to match the bathymetry. These datasets were from different sources and, therefore, had to be appended together using the Mosaic tool in the ArcMap toolset in order to produce a single backdrop layer for the San Pedro Channel.

\subsubsection{San Pedro Species Occurrence Data}

When initially received, the species occurrence datasets of the surveys conducted in the San Pedro Channel were already in a uniform format that enabled easy use in a geodatabase and queries of the sort that the OIToolset runs in order to produce its analysis. In approximately the last three years, the Ocean Institute has been utilizing an MS Access database to archive this information which has allowed them to conduct queries on the productivity of specific transects and the frequency of occurrence of specific species. Data preparation for this dataset simply required extraction of the data from the MS Access database in the form of a dbf and then importing it into the OIGIS.

\subsubsection{Dana Point Marine Wildlife Refuge Occurrence Data}

Species occurrence data for the Dana Point Marine Wildlife Refuge had been collected since 2002 and archived in MS Excel, in the form of individual tables which did not lend themselves to easy use in a database. These files required a substantial and time consuming rework into a single list format which could support queries and display on the Dana Point Marine Life Refuge map. As noted in section 4.1.4 Future Development, this data, once assessed to require substantial rework, adding significant complexity to 
the development of the OIGIS was documented as suggested future work, and developmental efforts were focused on the San Pedro Channel trawl data which was found to be in a much more useable format.

\subsection{System Implementation Plan}

This GIS must be, at a minimum, a vehicle for effective analysis and education pertaining to two finite, overlapping, and somewhat diverse regions. These regions are located in the tidal zone (Dana Point Marine Life Refuge), and the San Pedro Channel region (between Santa Catalina Island and the L.A. / Orange County coast). The two regions are diverse enough in extent, environmental type, and data that separate geodatabases have been created for each. The system has been equipped with an extensive, customized toolset and built in topologies that will enable the Ocean Institute to update, analyze and display data in a standardized fashion from either geodatabase. This toolset will be constructed utilizing Visual Basic for Applications which will allow a high degree of control over user's navigation within the ArcMap environment, as well as the means of updating analyzing and displaying data.

In the future, the Ocean Institute hopes to expand the functionality of this GIS to seek species occurrence variation correlation with environmental factors other than temperature. To that end, the customer has asked that this system be equipped with the locations of the major waste water exhaust pipes and runoff canals along the Los Angeles/Orange County coasts. For general orientation purposes, the customer has asked that the location of the major coastal cities and piers be depicted as well. To support the planning of future surveys, and the Ocean Institute's maritime history initiative, I have also included a layer depicting the location of all known shipwrecks in the San Pedro Channel region. This layer will be useful in the planning of future marine wildlife surveys, as shipwrecks are considered to be hazards for sampling equipment, but are also known to be sites of high biodiversity (Baker, 2006). These features are not necessarily central to the purpose of this GIS, but are useful ancillary datasets included at the request of the client.

\subsubsection{Hardware Requirements}

The environment into which this GIS is to be delivered is a network environment of moderate extent $(20+$ terminals, $512 \mathrm{mb}$ RAM on each) with Windows XP as the operating environment. The server is a Windows 2000 type, and the network is organized in the classic centralized database fashion with wires. The client institution currently has limited GIS capability (ArcView) with no formally trained employees. In order to provide for the effective implementation of this GIS into the client's environment, significant operator training and extensive interactions with the client's I.T. personnel are planned. Although this computer network could easily support an enterprise GIS, the client expects that utilization of the system will, initially be at the hands of a relatively small number of operators and, therefore, the decision was made to implement the OIGIS as a personal GIS available on four or five different computer terminals at the Ocean Institute. This will limit the system's use to a first-come-firstserve basis, but the client expects that this will not be a major problem. This system has 
been designed to function within the client's hardware environment, and aside from Internet access and a color printer, no special hardware requirements exist.

\subsubsection{Software Requirements}

The software required for operation of this GIS is not particularly exotic. Since the client currently has an older version of ArcView on their computer system, the risk that software compatibility issues may arise with ArcEditor version 9.1 is not considered to be very substantial. Minimum software requirements for this system include MS Excel, ArcView 9.1 or higher with a current license to operate. Development of the system has required ArcEditor version 9.1 level functionality. A number of the possible future developments for this system could be justified based on a user need analysis of the client. Foremost in the recommendations for future development contained in this paper is the implementation of an ArcPad system that would enable input and updating of the species occurrence datasets real-time as the surveys were being conducted out in the San Pedro Channel, or out in the DPMWR. In conjunction with this development, the option of obtaining the ocean temperature data from the R/V Sea Explorer instrumentation would be advisable. The potential benefits of this recommendation will be explained in more detail in the Recommendations for Future Work section of this paper.

\subsubsection{System testing and evaluation}

Of primary concern are the necessary internal complexities of this system (two separate geodatabases that must behave like a single system) as well as the level of experience and education of the prospective users and audience. Since neither of these characteristics (experience or education) is expected to include substantial knowledge of GIS concepts or operation, I hope to make the system as robust as possible by developing customized tools (mentioned in the last section of this paper) and extensive topologies to make the basic operation straightforward and error resistant.

Due to the straightforward nature of the map, data and analysis, these components of the OIGIS will simply be tested for interpretability by the target audience. The most rigorous portion of this GIS were the development of tools, interfaces, and topologies which automate the correlation analysis to more than 250 species of benthic fish. These tools, interfaces, and topologies are where the majority of the system testing was focused.

The overall scope of the testing process included two basic phases. The first phase was conducted prior to the system being uploaded onto the Ocean Institute's computer system and focused on system usability, durability, and understandability. The second phase was conducted once the system has been loaded on the client's computer. This phase included full system functionality with respect to the client's computer network, blending with, and into the training plan. In this way, it was hoped that all of the issues relating to topologies, user interfaces, and navigation between the two geodatabases could be resolved prior to deployment to the client's computer system. Once the geodatabase was running on the client's computer, issues related to its operation within the more complex network environment were focused on.

The first phase of testing, which will focus on usability, durability, and understandability will be further broken down into two distinct testing themes including data entry and data retrieval (data display). An ideal test subject will have an equivalent educational level 
(and field of study) to the rank-and-file of Ocean Institute specialists who will be using and maintaining this system in most cases. An individual that fits these criteria has been identified and has expressed willingness to participate in this phase of system development. Although not an employee of the Ocean Institute, this individual holds a Bachelor of Science in Biology and is employed in the related field of water quality control. Nearly all of the program directors at the Ocean Institute hold Bachelor-level Marine Biology degrees. A sampling of these individuals' computer skills has indicated a relatively high general knowledge and experience level as computer operators. This implies some experience with MS Office software suite and some data entry experience, which the test operator also possesses.

For this part of the system test, the test operator will be functioning in the capacity of an Ocean Institute technician with the goal being to evaluate the ease and understandability of the data entry and archiving procedure. Along with the custom user interface, the test operator will be supplied with a draft copy of a brief set of instructions and a graphic style flow chart depicting the actions to take to enter and archive a dataset. This testing activity will enable me to develop the written and graphic instructions that will accompany the inception of this system at the Ocean Institute and become the central format of the training that will subsequently be conducted with the Institute operators. In addition to a nearly ideal educational and employment background, the test operator is non-native to the U.S. and has English as a second language, which is an attribute that is anticipated to be beneficial to testing the understandability of the written and graphic instructions, which will be required to be clearly written and concise out of necessity. This will hopefully result in written and graphical instructions that are clearly written, uncomplicated, and easy for most native English speakers to understand and use.

At this stage, the specific features to be tested will include the written and graphic instructions (training documents), the system's user interface, and the built-in topologies designed to enforce accuracy and cartographically correct display. Direction from the consultant will be minimal and successful testing will be achieved by the test operator successfully completing all of the basic functions of data entry and data retrieval (data display) as outlined in the written instructions. These instructions will be comprised of the minimum functions with which an Ocean Institute technician will need to be familiar with in order to use the system to the level that will realize the functionality that the client wants from it. Due to the downstream effects that this phase of the testing will have (proving basic functionality and developing the training documents), time will be allotted for making any needed adjustments or changes to the system at this point, prior to moving forward with the project.

Along with the previously stated assumption that the state-of-the-art ArcMap software will run without major difficulties, there are some other features that will not be tested at this point, including the readability of the output and the network capabilities of the system. Both of these will have to be optimized for use with the client's computer system once the system is installed there; and for this reason, effective testing will have to wait until that time. For the purpose of satisfying MS GIS requirements, it is anticipated that only a limited number of the species represented in the sample data will be evaluated for correlation with the ocean temperature data. The number of species represented in the datasets is numbered in the thousands and MS GIS requirements can be 
satisfied by developing the statistical tools for the client, then applying them in one instance (species) where there is correlation, and another instance where there is not. For this reason, an exhaustive analysis on much of the data will be left to the discretion of the client, and as desired, conducted by Ocean Institute personnel.

Methodologies being evaluated in the first phase of testing will include the data input and retrieval conducted by the test operator, as well as an evaluation of understandability and clarity of the output format. As with data entry, retrieval and display, the understandability and clarity of the system's output can best be evaluated by persons of a similar age and education level as the Ocean Institute's typical audience. For this purpose, I have identified four high school students, and a junior college student who will be asked to examine the system outputs and to describe what characteristics they can deduce about the species for which the output was generated. These individuals have a typical education for their ages, and have no special skills in cartography, statistical analysis, or oceanography and therefore will be a good sample group for determining the clarity and understandability of the GIS outputs to the Ocean Institute audience. An additional desirable attribute of these individuals is that they have had very limited (and in some cases no) exposure to the project up to this point. They will be un-coached by the consultant with the exception of being shown a PowerPoint presentation briefly introducing the client institution. The testing approach at this point will be to see if the central theme of this GIS is clear to a sample group of high school and junior college students.

Data for this phase of the testing and acceptance plan, in the case of the San Pedro Channel map, consisted of the actual datasets that originated from the client, and that had been embedded into the OIGIS San Pedro geodatabase. Species sampling in the Dana Point Marine Wildlife Refuge (DPMWR) geodatabase portion of the GIS is currently much sparser and will be embedded into the Dana Point Marine Wildlife Refuge geodatabase. In order to ensure that the data being used to function test the OIToolset for the DPMWR was rich and extensive enough to demonstrate functioning of the custom tools during the testing phase, the test datasets were constructed of fictitious data which was removed immediately after successful testing was completed. Typically, the DPMWR is used by the Ocean Institute for specific experiments and to train younger students on sample gathering and species recognition. The client, however, wanted to make use of the increasing amount of data that is accumulating that pertains to this area as well. Due to the developing status of the data for this region, hypothetical data will most likely have to be extrapolated from the little that does exists in order to fully develop and test the statistical analysis tools with which this system is equipped.

It has been mentioned that the datasets possessed by the client for these two overlapping regions are still very much under development and, at this time, somewhat sparse for developing observations or drawing conclusions about many of the species comprising the Ocean Institute's survey. For this reason, the primary thrust of this GIS project was to develop a tool which will live on at the client institution and yield increasingly better, more accurate results as time goes on, and as more data is added. Therefore, since this GIS is primarily an analytical system, rather than a finished analysis unto itself, system design and functional testing of the custom toolset was considered very important to the ultimate success of this project. What follows is a description of the testing procedures 
that are currently being conducted along with test completion criteria, test environment, requirements, and test locations. These tests are considered critical functions of this system, and are the content of the written instructions that are being used in operator training, and will accompany the system after implementation.

Table 4 - System Test, Conditions and Operator Qualifications.

\begin{tabular}{|c|c|c|c|c|}
\hline Phase & Number & Test & Conditions & Tester \\
\hline \multirow[t]{5}{*}{1.} & 1) & Data Input & $\begin{array}{l}\text { Given: Sample Data and written } \\
\text { instructions regarding work flow, utilize } \\
\text { custom user interface to navigate to } \\
\text { appropriate file, create data table and } \\
\text { input data in correct format. }\end{array}$ & B.S. Biology \\
\hline & 2) & Data Retrieval / Display & $\begin{array}{l}\text { Given: Populated dataset, display } \\
\text { dataset on map and print out hardcopy. }\end{array}$ & B.S. Biology \\
\hline & 3) & Data Error Reconciliation & $\begin{array}{l}\text { Given: Sample Data and written } \\
\text { instructions for trouble shooting data } \\
\text { errors, that either will exist in the real } \\
\text { world dataset or be implanted by the } \\
\text { consultant, execute corrective action } \\
\text { steps to reconcile common error types } \\
\text { (i.e.; position errors, date errors, missing } \\
\text { attributes, etc. }\end{array}$ & B.S. Biology \\
\hline & 4) & $\begin{array}{l}\text { Generate Frequency Analysis and } \\
\text { Correctly Assess Positive, } \\
\text { Negative, or No Correlation }\end{array}$ & $\begin{array}{l}\text { Given: A complete, error free dataset, } \\
\text { select a species and evaluate using the } \\
\text { data analysis tools. Assess correlation } \\
\text { with ocean temperatures for the same } \\
\text { time period. Generate hard copy output. }\end{array}$ & B.S. Biology \\
\hline & 5) & Correlation Assessment & $\begin{array}{l}\text { Given: A basic knowledge of the Dana } \\
\text { Point Ocean Institute, it's mission and } \\
\text { activities, and a set of hardcopy (or } \\
\text { projected) species specific output, } \\
\text { correctly asses positive, negative, or no } \\
\text { correlation between species data and } \\
\text { ocean temperature data. }\end{array}$ & $\begin{array}{l}\text { High School and/or } \\
\text { Jr. College students }\end{array}$ \\
\hline \multirow[t]{2}{*}{ II. } & 1) & $\begin{array}{l}\text { Functional assessment of final GIS } \\
\text { product }\end{array}$ & $\begin{array}{l}\text { Given: Completion of phase I testing } \\
\text { and ArcMap software installation on the } \\
\text { client's computer system, Upload } \\
\text { datasets rasters and geodatabases and } \\
\text { check for basic functionality. }\end{array}$ & $\begin{array}{l}\text { Consultant and } \\
\text { Ocean Institute I.T. }\end{array}$ \\
\hline & 2) & $\begin{array}{l}\text { Functional assessment of final GIS } \\
\text { output }\end{array}$ & $\begin{array}{l}\text { Given: Completion of phase II, Step 1, } \\
\text { test output charts and maps to ensure } \\
\text { readability on the Ocean Institute's } \\
\text { printers and presentation media } \\
\text { (especially big screen projector system). }\end{array}$ & $\begin{array}{l}\text { Consultant and } \\
\text { Ocean Institute I.T. }\end{array}$ \\
\hline
\end{tabular}

\subsubsection{System Migration and Turnover}

The personnel comprising the rank-and-file of Ocean Institute employees are a combination of marine biologists and experienced mariners. All of these individuals are kept very busy supervising the various, ongoing programs running concurrently at the Ocean Institute. As with any group of busy people, a new system like this GIS will be seen to some extent as an additional burden on their already full schedule. In the case of the experienced mariners, this effect will be compounded by this group's well known conservatism about adopting genuinely new concepts into their practical point of view (Baker, 2006).

Client challenges to the successful implementation and use of this system will most likely be the pervading belief among the Ocean Institute specialists that the accurate and timely input of data that they have gathered is of secondary consequence to the training that they conduct with the students that they are assigned to work with. While this might seem to be true on the surface, deeper contemplation, or effective utilization clarifies the value of the maintenance and use of this GIS as a tool to support the very training that is perceived 
as competing with for the specialist's time. These opinions have been verbally related to the client and are, in part, exemplified by the lack of consistent data for the Dana Point Marine Wildlife Refuge.

The methodology that will be used in overcoming these challenges relies on the allure of modern GIS in geographical applications, the Mariner's affinity for nautical charts, and a strong training and support plan. Modern GIS is capable of generating visually stunning maps and professional looking charts and graphs as well. This simple fact has done much for its current acceptance in the mainstream of business, military, government, environmental management and education. A prime concern of the client, however, is that this GIS be attractive, accurate, and understandable since it is being designed to (among other things) be presented to inspire the students who are the future researchers, decision makers, and tax payers. Therefore, a great deal of effort is being invested into the aesthetics and accuracy of the map output and user interface. It is intended that these requirements be capitalized upon to create a system that the employees at the Ocean Institute will want to use and show off. The knowledge that the system is being showcased to the public and to educate students will support the desire for each specialist to keep the datasets for which they have responsibility for updating.

Mariners have a long standing familiarity with nautical charts. For this reason, I hope to diminish their resistance to this system by incorporating as many cartographic elements from nautical chart conventions as is practicable. This will make the output seem familiar to the more conservative (and potentially resistant) group of Ocean Institute employees. It is also hoped that this effort will result in output from this GIS that are more useful than they would otherwise be if they were patterned after terrestrial maps, or entirely abstracted into a chart devoted entirely to conveying geostatistical data.

As part of the implementation plan for this GIS, a training period was provided for the Ocean Institute specialists, as was significant support during the first couple of weeks of the system's existence on the Ocean Institute's computer system. Training documents were developed in conjunction with the client's operators for the purpose of supporting operator training and then to serve as operator reference for Ocean Institute personnel in the future. In addition, extended technical support will be provided for this system in exchange for membership privileges at the Ocean Institute to ensure a timely response to employee questions and issues pertaining to this GIS after implementation.

\subsubsection{System Deployment}

The purpose of this section is to provide a roadmap for deployment of the Ocean Institute GIS onto the client's network system as well as into the client's institutional culture.

At the time of system deployment, the client possesses only the most basic (ArcView) GIS software capability, and no formally trained personnel. For this reason, this GIS will be equipped with a highly developed user interface and an operator training program among the deliverables. The time line for delivering this system includes approximately 10 days for one-on-one training with client personnel. Specific personnel to be trained are currently being selected by the client. The user interface will be designed to (among other things) ease the query and map production processes for non-GIS trained users and this will be the focus of the training program. The training will be administered just after system deployment, and just prior to the formal turnover so that the experience will be 
fresh in the minds of trained individuals once they are expected to use it. During the training phase the client will be provided with regular progress reports on the deployment of the training being conducted so as to keep him apprised of potential issues or disruptions.

The client has already stated that he has had difficulty getting his personnel to support consistent data gathering and data maintenance (Baker, 2006). The user interface and the training that shall be provided will be focused on helping the users accomplish these facets of their jobs in an uncomplicated and timely manner. With the end product being that the sample data that is gathered is graphically displayed and accurately georeferenced, the client's hope is to overcome initial resistance to what may be seen by the staff as just another chore to perform.

Since the client personnel that will be making use of this system is relatively small in number, the training strategy will be to conduct scheduled one-on-one demonstrations and hands-on training supported by a programmed text that is under development. The written instructions will be retained by the trained individuals for reference purposes going forward. Examples of the written instruction sets that have thus far been identified as needed are found in Figure 4. In addition to the GIS, the client will be equipped with a dedicated email address established expressly for the purpose of contacting me when the user encounters operational issues. This will be temporarily in place for a few weeks after the formal turnover (at the completion of the training phase).

In order to effectively operate and maintain the delivered system over time, the written instructions will be a critical part of the system deployment. Although it is anticipated that some time will have to be expended to conduct refresher training as needed after the system has been formally turned over, this may not be needed if the user interface, initial training and written instructions are all well executed. It is anticipated that, after successful implementation, the next challenge to the survival of this system will come when the Ocean Institute conducts its next survey (after operator training has taken place) of benthic species out in the San Pedro Channel. These events will occur less frequently and generate considerably more data than the surveys conducted in the tidal zone comprising the Dana Point Marine Wildlife Refuge. This will afford the personnel involved ample opportunity to forget what they were trained to do with respect to the OIGIS. In anticipation of this challenge, relatively more detail will be put into the written instructions produced for employees involved in surveying the San Pedro Channel region. 


\section{Deliverables}

Due to a consistent dialogue with the client and the straightforward and functional nature of the proposed GIS, the scope of this project gradually narrowed and clarified since the concept was initially put forward. The expected deliverables have become more accurately defined which has likewise resulted in the shortening of the list of deliverables that will satisfy the client. The client for this project, a marine biologist by profession, has expressed the opinion that current environmental trends point to an El Nino event occurring within the near future (Baker, 2006; NOAA, 2006). Anticipating this upcoming event, the client's desire is that the GIS be structured not only to archive the years of accumulated marine species occurrence data, but to seek correlations between frequency changes in this data and changes in the ocean temperature in the region being studied. Specific deliverables comprising the complete OIGIS include written Standard Operating Procedures for the typical work flow sequences identified in Table 4-1, a geodatabase containing data layers, tables and topologies for the Dana Point Marine Wildlife Refuge, a geodatabase containing data layers, tables and topologies for the San Pedro Channel, a map document containing a fully developed custom toolset for editing analyzing and displaying the data generated at the Ocean Institute, an informational poster introducing the system and explaining basic functionality and this document.

\subsection{Final Geodatabase Design}

At the time of deployment, the basic design of the geodatabases will not have changed appreciably from when it was originally conceived (see Figure 7). As of this time, the two maps probably could have been maintained within the same geodatabase, as the layer structure is nearly identical. This design approach becomes too simplistic when topologies for the diverse environments are introduced. For instance in the case of the San Pedro Channel map, the ocean side of the coastal delineation is underlain with a polygon which extends from the coastline to the outer edges of the ocean side of the map. The primary purpose of this polygon is to enforce topology preventing terrestrial phenomena, such as cities, from occurring in the ocean, and to prevent ocean phenomenon, such as kelp forests, marine protected areas and species occurrence from occurring on dry land. This data layer serves a secondary purpose of masking the bathymetric portion of the background raster surface when a clearer view of the map details is desired.

The Dana Point Marine Wildlife Refuge (DPMWR) map is likewise equipped with an ocean polygon, but the topology is only enforced for terrestrial features and for kelp forests. The features such as marine protected areas and species occurrence are not strictly required to be entirely in the ocean in this map. The logic behind this decision is that the Dana Point Marine Wildlife Refuge contains about 2/3 tidal zone which can be considered land part of the time and ocean at other times. Some of the species that occur within this region are amphibious and will be found above the normal high tide range. For this reason, as well as a dramatic difference in map extents, species types and characteristics, as well as a different frequency of sampling these two regions are 
supported by two independent geodatabases, but depicted in one map document equipped with tools to assist the map viewer in easily transitioning from one map to the other.

\subsection{Custom toolset}

From an academic standpoint, the main rigor characterizing the development of this project is the extensive customized toolset (OIToolset) with which the GIS is equipped. It is understood that the species occurrence datasets will continue to grow over time and that other surveys will be started up in the San Pedro Channel, all of which will make the actual analysis increasingly more meaningful. In the near term, the emphasis during the development of this project has been to create a system which is capable of detecting correlation (negative or positive) between the species occurrences of a given species in the Ocean Institute's survey data and the local ocean temperature. This fulfills the client's need for a tool with which to observe their survey activities and the effects of an upcoming El Nino upon the local benthos of the San Pedro Channel and the Dana Point Marine Wildlife Refuge.

During early conceptual design of the OIGIS, a number of different systems were contemplated for achieving the functionality needed to fulfill the client's design specifications. The two possible alternative systems were Python Script and the Model Builder contained in ArcEditor software. Both of these were extensively investigated for suitability before a selection was made. Python, Model Builder, and Visual Basic for Applications (VBA) have highly developed user interfaces and interact nearly seamlessly with the ESRI software. What follows is a brief comparison of each option as well as the reasons for the final selection of VBA in development of the OIToolset.

\subsubsection{ModelBuilder}

Within the ESRI software packages there is a wide selection of tools available with which to analyze and edit data associated with map documents. Each tool can be more accurately described as a process. In instances where there are many steps involved in a geoprocessing work flow, it can become difficult to keep track of the assumptions, tools, datasets, and other parameter values that are required. One of the easiest ways to manage and automate a work flow, and keep track of geoprocessing tasks is to create a model. A model consists of data flow diagrams that link together a series of tools and data to create advanced multi-part procedures and work flows, (ESRI, 2005). The ModelBuilder interface in ArcMap provides a graphical modeling framework for designing geoprocessing models that can include tools, scripts, and data. To build processes, the operator adds tools into the ModelBuilder window, and then supplies values for the parameters of each tool. Both system tools and custom tools can be dragged into the ModelBuilder window, or you can use the Add Data or Tools button in the ModelBuilder window. Due to the number of geoprocessing tools already available in ArcMap softwares, ModelBuilder offers considerable functionality, and typically most of the processes (or tools) are already made, and just need to be strung together in the appropriate sequence.

For conducting a complex analysis that may have to be run a number of times with different parameters, and to automatically generate a diagrammatic flowchart depicting 
the analysis, ModelBuilder is an ideal tool. This piece of software can add text labels to the display window, elements, or connector lines of the model to make the diagram even more descriptive without affecting the actual functionality of the model. The model diagram can be reused, can share parameters with other models or parts of the same model and can be printed out along with generating a report. Custom processes can be developed and added in the same fashion as the tools that are already included in the ArcMap toolbox.

Despite the convenience and functionality of having many pre-existing tools available, the flexibility of being able to program additional tools which subsequently behave just as the other tools, and the nearly automatic generation of a diagrammatic flowchart, the use of model builder presupposes some level of training on the ESRI software. Finished models are also relatively fragile in that their complexity is readily exposed to the operator and, therefore, susceptible to alteration whenever they are opened to be run. In the development of this project, a lack of formal GIS training on the part of the system operators must be accounted for. For this reason, a degree of tamper resistance in the system is desirable. Additionally, the analysis that the client wants to perform is not complex as with most of the instances in which ModelBuilder is applied, and it will be run frequently with many different parameters in the form of the attributes associated with each of the 234 species occurring in the client's species occurrence dataset. Although the first attempts at analyzing the Ocean Institute's species occurrence data were conducted using ModelBuilder, it was decided that a more robust analytical tool should be permanently built into this GIS that would be easily manipulated by operators with very little familiarity with the software.

\subsubsection{Python}

Python is an interpreted programming language (a computer program that executes other programs) created in 1990 and named for the creator's favorite comedy series (Monty Python's Flying Circus), (Lutz \& Ascher, 2004). The Python programming language is in common use by many people, both in industry and academia for a wide variety of applications. Python uses automatic memory management (the automated allocation and de-allocation of computer memory resources used in the operation of a program) which makes running it much easier on computer resources. Python is developed as an open source project, managed by the non-profit Python Software Foundation, and is available for free from the project website (http://www.python.org). Python is a multi-paradigm language, meaning that, rather than forcing programmers to adopt one particular style of coding, it permits several. Python can also be used as an extension language for existing modules and applications that need a programmable interface. Another capability designed into this language is ease of extensibility. Python has a large standard library (the library of subroutines, macro definitions, global variables, class definitions, templates, etc., that is available in every implementation of that language), which makes it extremely adaptable. The modules of the standard library in Python can be augmented with custom modules written in either $\mathrm{C}$ or Python. Custom modules are easily written to enable Python to work with C. C++ or VBA.

A limitation of Python, however, is its inability to create forms of the sort necessary for a user interface such as the OIToolset. Although the functionality that is embedded in this 
system could have been achieved by the exclusive use of Python, this would have necessitated a user interface that only a professional computer programmer would have been comfortable with. One of the design parameters impacting the development of the OIGIS is an assumption that the system operators will only posses a basic level of computer literacy. The actual level of computer skill possessed by the Ocean Institute personnel comprising the operators of this system will, in actuality, vary greatly. However, given a variety of computer skill and comfort levels among Ocean Institute system operators, the necessity of designing the user interface to accommodate the least experienced operators is logically obvious.

\subsubsection{Visual Basic for Applications}

Visual Basic (VB) is an event-driven programming language (meaning it relies on interaction and guidance from the operator to run) prototyped in 1987, then bought and vastly improved upon by Microsoft in 1991 (Starks \& Tustanouski, 1996). Visual Basic is popular because it makes it possible to develop complicated applications very quickly. The older version of VB was derived heavily from the BASIC programming language of the late 1970's. Visual Basic is not only a programming language but also a true graphical development environment. This environment allows programmers with little programming experience to quickly develop powerful Windows applications. Visual Basic also has the ability to develop programs that can be used as a front-end application to a database system, serving as the user interface which collects user input and displays formatted output in a more appealing and useful form.

Visual Basic is very popular for the ease with which it allows the programmer to create esthetically pleasing graphical user interfaces with less coding relative to most other languages that take thousands of lines of programmer keyed code to accomplish the same thing (Sybex, 1999). As the programmer works in the graphical environment, much of the program code is automatically generated by the Visual Basic program. This ease and speed of development is referred to as rapid application development (RAD) of graphical user interface (GUI)

The simplicity of coding (RAD) and using (GUI) are the main strengths of Visual Basic, allowing very rapid application development to experienced Visual Basic coders and an easy learning curve for programmers coming from other languages. Additionally, Visual Basic applications can easily be integrated with databases, including geodatabases. In business programming, Visual Basic has one of the largest user bases of any programming language.

Visual Basic for Applications (VBA) is an implementation of Visual Basic. This variety of VB is built into all Microsoft Office applications and Microsoft Visio - as well as some other applications such as AutoCAD and ESRI software. As its name suggests, VBA is closely related to Visual Basic, but can normally only run code from within a host application such as ArcMap, rather than as a standalone application.

During the development of this GIS, a solid course for learning basic programming in VB was available. Towards the conclusion of this course a small amount of VBA training in the ArcMap application was undertaken. The easy development of graphic user interfaces and the capable handling of map layers were apparent. VBA interacted with 
ArcMap seamlessly and so long as an untrained system operator does not stray into the VB Editor in ArcMap, the interface created is very robust and tamper resistant. The ability to rapidly develop a user interface that was robust and tamper resistant enough to be run and re-run nearly every time the ArcMap software was started fit with the client's requirements as well as the time constraints under which this GIS was being developed. For these reasons, VBA was selected as the primary platform on which to base the user interface and to construct the OIToolset.

Extensive VBA development constitutes most of the time and effort involved in the development of the OIGIS. VBA applications are automatically activated when the OIGIS is initially opened in Arcmap. When the system is first activated, the VBA tools needed for running the correlation analysis are loaded into the ArcMap user interface, and a disclaimer message regarding use of the system is displayed and must be acknowledged by the system operator prior to system use (see Figure 19).

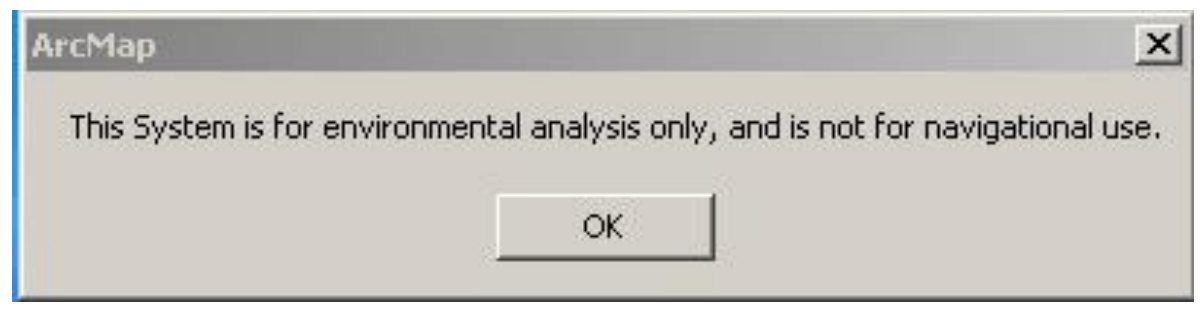

Figure 19. OIToolset toolbar and system icons.

After the disclaimer message is acknowledged by the system operator, the OIGIS loads into the Arcmap application interface. Once the system has loaded, the system operator can access the OIGIS analytical tools via a toolbar titled the OIToolset. The OIToolset displays icons, each of which execute one of the various functions necessary to set-up and run a correlation analysis between a specific fish species, and ocean temperature. Although the custom tool set developed for the Ocean Institute does fit the commonly accepted description of a graphic user interface (GUI), it was primarily developed to manage a number of VBA tools developed to process the temperature and species occurrence data, and to run the correlation analysis desired by the client and a graphic arrangement designed to be simple and clear enough for school aged children to understand. The tools are accessed via a custom toolbar for which unique icons were designed (see Figure 20). The OIToolset toolbar is equipped with all the tools needed for running the analysis: one tool for data entry of new species occurrences, a help button, as well as three standard tool icons which expedited getting around within the GIS for those without familiarity with the software. A basic description of the function of each or the rational for including each tool follows:

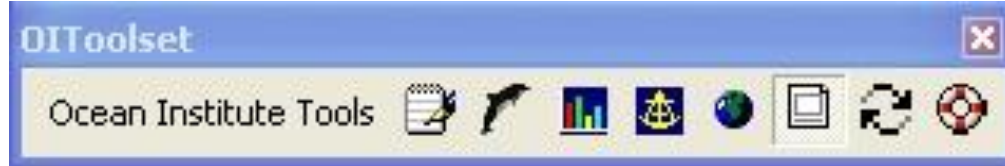

Figure 20. OIToolset toolbar and system icons. 
The Ocean Institute Tools title has been included on the toolbar for the purpose of clear identification of the toolset for those without familiarity with the software when the OIToolset toolbar is docked and the frame is not visible. In addition, this text is associated with a VBA click event which will display a brief description of the consultant's name, the purpose of these tools, and the date of their creation. Inclusion of this information was considered important due to the ongoing nature of the study which this GIS supports. The intent was to build a form of metadata into the system so as to facilitate further development of the system, or trouble shooting of the system in the event that technical support is needed in the future.

Add New Species Data is the title of the tool that is symbolized by the icon depicting a notepad and pen on the OIToolset toolbar. When activated, this VBA script opens the appropriate dbf containing the species occurrence data for either the San Pedro Channel Map or the Dana Point Marine Wildlife Refuge. This tool is included to enable quick and easy updating of the database files with data from new surveys without having to navigate to them through the file structure. The intent was to enable Ocean Institute personnel to access these database files (dbfs), which are located within the geodatabases without having to penetrate the geodatabases, and navigate within them to access the files by some other, potentially, damaging method such as MS Windows Explorer.

Print Report is the title of the tool that is symbolized by the icon depicting a porpoise breaching. When this tool is activated, it prints a copy of the layout view of the active map and charts for whatever marine species has been selected and analyzed.

Programming supporting this tool ensures that the operator is in layout view, and communicates with the printer to ensure that the printout is accomplished with the printer settings on landscape and $81 \frac{1}{2} \times 11$ inch paper size (See Appendix C).

Generate Reports is the title of the tool that is symbolized by the icon depicting a histogram type chart. When this tool is activated, it calls up a dialogue box that enables the system operator to select a species and a date range for which to generate an analysis (see Figure 21). Programming supporting this tool makes use of files on all common and scientific fish species names, and files covering the span of all available ocean temperature data. The programming also loops through the species datasets identifying all unique species names and creates a dictionary of them for the purpose of identifying the occurrence of typographical errors as well as newly encountered species that are input by the OIGIS operator. This tool specifies and populates an array which is then used to generate the charts and calculate the coefficient of correlation (R-value) between the ocean temperature variation and the Species occurrence for the specified time period (See Appendix A). 


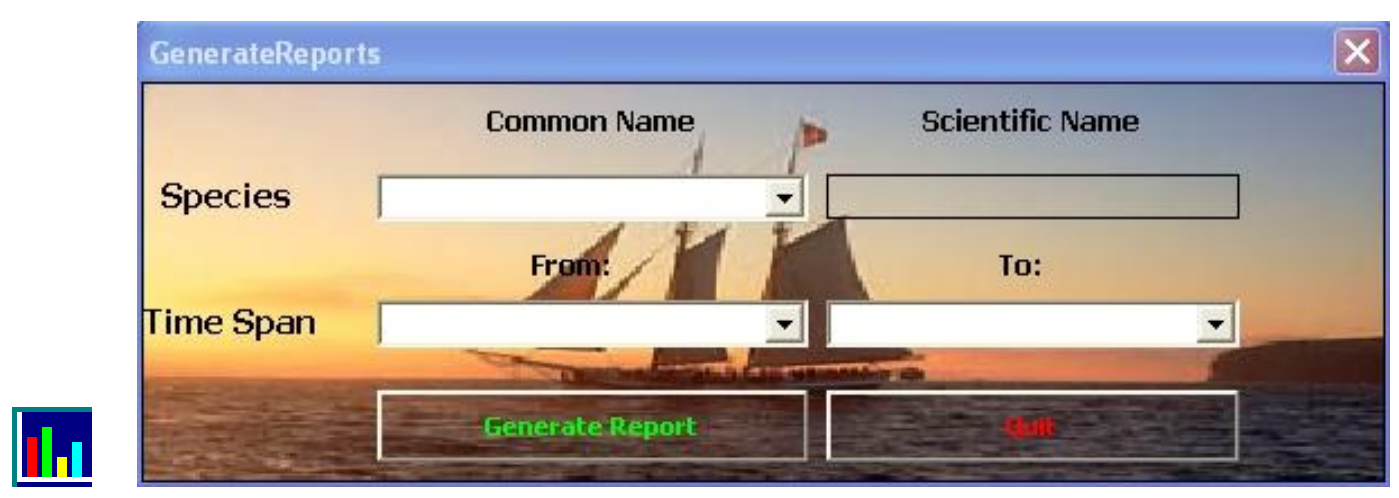

Figure 21. Generate Reports Icon and Dialogue Window.

Swap Maps is the title of the tool that is symbolized by the icon depicting a navigational sextant. When this tool is activated, it calls a dialogue box in which the system operator can select between the San Pedro Channel map, and the Dana Point Marine Wildlife Refuge map (see Figure 22). Programming supporting this tool selects and displays the appropriate data frame thus facilitating an operator switching back and forth as needed between the client's two areas of interest (AOIs), despite an assumed lack of familiarity with the software.

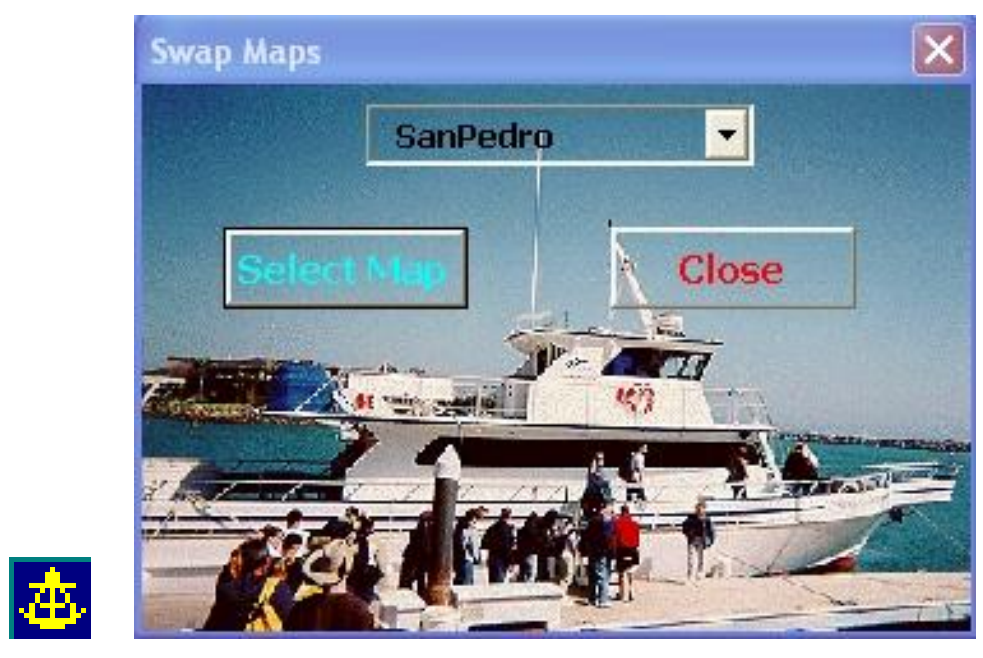

Figure 22. Swap Maps Icon and Dialogue Window.

The Layout View and the Refresh View tools normally found in other toolbars have been included to aid the system operator in adjusting the views of the maps and the data to the optimum display for the survey prior to running the analysis and, if desired, print the report in hardcopy. This supports the client's concept of simplifying the user interface to facilitate system operation by non-GIS trained Ocean Institute employees.

A Help button is included that is symbolized by the icon depicting a life preserver. When activated, this tool brings up a frame with detailed descriptions of each tool, and a workflow sequence for its proper usage with the other tools on the OIToolset Toolbar. Included in the help text is a hyperlink to the ESRI ArcObjects developer webpage if more in-depth troubleshooting or research is needed to correct potential problems or further develop the custom tools. 


\subsection{Conclusions and Recommendations}

Despite the limitations that have been discussed in this document, the IOGIS is an extremely effective tool in its current form. Although limitations to the surveys and, therefore, within the data do exist, the IOGIS analytical capability will get stronger as data continues to be gathered going forward. This will likely happen only as fast as more money and personnel become available. Even without additional survey sites, as the Ocean Institute continues to survey at the existing sites, it will generate more data, and with more data, the OIGIS analysis becomes more effective at detecting species occurrence / ocean temperature correlations. As has been stated in this document, the OIGIS analysis is currently only effective for the more commonly occurring species represented in the data with which the system is currently equipped. As the Ocean Institute's surveys continue, and more data is archived into this system, the OIGIS analysis will become effective for an ever broadening array of the species that occur less frequently in the data. As the Ocean Institute benthic surveys are an integral part of their educational efforts, it is highly likely that the OIGIS will continue to accumulate data and therefore increase in effectiveness. Due to the data layers included in the OIGIS maps, which constitutes a unique combination of diverse features that are normally only available through diverse (and not always easily compatible) sources, it is also highly likely that this system will be used in the planning of future surveys.

The client expects that utilization of this system will heighten motivation to accurately gather and archive species data within the Ocean Institute since the Ocean Institute personnel and everyone else will now be able to see the results (Baker, 2006). Additionally, use of this system will promote more homogeneous standards in the recording of data by the Ocean Institute personnel since the San Pedro Channel species data is already archived in the OIGIS in an organizational format that readily supports utilization by a GIS. Prior to the deployment of this system, Ocean Institute personnel used diverse methods and organizational layouts for recording their species occurrence data, and were not always disciplined about archiving the data promptly since weeks frequently would elapse before the data was utilized for anything.

Recommendations to the client based on the undertaking of this project are threefold. The first recommendation would be to look critically at the results yielded by this GIS tool and evaluate the quality of the data upon which they are based. Important limitations to the system have been identified and discussed in this document which may be acceptable to the client based upon their mission focus on education rather than pure research. On the other hand, the client possesses the capabilities needed to produce richer data with more detailed attributes which would allow for a more elaborate analysis to be conducted and therefore better conclusions to be supported by the results. This recommendation encompasses many facets of possibilities with respect to the data; however two of the more basic enhancements would be to develop a system to evenly distribute the survey activity among the trawl lines and this would be regardless of the results of the trawl. This would open new possibilities in terms of analyzing the distribution of species occurrences within the survey extents. As the data currently exists, the symbology projected onto the map will rightly indicate from which trawl lines 
the occurrences of a given species are coming from, but this will essentially be a depiction of anecdotal data based on the knowledge of the Ocean Institute staff regarding which trawl lines have been productive in the past. Although this is likely to be an acceptably accurate reflection of the distribution of a given species, in reality OIGIS programming derives its ocean temperature data from surface temperature data generated by a remote buoy located in the San Pedro Channel.

\subsection{Suggestions for Further Research}

The client has expressed two desires for this system's future development. One of these is that the system be made compatible with display and use on the web, and uploaded onto the Ocean Institute website. This possibly could have been accommodated within the time constraints of this year, except that both the GIS for the Web class, and the client's idea to do this were not conceived of until quite late in the year when the project was well under development in its current form. This, however, would be a worthwhile future project in its own right.

A significant limitation of this system in its current form is that if new species are encountered, their occurrence can be entered into the dbf's containing the new species, but the system cannot immediately access them for running the analysis. In order to accommodate the occurrence of a new species that is not among the 234 species that are found in the survey data to date, the occurrence has to be realized by the system operator and the VBA code must be manually modified in two places. If time constraints had not prevented it, the next development for this system would have been a method of querying the species occurrence data for newly occurring species and when detected, to flag the occurrence, in case it happens to be a simple spelling error, and then automating the addition of new species into the toolset. This functionality would be important to have due to the fact that in past years in which strong El Nino effects have been present, the San Pedro channel area has seen an incursion of species that typically inhabit waters to the south, but that have been driven north by the increased water temperature consistent with an El Nino event.

An improved raster backdrop would be of help to the client's survey planning efforts. As has been stated, the resolution of the current raster backdrop for the San Pedro map is 10 meters, which is appropriate for displaying the entire San Pedro Channel, but has low resolution when viewed at the scales that clearly represent the current survey extents. This may turn out to be a self-correcting problem, as additional survey sites are started up elsewhere in the San Pedro Channel which will effectively broaden the extent of the map view that would be appropriate for viewing all the surveys. As the Ocean Institute develops its plans for dropping delicate survey equipment onto the ocean floor in new areas, and subsequently dragging the equipment along a trawl line of uniformed depth, they will need as much detail as possible about the environment that they will be surveying. Therefore, higher resolution, more accurate bathymetry would be desirable in order to more precisely plan out the surveys. 


\subsubsection{Improved Spatial Analysis}

From a spatial analysis standpoint, the only deliverable from this system is an indication about how the species occurrences of a given species are distributed throughout the range of the Ocean Institute survey. This is less an analysis than it is simple information about the data presented to the system operator in graphic form. The client's desired analysis is of a non-spatial variety, a measure of how correlated or non-correlated the occurrence of a benthic species is to variations in ocean temperature over a user specified range of time. As more spatially extensive and less sparse data populates this system, additional options become available for incorporation into this system. With more extensive data the ability to investigate a given species' distribution throughout the San Pedro Channel, or an investigation into biodiversity measuring the number of species occurring at a given survey site become viable options. With tools designed to address these investigations, the OIGIS will be able to more effectively leverage the strengths that are generally inherent in Geographic Information Systems (Davis, 2003) to the benefit of the client.

\subsubsection{Improved Data Entry Tools}

Although the OIGIS has been equipped with tools for rapidly accessing and editing the species data tables as well as the ocean temperature data table, this is primarily designed to correct errors that become apparent from manipulating the data in the course of running an analysis. In its current form, this system requires that new surveys which generate numerous records must be added to the species occurrence dbfs prior to being brought into the ArcMap software, by other software such as MS Excel or MS Access. ArcMap toolbox features the Append tool, located under the Data Management subdirectory which can append data onto an existing point, line or polygon feature class, rasters, raster catalogues, or data tables. Accomplishing this requires that the system operator have some experience navigating throughout the ArcMap interface including the use of the toolbox. To expand upon the theme of the VBA based user interface with which this system has been equipped, functionality could be developed to enable the untrained operator to enter entire surveys featuring many records. An improvement of this sort could be to incorporate a function into the VBA code to allow an entire survey to be added into a dbf by simply pressing a button on a VBA form. This could be accomplished by creating a VBA script that calls up the Append tool from the toolbox, prompts the user for the needed parameters to run the tool, and then initiates the tool. This would most likely be the next development for this system if existing time constraints were less restrictive. 


\section{Conclusion}

This project was designed to utilize GIS to investigate changes in benthic and demersal habitats in the San Pedro Channel over time. This analysis constitutes a first tentative step into GIS technology for the Ocean Institute. As the Ocean Institute's first GIS, there are numerous opportunities and potential pitfalls associated with its deployment and subsequent use by the client (Tomlinson, 2003). If reliability, clarity of presentation, or usability of this GIS were to become an issue for the client, the institutional resistance to the future use of GIS in general would grow strong. If usability, clarity of presentation, and reliability are perceived to be strengths of this system, this will have a positive effect on the future development of GIS at the Ocean Institute which has many potential opportunities for its use among their range of normal activities. With first impressions of GIS in mind, an abiding focus during the development of this project has been to create a state-of-the-art geodatabase for the Ocean Institute that will receive and meaningfully display the species occurrence data from both the San Pedro Channel and from the Dana Point Marine Wildlife Refuge in a basic reliable manner that is easy for the non-GIS trained system operators to use and which, at the same time, is understandable to a young audience (See Figure 23).

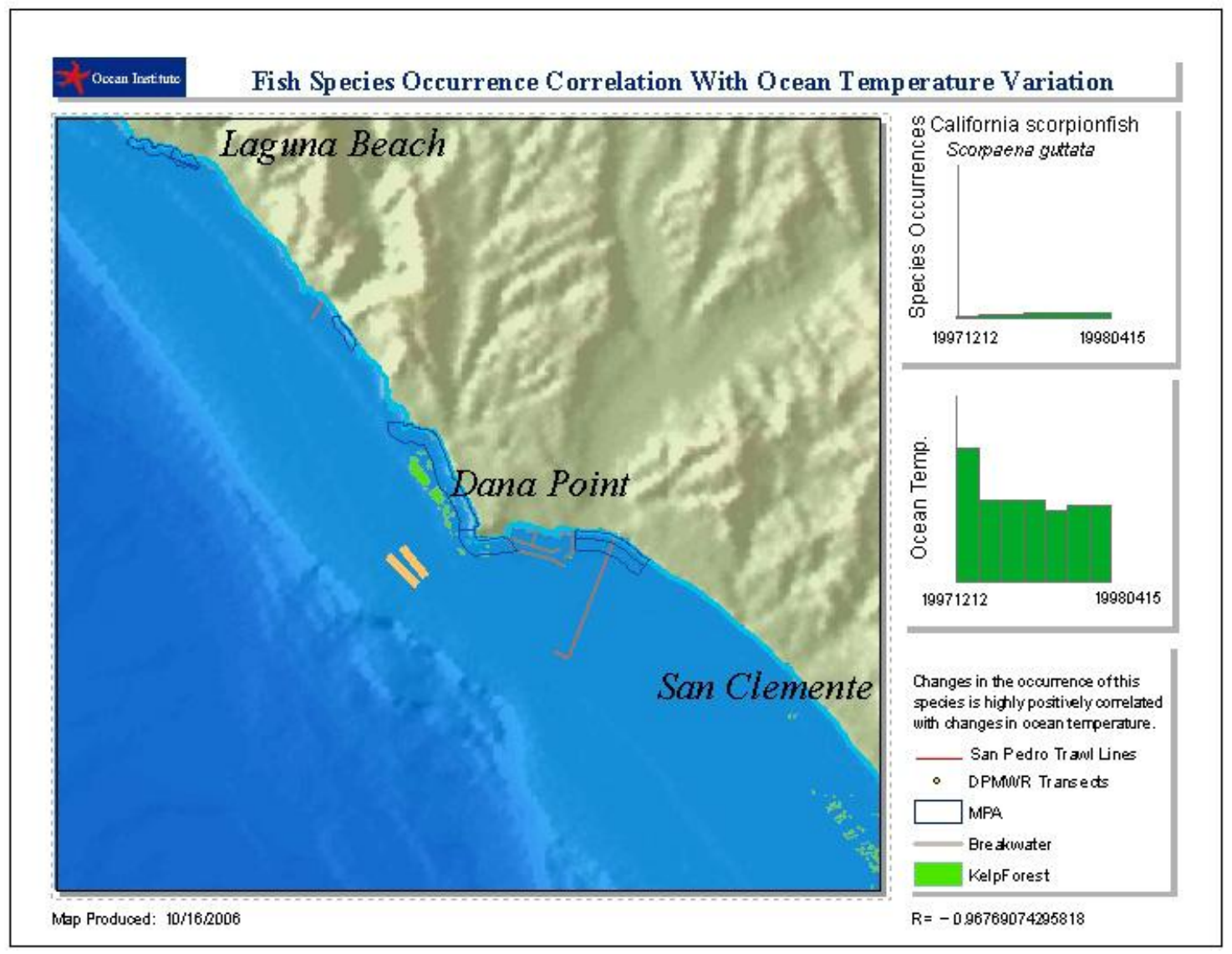

Figure 23. Sample correlation report output for the San Pedro Channel. 
In its current form, this system does execute a credible analysis for detecting changes to the frequency of occurrence of the various species in the survey area due to the effects of ocean temperature change, and to determine the extent of correlation between the two phenomena. The client's requirements have been satisfied and the OIGIS is considered a successful project at the Ocean Institute. It is hoped that this will be a successful first step for the client in the further development of this and other GIS at the Ocean Institute.

The Visual Basic code and ArcObjects tools that drive the OIGIS correlation analysis could easily be used as the basis for seeking correlations between benthic species occurrences and many other phenomena that are persistent variables effecting this environment. Pollution levels associated with storm water runoff from Orange County and L.A. County, as well as salinity or PH levels are variables for which data sources currently exist at NOAA, SCCWRP, and Scripps Institute, and for which this analysis could be run. The flexibility and adaptability of the tools developed for this project can serve the client as an important first step in a wide variety of environmental studies on the San Pedro Marine Habitats.

The biggest limitations of the OIGIS as it currently exists are the lack of extensive surveys which would allow a more exhaustive examination of what is happening throughout the San Pedro Channel, and the fact that the system, although adaptable to other environmental variables, is only capable of investigating correlation with species occurrence for one environmental variable at a time. By investigating only one environmental variable at a time, conclusions drawn from this system's output could be overly simplistic when considering the complexity of the environment being examined. Coastal zones are an especially complex environment containing terrestrial, marine, and atmospheric components. Changes introduced into an ecosystem most likely have complex causes which induce change by effecting more than one environmental variable. Should the OIGIS equip themselves to gather long duration data for other environmental phenomena in addition to temperature, a much more comprehensive analysis in the form of a multivariate regression analysis would become possible. The OIGIS evaluates the variations in species occurrence with respect to possible correlation with only one environmental variable. Therefore, this system should be regarded as a logical first step in investigating changes which have thus far been anecdotally observed in the Ocean Institute's species occurrence survey data, and as the Ocean Institute's first analytical use of a GIS.

The Ocean Institute directors have recognized the need to have a dedicated GIS to receive and display their benthic species occurrence data to enable themselves to more effectively conduct analysis, decision making, and public education. Due to the fact that this GIS is primarily concerned with the mapping of surveys, bathymetry, and potential obstacles located on the ocean floor, the conceptual basis for the maps on which this system is based was not unrelated to the mapping of terrestrial phenomenon that are the more common applications for GIS technology. The on-going nature of the analysis contained in this GIS, and the automation that make it capable of accommodating more than 200 different species of marine organism are what make this project unique. This GIS is intended to provide the Ocean Institute at Dana Point with an effective analytical tool for identifying opportunities for subsequent research, initial planning for future surveys, and for public education. This project has produced a GIS capable of conducting and 
communicating the results of a simple analysis for a very wide array of species and for a very extensive span of time. The future application of GIS at the Ocean Institute will invariably be effected for good or ill, based upon how reliably and easily this system communicates the results of the built-in correlation analysis, as well as how adaptable the components contained in this system are to supporting survey planning and public education.

"Just as fish adapted to the terrestrial environment by evolving into amphibians, so GIS must adapt to the marine and coastal environment by evolution and adaptation." (Goodchild, 1999, p. XV) 



\section{REFERENCES}

Anderson, J. (2003). The world ocean. Santa Barbara, California: Santa Barbara City College (p. 6).

Arctur, D., \& Zeiler, M. (2004). Designing geodatabases. Redlands, California: ESRI.

Armstrong, A., Calder, B., Jakobsson, M., \& Mayer, L. (06-21-04). On the estimation of errors in sparse bathymetric data sets. Retrieved July 27, 2006, from http://www.ccom-jhc.unh.edu/error.htm

Ascher, D., \& Lutz, M. (2004). Learning python (2nd ed.). Sebastopol, California: O'Reilly \& Associates Inc.

Baker, R. (2006). Conversation on characteristics of benthic species distribution in the San Pedro Channel (personal communication, May 13, 2006). Dana Point.

Bartlett, D. (2000). Working on the frontiers of science: Applying GIS to the coastal zone. London: Taylor \& Francis.

Bartlett, D., \& Smith, J. (2004). GIS for coastal zone management. Boca Raton, Florida: CRC Press.

Bartlett, D. J. W., \& Dawn J. (1999). Marine and coastal Geographic Information Systems: Taylor \& Francis Inc.

Bates, C.R., \& Byham P. (2001). Swath-sounding techniques and near-shore surveying. The Hydrographic Journal, 100, 13 - 18.

Bizzarro, J., Erdey, M., Green, G., Lopez, H., \& Tilden, J. (2005). Place matters. Corvalis: Oregon State University Press.

Bobbitt A.M., Fox, C.G., \& Wright, D.J. (1997). A scientific information model for deepsea mapping and sampling. Mapping and Sampling, 20, 367 - 379.

Black, M. (1985). The prevalence of humbug. Ithica: Cornell University Press

Breman, J. (2005). Mapping benthic habitats: The marine GIS challenge. ARC News, Spring 2005.

Bryan, B., \& Gerner, D.B. (2000). Geographic Information Systems and optimization algorithims to assist in the design of marine protected areas. International Journal of Geographic Information Systems, 4(1), 55 - 78.

Buckley, A. (2006). Cartographic design - Lecture 07. In P. C. Bigley (Ed.) (p. 8 Class Content, GIS 615). Redlands.

Burke, R. (2003). Getting to know ArcObjects. Redlands, California 1-58948-018-X.

Bushing, W. W. (1995). Identifying regions of persistent giant kelp (Macrocystis pyrifera) around Santa Catalina Island for designation as marine reserves Santa Barbara: University of California, Department of Biological Sciences.

California Department of Fish and Game (1993). Fish and game code, Section 109001091. Sacramento, California. 
Cava, F., Schoedinger, S., Straing, C., \& Tuddenham, P. (2005). Science content and standards for ocean literacy. Unpublished manuscript.

Caviedes, C. N. (2001). El Nino in history: Storming through the ages: Gainsville, Florida, University Press of Florida.

Charles Bracs, C. B. (1987). Understandable statistics (3rd ed.). Lexington, Massachusetts: D.C. Heath and Company.

Chavez, F. P. (2003). From anchovies to sardines and back: Multidecadal change in the Pacific Ocean. Science, 299, 217 - 221.

Chau, M., Dzieszko, M., Gold, C., \& Goralski, R. (2004) The "Marine GIS" - dynamic GIS in action, 20th Annual Conference of the International Society for Photogrammetry and Remote Sensing. Istanbul, Turkey.

Christopherson, R. W. (2005). Geosystems: An introduction to physical geography. Upper Saddle River, New Jersey: Prentice Hall.

Clarke, J.H., Dijkstra, S., Mayer, L., Paton, M., \& Ware, C. (1997). Interactive tools for the exploration and analysis of multibeam and other seafloor acoustic data. Paper presented at the SACLANTCEN, Italy.

Cohen, J. (1988). Statistical power analysis for the behavioral sciences (2nd ed.). New Jersey: Lawrence Erlbaum.

Colgan, M., Halpin, P., Treml, E. (2002). Marine geography. Redlands, California: ESRI.

Convis, C.L. (2001). Conservation geography. Redlands, California: ESRI Press.

Cooper, L. (2006). Discussion on species occurrence georeferencing procedures. In P. C. Bigley (Ed.). Westminster.

Davis, D. (2003). GIS for everyone (3rd ed.). Redlands: ESRI.

De Leo, G. A., \& Levin, S. (1997). The multifaceted aspects of ecosystem integrity. Conservation Ecology, 11(1), 1 - 16.

Degnan, C.H., Eittreimen, S.L., Lee, W.C., Wong, F.L. (1999). USGS seafloor GIS for Monterey Sanctuary: Selected data types. Paper presented at the 19th Annual ESRI User Conference, San Diego, California.

Department of Atmospheric Sciences (DAS) at the University of Illinois (04-28-98). Economic impacts during an El Nino event, Retrieved June 23, 2006, from http://ww2010.atmos.uiuc.edu/(Gh)/wwhlpr/eln_economic_yes.rxml?hret=/guides $/ \mathrm{mtr} / \mathrm{eln} / \mathrm{def} . \mathrm{rxml}$

Department of Atmospheric Sciences (DAS) at the University of Illinois (1999). El Nino (Educational CD-ROM). Urbana-Champaign: University of Illinois.

Duncan, S. L., Wright, D. J., \& Lach, D. H. (2005). Social power and GIS technology: What's at stake for natural resource management? Annals of the Association of American Geographers.

ESRI. (2004). ArcGIS Desktop Help.

ESRI. (2001). Dictionary of GIS terminology. Redlands, California: ESRI Press. 
ESRI. (2002). Undersea with GIS. Redlands, California: ESRI Press

Evans, D. H. (1998). The physiology of fishes (2nd ed.). Boca Raton, Florida: CRC Press LLC.

Federal Geographic Data Committee (2003; February 18, 2005). NOAA Coastal Services Center; Marine \& Coastal Spatial Data Subcommittee, Retrieved June 30, 2006, from http://www.csc.noaa.gov/mcsd/menu2.html

Francour, P. (1998). Re: global warming: it's happening. Natural Science, December.

Frankfurt, H. (2005) On bullshit. Princeton: Princeton University Press

Gibeaut, J., Gutierrez, R., \& Kysera, K. (1998). Increasing the accuracy and resolution of coastal bathymetric surveys. Journal of Coastal Research, 14(3), 1082-1098.

Gill, T., Gilliland-Swetland, A., \& Baca, M. (1998). Introduction to metadata. Los Angeles, CA: Getty Research Institute.

Goodchild, M. F. (1999) Forward. In D. Wright \& D. Bartlett (Eds.), Marine and Coastal Geographic Information Systems, (p.xv). Philadelphia, Pennsylvania: Taylor \& Francis Inc.

Goodchild, M. F., Longley, P. A., Maguire, D. J., \& Rhind, D. W. (2005). Geographic Information Systems and Science (2nd ed.). London: John Wiley \& Sons Ltd.

Goodchild, M.F., \& Wright D.J (1997). Data from the deep: Implications for the GIS community. International Journal of Geographic Information Science, 11, 523 528.

Government of the Commonwealth of Australia (2006). Climate variability and El Nino, Retrieved July 21, 2006, from http://www.bom.gov.au/climate/glossery/elnino/elnino.shtml

Graham, W. (2001). A virtual sea; Submarine topography, Retrieved July 7, 2006, from http://www.ecovis.org/SubmarineTopography.htm

Howe, M. (2005). Conversation on annual variations of the San Pedro Channel thermocline In P. C. Bigley (Ed.) (Personal Conversation). San Diego, CA.

Howe, M. (2006). Conversation on marine mapping conventions and OIGIS map design In P. C. Bigley (Ed.) (Personal Conversation). Dana Point, CA.

Lockwood, M. \& Li R. (1995). Marine Geographic Information Systems: What sets them apart? Marine Geodesy, 18(3), 157 - 159.

Li, R., Saxena, N.K. (1993). Development of an intergrated marine Geographic Information System. Marine Geodesy, 16, 293 - 307.

Maguire, R. (2006). GIS 612, Information Systems Foundations for GIS. In P. C. Bigley (Ed.) (Lecture on Spatial Data Infrastructure). Redlands, California.

Mantua, N.J., \& Hare, S.R. (2002). Pacific decadal oscillation. Oceanography(58), 35 44.

Mitasova, H. (2004). Quantifying rapid changes in coastal topography using modern mapping techniques... Geo World, 10, 1 - 11. 
National Marine Mammal Laboratory (2006). El Nino impacts on pinnipeds by species, Retrieved June 9, 2006 from http://www.afsc.noaa.gov/NMML/CaliforniaCurrent/El_Nino/El_ninoImpacts.ht $\mathrm{m}$

National Marine Protected Areas Center, (2000). Dana Point Marine Wildlife Refuge, Retrieved May 13, 2006, from http://www3.mpa.gov/exploreinv/

National Oceanic and Atmospheric Administration (NOAA) - Coastal Services Center (2005, September 28, 2005). Remote Sensing for Coastal Management; Nearshore Habitat Mapping, from http://www.csc.noaa.gov/crs/rs_apps/issues/nearshore.htm

NOAA. (2006, August, 2006). El Nino in this winter's forecast. NOAA Magazine

NOAA. (2005). Impacts of El Niño on fish distribution, Retrieved August 10, 2006, from http://www.elnino.noaa.gov/enso4.html

Ocean Institute (2005). The Ocean Institute, Retrieved July 16, 2006, from http://www.ocean-institute.org/

O'Neill, R. V. (2001). Is it time to bury the ecosystem concept? (with full military honors of course!). Ecology, 82(12), 3275 - 3284.

Pidwirny, M. (2006, 02-02-06). Fundamentals of physical geography, Retrieved June 14, 2006, from http://www.physicalgeography.net/fundamentals/7z.html

Roelfsema, C., \& Bansener, C. (2003). Volunteer divers mark habitats of endangered grey nurse sharks. ARCNews, 25(4).

Scripps Institute of Oceanography (1981 - 2006). The coastal data information program, Retrieved July 15, 2006 from http://cdip.ucsd.edu/

Scholz, A. J., \& Wright, D. J. (2005). Place Matters. Corvalis: Oregon State University Press.

Smith, S. (1997). Scientists concerned about El Nino effects on California marine life: NOAA.

Starks, J., \& Tustanowski, R. (1996). The Visual Basic programming language. Retrieved June 23, 2006, from http://www.engin.umd.umich.edu/CIS/course.des/cis400/vbasic/vbasic.html

Stenbel, O. (2006). Conversation regarding U.S. vector shoreline derived from NOAA nautical charts. In P. C. Bigley (Ed.). Redlands: NOAA.

SYBEX Inc. (1999). Visual Basic 6 complete. Alameda, California: SYBEX Inc.

Tomlinson, R. (2003). Thinking about GIS. Redlands, CA: ESRI Press.

Valavanis, V. D. (2002). Geographic Information Systems in oceanography and fisheries: Taylor \& Francis Inc.

Whitman, D.C. (1996). Laser airborne bathymetry: Lifting the littoral. Sea Technology, 37(8), 95 - 98. 
Wilson, J. P., Mitasova, H., \& Wright, D. J. (2000). Water resource applications of GIS. Journal of the Urban and Regional Information Systems Association, 12(2), 61 79.

Wright, D. J. (1996). Rumblings from the sea floor: GIS supports deep sea research. Geo Info Systems, 6, 22 - 29. 
The appendix sections on the following pages of this document have been devoted to the documentation and description of some of the more unique portions of the OIGIS programming. VBA and ArcObjects are the bases for the functionality that has been achieved with this system. The OIGIS VBA programming is extensive and includes much more script than is shown in the following appendices. While the entirety of the programming constitutes much of the academic rigor of this project, most of the script is not unique or unusual enough to warrant special emphasis as are the following excerpts. In addition, during the course of development of the OIGIS, numerous ArcMap functionalities were applied repeatedly, and were therefore developed into VB routines to reduce duplication of effort. As these routines were applied during system development, and do not contribute to the final system's functionality, they were not included in this appendix.

Appendix A documents that portion of the OIGIS VBA code which creates the VB dictionary. The Dictionary VBA object enable methodologies for determining if a species exists as input into the OIGIS. This code makes use of the exists method. This method can determine whether a particular key, and its corresponding item, exist in a dictionary object.

Appendix B documents that portion of the OIGIS VBA code which programmatically adjusts the map display to one of two bookmarks, and creates scale bars of a specified design and of correct scale for the two diverse maps comprising the OIGIS. Since the OIGIS consists of two distinctly different maps, bookmarks were created to ensure an appropriate region of each map would be displayed in association with operator generated reports for each region. The code in this section accesses the Map object through its IMapBookmarks interface and adjusts the layout view to the appropriate bookmark. In addition, this part of the code generates a scalebar which is programmatically adjusted to the scale at which the maps are being viewed.

Appendix $\mathrm{C}$ documents the portion of the OIGIS VBA code which programmatically checks to ensure that the OIGIS operator is currently in layout view, then specifies all necessary parameters for correctly printing the reports, and overrides the default print settings in order to enable the reports to be printed in landscape layout.

Appendix D documents the portion of the OIGIS VBA code which sets the range values that are utilized in this system for evaluating the correlation coefficient, and then generates the plain English statement about the relative strength or weakness of the correlation. The value ranges are derived from thresholds developed by Dr. Jacob Cohen for applications in the field of Psychology (Cohen, 1988). 


\section{Appendix A}

The following VB Code is an excerpt from the OIGIS, generate reports function. This code loops through the species datasets identifying all unique species names and creates a dictionary of them. In this way, the system is able to alert the OIGIS operator to the occurrence of previously non-occurring species and to catch typological errors during normal system operation. This serves to both catch data input errors as well as alert the Ocean Institute scientists of the presence of possible invasive species, or species native to more southern regions that have been displaced into the San Pedro Channel region.

\section{Private Sub UserForm_Initialize() \\ Dim pMxDoc As IMxDocument \\ Set $\mathrm{pMxDoc}=$ ThisDocument \\ Dim pPageLayout As IPageLayout \\ Set $\mathrm{pPageLayout}=$ pMxDoc.PageLayout}

'Now loop on the fish table, to build combo list

'Get the Fish table

Dim pMap As IMap

Set $\mathrm{pMap}=\mathrm{pMxDoc}$.FocusMap

Dim pTablesInAMap As ITableCollection

Set $\mathrm{pTablesInAMap}=\mathrm{pMap}$

'Getting table 1, which should be fish table

Dim pTable As ITable

Set $\mathrm{pTable}=$ pTablesInAMap.Table $(1)$

Dim pCursor As ICursor

Set $\mathrm{pCursor}=\mathrm{pTable}$. Search$($ Nothing, True $)$

Dim pRow As IRow

Set $\mathrm{pRow}=\mathrm{pCursor}$.NextRow

'Create a variable, Dim d, Set d = CreateObject(Scripting.Dictionary)

Dim d As Dictionary 


Set $\mathrm{d}=$ New Dictionary
Do Until pRow Is Nothing
If Not d.Exists(pRow.Value(2)) Then
d.Add pRow.Value(2), pRow.Value(0)
End If
Set pRow = pCursor.NextRow
Loop
'Dim i As Integer
Dim keys2 As Variant
keys2 = d.keys
Dim counter As Integer
For counter $=0$ To UBound(keys2)
ComboBox1.AddItem keys2(counter)
Next




\title{
Appendix B
}

The following VB Code is an excerpt from the OIGIS print reports function. Each map comprising the OIGIS was specified by the client to include regions in which future benthic surveys may be conducted. For this reason, each map includes extents which are much larger than is appropriate for communicating information about the surveys as they currently exist. The following code is used to programmatically adjusts the map view to predefined bookmarks that are of appropriate extent to presentation of the correlation analysis.

\author{
Private Sub UserForm_Initialize() \\ 'initialize variables \\ Set $\mathrm{m} \_$pApp $=$Application \\ Set $\mathrm{m} \_$pMxDoc $=$ThisDocument \\ Set m_pMap = m_pMxDoc.FocusMap \\ 'List of dataframe in TOC and add into drop down list \\ Dim pMaps As IMaps \\ Set $\mathrm{pMaps}=\mathrm{m} \_$pMxDoc.Maps \\ Dim i As Integer \\ For $\mathrm{i}=0$ To pMaps.Count -1 \\ Me.ComboBox1.AddItem pMaps.Item(i).Name \\ Next i \\ Me.ComboBox1.ListIndex $=0$
}

End Sub

Private Sub CommandButton1_Click()

Set $\mathrm{m} \_$pMxDoc $=$Application.Document 
If Not TypeOf m_pMxDoc.ActiveView Is IPageLayout Then

MsgBox "You will need to switch to Page Layout view to see the report!"

Exit Sub

End If

' Access the Map object through its IMapBookmarks interface

Dim pMapBookmarks As IMapBookmarks

Set $\mathrm{pMapBookmarks} \mathrm{=} \mathrm{m \_ pMxDoc.FocusMap}$

' get an enumeration of bookmarks

Dim pEnumBookmarks As IEnumSpatialBookmark

Set $\mathrm{pEnumBookmarks}=$ pMapBookmarks.Bookmarks

pEnumBookmarks.Reset

Dim pBookmark As ISpatialBookmark

parse the enum

Set $\mathrm{pBookmark}=\mathrm{pEnumBookmarks.Next}$

Do While Not pBookmark Is Nothing

If Me.ComboBox1.ListIndex $=0$ Then pBookmark.ZoomTo m_pMxDoc.FocusMap ' zoom to bookmark m_pMxDoc.ActiveView.Refresh

ElseIf Me.ComboBox 1. ListIndex $=1$ Then pBookmark.ZoomTo m_pMxDoc.FocusMap ' zoom to bookmark m_pMxDoc.ActiveView.Refresh 


\begin{tabular}{|l|}
\hline Exit Sub \\
End If \\
. \\
Set pBookmark = pEnumBookmarks.Next \\
Loop \\
GenerateReports.Show \\
SelectMap.Hide \\
End Sub
\end{tabular}




\section{Appendix C}

The following VB Code is an excerpt from the OIGIS print report function. This code programmatically checks to ensure that the OIGIS operator is currently in layout view, then specifies all necessary parameters for correctly printing the reports. Since ArcMap layout view defaults to portrait layout when printed, the code includes overrides to make it print in landscape. This function is designed to ensure a consistent appearance to all the printed reports, while allowing the OIGIS operator to alter their view of the San Pedro Channel and DPMWR as desired during use.

Private Sub Print_Reports_Click()

' Print Page Layout View

Dim pMxApp As IMxApplication

Set $\mathrm{pMxApp}=$ Application

Dim pMxDoc As IMxDocument

Set $\mathrm{pMxDoc}=$ ThisDocument

Dim pPageLayout As IPageLayout

Set pPageLayout $=$ pMxDoc .PageLayout

' Make sure we're in layout view

If Not TypeOf pMxDoc.ActiveView Is IPageLayout Then

MsgBox "You must be in Page Layout mode for this function to work"

\section{Exit Sub}

End If

'Change Page and Paper layout to print in landscape

Dim pPrinter As IPrinter

Dim pClone As IClone

Set $\mathrm{pClone}=\mathrm{pMxApp}$.printer

Set $\mathrm{pPrinter}=\mathrm{pClone}$. Clone

pPrinter.Paper.Orientation $=2$

Set $\mathrm{pMxApp} \cdot$ printer $=$ pPrinter 


pPageLayout.Page.Orientation $=2$
'Inform of printer change
Dim pActiveView As IActiveView
Set pActiveView = pPageLayout
pActiveView.PrinterChanged pPrinter
' Get the PageLayout by a QI with the active view,
' and then get the Page object representing the on screen page
Set pPageLayout = pMxDoc.ActiveView
Dim pPage As IPage
Set pPage = pPageLayout.Page
' Get ArcMaps current Printer object
Set pMxApp = ThisDocument.Parent
'
' than ArcMaps current printer then uncomment the two lines below:
'Set pPrinter = New PsPrinter
' This will only be the case if pPage.PageToPrinterMapping = esriPageMappingTile
Dim INumPages As Integer




\begin{abstract}
'Set pPrinter.Paper $=$ pMxApp.Paper
Dim 1CurrentPageNum As Long

For lCurrentPageNum $=1$ To lNumPages

' Get dots per inch from printer

Dim printerDpi As Long

printerDpi $=$ pPrinter.Resolution

' Get device bounds - this is in printer device coordinates (number of dots across page
\end{abstract} to a page)

Dim pDeviceBounds As IEnvelope

Set $\mathrm{pDeviceBounds} \mathrm{=} \mathrm{New} \mathrm{Envelope}$

pPage.GetDeviceBounds pPrinter, 1CurrentPageNum, 0 , printerDpi, pDeviceBounds

' Get values (as doubles) out of the envelope and put them into a rectangle (as Longs)

Dim rectDeviceBounds As tagRECT

rectDeviceBounds.Left $=$ pDeviceBounds.XMin

rectDeviceBounds.Top $=$ pDeviceBounds. YMin

rectDeviceBounds.Right $=$ pDeviceBounds. $X$ Max

rectDeviceBounds.bottom $=$ pDeviceBounds. YMax

If TypeOf pPrinter Is IEmfPrinter Then

' For emf printers we have to remove the top and left unprintable area

' from device coordinates so its origin is 0,0 .

rectDeviceBounds.Right $=$ rectDeviceBounds.Right - rectDeviceBounds.Left rectDeviceBounds.bottom $=$ rectDeviceBounds.bottom - rectDeviceBounds.Top 
rectDeviceBounds. Left $=0$

rectDeviceBounds. Top $=0$

End If

' Compute the area of the page layout to send to the printer,

' this is in page layout units (inches or $\mathrm{cm}$ )

Dim pVisBounds As IEnvelope

Set $\mathrm{pVisBounds}=$ New Envelope

pPage.GetPageBounds pPrinter, 1CurrentPageNum, 0, pVisBounds

' Build envelope in device coordinates - this must be the whole paper

Dim paperWidthInch As Double

Dim paperHeightInch As Double

pPrinter.QueryPaperSize paperWidthInch, paperHeightInch

Dim devFrameEnvelope As IEnvelope

Set devFrameEnvelope $=$ New Envelope

devFrameEnvelope.PutCoords 0, 0, paperWidthInch * printerDpi, paperHeightInch * printerDpi

' StartPrinting takes a device frame (whole page) and returns a handle to a device context (hDC)

' - we direct further output to the hDC

Dim hDC As Long

$\mathrm{hDC}=$ pPrinter. StartPrinting $($ devFrameEnvelope, 0$)$

' This draws the visible bounds (pVisBounds) area of the

' active view to the printer 

pMxDoc.ActiveView.Output hDC, printerDpi, rectDeviceBounds, $\mathrm{pVisBounds,}$
Nothing

' Flush output to the printer

pPrinter.FinishPrinting

Next

End Sub 


\section{Appendix D}

The following VB Code is an excerpt from the OIGIS generate reports function. This code documents the range values that are utilized in this system for evaluating the correlation coefficient, and then generating the plain English statement about the relative strength or weakness of the correlation. The value ranges are a commonly applied thresholds conceived by Dr. Jacob Cohen for applications in the field of Psychology (Cohen, 1988). As Dr. Cohen himself admits, all such criteria are in some ways arbitrary because the interpretation of a correlation coefficient depends on the context and purposes. After system deployment, regular usage may necessitate the adoption of a less stringent set of threshold values for this function.

'Plain English correlation statement base on Cohen, 1988

Set $\mathrm{pTextElement}=\mathrm{pElementProp}$

Dim CorrText As String

Dim correlation1 As Double

correlation $1=0 \#$

correlation 1 = CorrelationCoefficient(RawData, , , Weightfactor)

correlation $1=$ Round $($ correlation 1,0$)$

If (correlation $1>=0.5$ And correlation $1<=1$ ) Then

CorrText $=$ "species is highly positively correlated"

ElseIf (correlation $1<0.5$ And correlation $1>=0.3$ ) Then

CorrText $=$ "species is moderately positively correlated"

ElseIf (correlation1 <0.3 And correlation1 >=0.1) Then

CorrText $=$ "species is weakly positively correlated"

ElseIf (correlation1 < 0.1 And correlation1 > -0.1) Then

CorrText $=$ "species is completely un-correlated"

ElseIf (correlation1 <=-0.1 And correlation1 > -0.3) Then

CorrText = "species is weakly negatively correlated"

ElseIf (correlation $1<=-0.3$ And correlation $1>-0.5$ ) Then

CorrText = "species is moderately negatively correlated"

ElseIf (correlation $1<=0.5$ And correlation $1>=1$ ) Then

CorrText = "species is highly negatively correlated"

End If

pTextElement. Text $=$ CorrText 